\title{
Lifestyle interventions for the treatment of urinary incontinence in adults (Review)
}

\author{
Imamura M, Williams K, Wells M, McGrother C
}

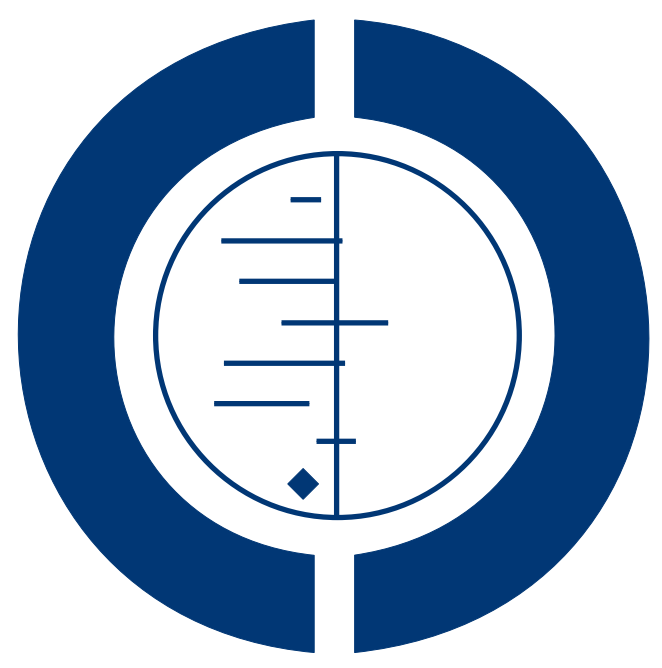

\section{THE COCHRANE COLLABORATION $^{\circledR}$}

This is a reprint of a Cochrane review, prepared and maintained by The Cochrane Collaboration and published in The Cochrane Library 2015, Issue 12

http://www.thecochranelibrary.com

\section{WILEY}


TABLE OF CONTENTS

HEADER

ABSTRACT

PLAIN LANGUAGE SUMMARY

SUMMARY OF FINDINGS FOR THE MAIN COMPARISON

BACKGROUND

OBJECTIVES

METHODS

RESULTS

Figure 1.

Figure 2.

Figure 3.

ADDITIONAL SUMMARY OF FINDINGS

DISCUSSION

AUTHORS' CONCLUSIONS

REFERENCES

DATA AND ANALYSES

Analysis 1.1. Comparison 1 Weight loss versus no active intervention, Outcome 1 Improvement rates based on women's perception (all types UI).

Analysis 1.4. Comparison 1 Weight loss versus no active intervention, Outcome 4 Cure rates based on quantification of symptoms (all types UI).

Analysis 1.6. Comparison 1 Weight loss versus no active intervention, Outcome 6 Improvement rates based on quantification of symptoms (all types UI).

Analysis 1.8. Comparison 1 Weight loss versus no active intervention, Outcome 8 Prevalence of weekly urinary incontinence after intervention (all types UI).

Analysis 1.10. Comparison 1 Weight loss versus no active intervention, Outcome 10 Incontinent episodes per week (\% change from baseline; all UI types).

Analysis 4.2. Comparison 4 Caffeine reduction versus control, Outcome 2 Mean number of UI episodes per 24 hours (SD).

Analysis 5.1. Comparison 5 Lifestyle weight loss versus metformin, Outcome 1 Prevalence of weekly UI after intervention. APPENDICES

HISTORY

CONTRIBUTIONS OF AUTHORS

DECLARATIONS OF INTEREST

SOURCES OF SUPPORT

DIFFERENCES BETWEEN PROTOCOL AND REVIEW 


\title{
[Intervention Review]
}

\section{Lifestyle interventions for the treatment of urinary incontinence in adults}

\author{
Mari Imamura ${ }^{1}$, Kate Williams ${ }^{2}$, Mandy Wells ${ }^{3}$, Catherine McGrother ${ }^{4}$ \\ ${ }^{1}$ Academic Urology Unit, University of Aberdeen, Aberdeen, UK. ${ }^{2}$ Department of Health Sciences, University of Leicester, Leicester, \\ UK. ${ }^{3}$ Integrated Bladder and Bowel Care Services, NHS Devon, Exeter, UK. ${ }^{4}$ Dept of Health Sciences, University of Leicester, Leicester, \\ UK
}

Contact address: Mari Imamura, Academic Urology Unit, University of Aberdeen, Health Sciences Building, Foresterhill, Aberdeen, AB25 2ZD, UK. m.imamura@abdn.ac.uk.

Editorial group: Cochrane Incontinence Group.

Publication status and date: New, published in Issue 12, 2015.

Review content assessed as up-to-date: 3 July 2013.

Citation: Imamura M, Williams K, Wells M, McGrother C. Lifestyle interventions for the treatment of urinary incontinence in adults. Cochrane Database of Systematic Reviews 2015, Issue 12. Art. No.: CD003505. DOI: 10.1002/14651858.CD003505.pub5.

Copyright (C) 2015 The Cochrane Collaboration. Published by John Wiley \& Sons, Ltd.

\begin{abstract}
A B S T R A C T
Background

Low cost, non-invasive alterations in lifestyle are frequently recommended by healthcare professionals or those presenting with incontinence. However, such recommendations are rarely based on good evidence.

\section{Objectives}

The objective of the review was to determine the effectiveness of specific lifestyle interventions (i.e. weight loss; dietary changes; fluid intake; reduction in caffeinated, carbonated and alcoholic drinks; avoidance of constipation; stopping smoking; and physical activity) in the management of adult urinary incontinence.

\section{Search methods}

We searched the Cochrane Incontinence Group Specialised Register, which contains trials identified from the Cochrane Central Register of Controlled Trials (CENTRAL), MEDLINE and MEDLINE in process, and handsearching of journals and conference proceedings (searched 3 July 2013), and the reference lists of relevant articles. We incorporated the results of these searches fully in the review. We undertook an updated search of the Specialised Register, which now includes searches of ClinicalTrials.gov and WHO ICTRP, on 27 October 2014; potentially eligible studies from this search are currently awaiting classification.
\end{abstract}

\section{Selection criteria}

Randomised and quasi-randomised studies of community-based lifestyle interventions compared with no treatment, other conservative therapies, or pharmacological interventions for the treatment of urinary incontinence in adults.

\section{Data collection and analysis}

Two authors independently assessed study quality and extracted data. We collected information on adverse effects from the trials. Data were combined in a meta-analysis when appropriate. We assessed the quality of the evidence using the GRADE approach. 


\section{Main results}

We included 11 trials in the review, involving a total of 5974 participants.

Four trials involving 4701 women compared weight loss programmes with a control intervention. Low quality evidence from one trial suggested that more women following weight loss programmes reported improvement in symptoms of incontinence at six months $(163 / 214(76 \%)$ versus $49 / 90$ (54\%), risk ratio (RR) $1.40,95 \%$ confidence interval (CI) 1.14 to 1.71 ), and this effect was sustained at 18 months $(\mathrm{N}=291,75 \%$ versus $62 \%$, RR not estimable, reported $\mathrm{P}$ value 0.02$)$. No data were available for self-reported cure and quality of life. One of the weight loss trials involving 1296 women reported very low quality evidence for a reduction in weekly urinary incontinence a mean of 2.8 years after following a lifestyle weight loss intervention that had been compared with a pharmacological weight loss intervention.

Three trials involving 181 women and 11 men compared change in fluid intake with no change. Limited, very low quality evidence suggested that symptom-specific quality of life scores improved when fluid intake was reduced, although some people reported headaches, constipation or thirst. A further three trials involving 160 women and nine men compared reduction in caffeinated drinks with no change, and one trial involving 42 women compared a soy-rich diet with soy-free diet. However, it was not possible to reach any conclusions about the effects of these changes, due to methodological limitations, that resulted in very low quality evidence.

Adverse effects appeared relatively uncommon for all interventions studied.

All included studies had a high or unclear risk of bias across all bias parameters, but most notably for allocation concealment. The main factors for our downgrading of the evidence were risk of bias, indirect evidence (less than 12 months of follow-up; and not all participants having confirmed urinary incontinence at baseline in some studies), and imprecise results with wide confidence intervals.

Other interventions such as reduction in consumption of sweetened fizzy or diet drinks; reduction in alcohol consumption; avoiding constipation; smoking cessation; restricting strenuous physical forces; or reducing high levels of, or increasing low levels of, physical activity, could not be assessed in this review, as no evidence from randomized controlled trials or quasi-randomised trials was available.

\section{Authors' conclusions}

Evidence for the effect of weight loss on urinary incontinence is building and should be a research priority. Generally, there was insufficient evidence to inform practice reliably about whether lifestyle interventions are helpful in the treatment of urinary incontinence.

\section{PLAIN LANGUAGE SUMMARY}

\section{Lifestyle interventions for the treatment of urinary incontinence in adults}

\section{Background}

Urinary incontinence imposes a considerable burden on individuals and on society. Although a range of treatments is available, alterations in lifestyle are frequently recommended for the treatment of urinary incontinence, as they are relatively low in cost and have few unwanted side-effects. Advice commonly given includes losing weight, changes in diet, adjusting volume of fluid intake, decreasing caffeine or alcohol consumption, avoiding constipation and straining (when passing faeces), stopping smoking, and being more physically active - though restricting excessive heavy activity.

\section{What we wanted to find out}

We (a team of Cochrane researchers) wanted to see whether lifestyle interventions have a beneficial effect on any type of urinary incontinence in adults

\section{What we did}

We searched the medical literature extensively up to July 2013 for studies that compared the effects of community-based lifestyle alterations with either no treatment, or other non-surgical treatments, or medical (medicine) treatment, on urinary incontinence in adults.

\section{What we found}

We identified 11 studies, with 5974 participants (nearly all women, only 20 were men), that investigated the effect of lifestyle alterations on urinary incontinence. Four investigated weight loss; one compared a soy-rich diet with a soy-free diet; three investigated changes in 
volume of fluid intake; and three investigated the effect of reducing caffeine intake. We identified no trials that investigated reducing alcohol intake, avoiding constipation and straining, stopping smoking or levels of physical activity.

Findings from four studies suggested that weight loss may reduce incontinence among overweight women and this merits further research. However, it should be noted that a large proportion of the participants contributing to this result were part of two diabetes studies that, while they recorded the effect of weight loss on urinary incontinence, did not record how many participants suffered from it at the start of the study. The duration of the weight loss programmes in these studies ranged from three to 12 months.

A small amount of very low quality evidence from the studies that investigated volume of fluid intake suggested that symptoms of urinary incontinence may reduce when fluid intake is reduced, although some participants in the studies reported headaches, constipation or thirst.

We could not combine the findings from other studies that investigated a similar treatment (e.g. caffeine reduction) because they measured their results in different ways, and/or were of poor quality, which means their results may be unreliable. Much more welldesigned research is needed, so that lifestyle recommendations for the treatment of incontinence can be based on good evidence. At present there is not enough evidence to establish whether any lifestyle treatments work. 


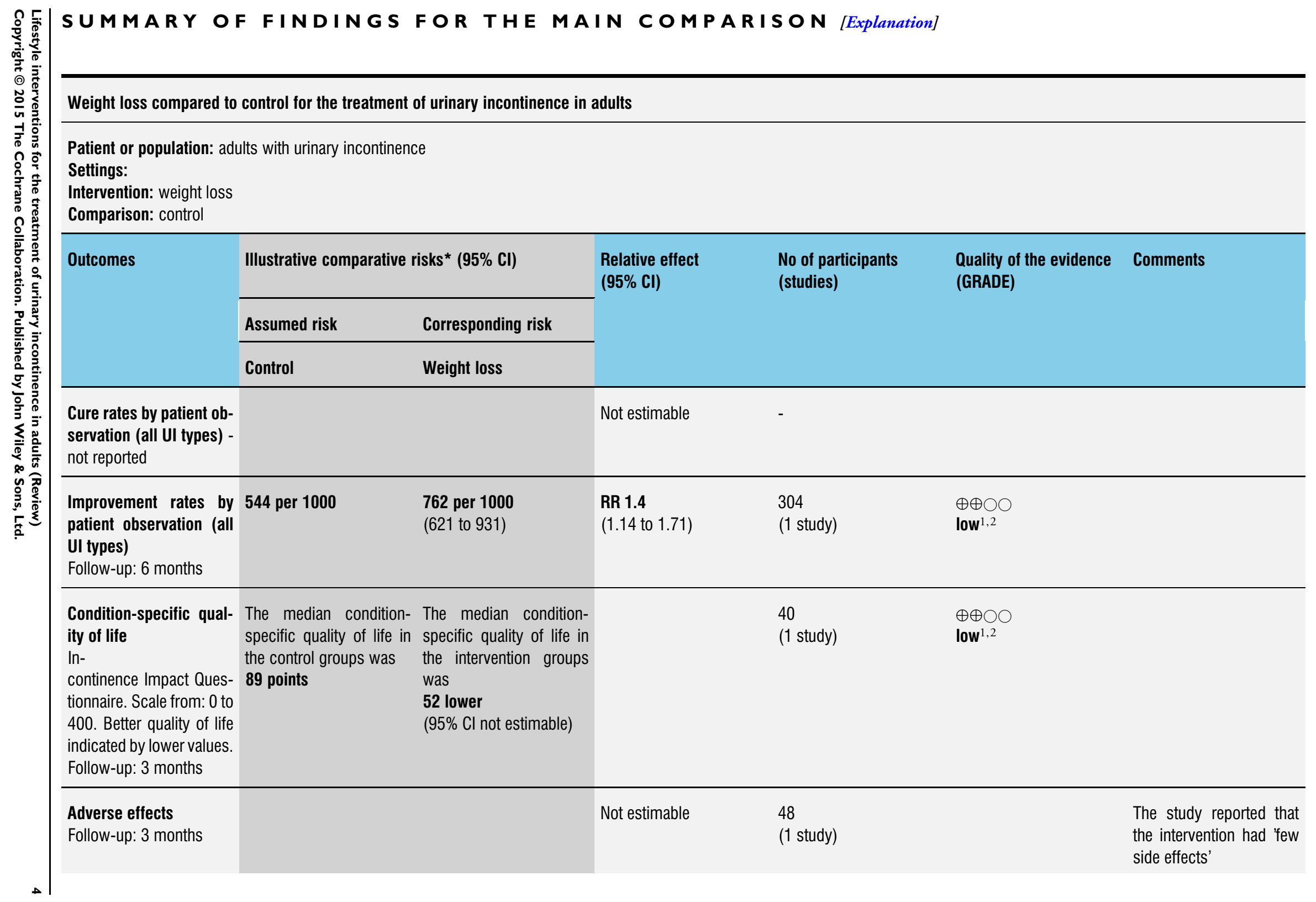




\begin{tabular}{|c|c|c|c|c|c|}
\hline $\begin{array}{l}\text { Cure rates by symp- } \\
\text { tom quantification (all UI } \\
\text { types) } \\
\text { Follow-up: } 12 \text { months }\end{array}$ & 315 per 1000 & $\begin{array}{l}350 \text { per } 1000 \\
(287 \text { to } 431)\end{array}$ & $\begin{array}{l}\text { RR 1.11 } \\
\text { (0.91 to 1.37) }\end{array}$ & $\begin{array}{l}738 \\
\text { (1 study) }\end{array}$ & $\begin{array}{l}\oplus \oplus \bigcirc \bigcirc \\
\text { low }^{1,3,4}\end{array}$ \\
\hline $\begin{array}{l}\text { Improvement rates by } \\
\text { symptom quantification } \\
\text { (all Ul type) } \\
\text { Follow-up: } 12 \text { months }\end{array}$ & 325 per 1000 & $\begin{array}{l}393 \text { per } 1000 \\
(332 \text { to } 468)\end{array}$ & $\begin{array}{l}\text { RR 1.21 } \\
\text { (1.02 to 1.44) }\end{array}$ & $\begin{array}{l}1032 \\
\text { (2 studies) }\end{array}$ & $\begin{array}{l}\oplus \oplus \bigcirc \bigcirc \\
\text { low }^{1,3,4}\end{array}$ \\
\hline $\begin{array}{l}\text { Prevalence of weekly UI } \\
\text { (all UI type) } \\
\text { Follow-up: } 12 \text { months }\end{array}$ & 286 per 1000 & $\begin{array}{l}252 \text { per } 1000 \\
(223 \text { to } 286)\end{array}$ & $\begin{array}{l}\text { RR } \mathbf{0 . 8 8} \\
(0.78 \text { to } 1)\end{array}$ & $\begin{array}{l}2739 \\
\text { (1 study) }\end{array}$ & $\begin{array}{l}\oplus \bigcirc \bigcirc \bigcirc \\
\text { very low } \mathbf{l}^{1,3,4,5}\end{array}$ \\
\hline
\end{tabular}

${ }^{*}$ The basis for the assumed risk (e.g. the median control group risk across studies) is provided in footnotes. The corresponding risk (and its $95 \%$ confidence interval) is based on the assumed risk in the comparison group and the relative effect of the intervention (and its $95 \% \mathrm{Cl}$ ).

Cl: confidence interval; RR: risk ratio; UI: urinary incontinence

GRADE Working Group grades of evidence

High quality: Further research is very unlikely to change our confidence in the estimate of effect.

Moderate quality: Further research is likely to have an important impact on our confidence in the estimate of effect and may change the estimate.

Low quality: Further research is very likely to have an important impact on our confidence in the estimate of effect and is likely to change the estimate.

Very low quality: We are very uncertain about the estimate.

${ }^{1}$ Risk of bias: We downgraded the evidence by one level because blinding of participants and personnel was unlikely.

2 Indirectness: We downgraded the evidence by one level because of short follow-up $<12$ months

${ }^{3}$ Risk of bias: We downgraded the evidence by one level because the authors did not report or provide a description of an allocation

concealment method in one study (Phelan 2012).

${ }^{4}$ Missing outcome data in $7 \%-10 \%$ of the participants in one study (Phelan 2012).

- Indirectness: We downgraded the evidence by one level because data include a sub-study of a trial (Phelan 2012) for diabetes that

included continent as well as incontinent patients; only $27 \%$ had weekly urinary incontinence at baseline. 


\section{B A C K G R O U N D}

\section{Description of the condition}

Urinary symptoms pose a considerable health care burden with 200 million people suffering from incontinence worldwide ( Abrams 2005). The Leicestershire Medical Research Council (MRC) incontinence study, which was the largest comprehensive study of urinary symptoms in a UK general population, reported that $29 \%$ of men and $34 \%$ of women aged 40 years or over experience clinically significant incontinence or voiding symptoms (McGrother 2004), with substantial impact on quality of life. This represents a financial burden to the National Health Service (NHS) of $1 \%$ of its annual budget (Turner 2004). Overall prevalence and service needs will continue to grow as the population ages.

Lifestyle factors may play a role in either in the improvement, or maintenance, of continence. While published literature about lifestyle factors and incontinence is sparse (Hannestad 2004), alterations in lifestyle are frequently recommended by both healthcare professionals and lay people in the belief that they will decrease urine leakage. For example, advice is commonly given to lose weight, increase or decrease fluid intake, stop using caffeinated drinks, reduce alcohol consumption, or to be more physically active - but restrict excessive heavy activities that put pressure on the pelvic floor, such as aerobics or lifting - to stop smoking and avoid constipation and straining. Such recommendations are rarely based on evidence from clinical trials, but on the basis that there are plausible explanations for why these changes might work, and that they are unlikely to cause harm.

Theoretically, the potential for diet and lifestyle to impact upon incontinence is wider than factors currently identified from a purely empirical viewpoint. It is generally recognised that nutritional and metabolic mechanisms impinge upon all systems of the body including the urinary tract. In practice, incontinence is more commonly observed in patients with specific morbidities such as cerebrovascular disease, dementia, depression and diabetes, and this is supported by scientific evidence (McGrother 2007). In these chronic conditions, diet and lifestyle factors have been identified as probably causal: for example, high saturated fat, low fatty fish/ omega-3 fat, low fibre, high glycaemic index, low vegetable and high salt intakes (Chowdhury 2012; He 2006; Baumgart 2015; Ortega 2012; Skerrett 2010). More generally, the WHO and statutory guidance in the UK and USA currently recognize the importance of poor diet, physical inactivity, excess alcohol and sugary drinks plus smoking in the prevention of such chronic conditions. On this basis, modifications to such diet and lifestyle factors may prevent or reduce bladder dysfunction.

A wide range of interventions and treatments has been used in the management of urinary incontinence, including conservative interventions such as physical therapies: a review by Dumoulin and colleagues broadly supported the recommendation for pelvic floor muscle training in women (Dumoulin 2010); and Herbison and colleagues reported that the evidence tentatively supported the use of vaginal cones in women who find them acceptable (Herbison 2002). In the area of behavioural training, Wallace and colleagues identified that there was limited evidence on the use of bladder training (Wallace 2004), but it was unlikely to do harm. The Lipp 2011 review on anti-incontinence devices identified insufficient evidence for the use of devices and suggested further well designed trials in the area. The Nabi 2006 review on pharmaceutical interventions, e.g. anticholinergics, reported statistically significant improvements in symptoms, while for surgical interventions, the Ogah 2009 review reported that minimally invasive surgery was as effective as traditional surgery. For absorbent products, Fader and colleagues identified minimal evidence (Fader 2007; Fader 2008), although there was sufficient evidence to support the use of some pads over others. However, this review specifically focuses on the use of lifestyle interventions for the treatment of urinary incontinence.

\section{Description of the intervention}

\section{I) Weight loss}

Both obesity and urinary incontinence are common problems in women and men. Obese women have higher intra-abdominal pressure than non-obese women, and it is thought that this chronically elevated pressure may predispose to incontinence by weakening pelvic floor support structures. In recent years, a number of trials (Hunskaar 2008; Subak 2002; Subak 2009a) including three which specifically reported on weight loss by obese or overweight adults compared to no treatment (Brown 2006a; Subak 2005a; Subak 2009b) have reported an association between increased weight and urinary incontinence.

\section{2) Dietary factors}

Dietary factors are recognised as contributing to the maintenance of good health, which is strongly related to low levels of incontinence (McGrother 2007). Indications from epidemiological data suggest that poor diet may play a specific role in urinary incontinence. The prospective Leicestershire MRC Incontinence Study, which examined food items and nutrients in relation to incidence of urinary incontinence, found associations between 1) stress urinary incontinence and low intake of bread plus high saturated fat, zinc and Vitamin B12, and 2) overactive bladder and low intakes of bread, vegetables, chicken, protein, vitamin $\mathrm{D}$ and potassium in women (Dallosso 2003; Dallosso 2004a; Dallosso 2004b). Overactive bladder was associated only with high potato intake in men (Dallosso 2004c). The ratio of high saturated fat to polyunsaturated fat intake has also been related to the severity of incontinence in women (Maserejian 2010). 


\section{3) Fluids}

Worsening of urinary urgency, frequency and incontinence is often reported after consuming caffeine, alcohol, fizzy (carbonated) drinks, sweetened diet drinks (Cartwright 2007), or excessive fluids. In a large prospective cohort study, fizzy drinks was the only type of fluid intake independently associated with incontinence in women (Dallosso 2003), whereas in men, beer intake appeared to be protective (Dallosso 2004c). In a study of urinary symptoms in younger men, caffeine, exercise and tobacco were all associated with worse symptoms in the lower urinary tract (Moon 1997). Caffeine may increase bladder muscle contractility (Creighton 1990), whereas alcohol or excessive fluids may have a diuretic effect, while it has been hypothesised that some sweeteners lead to increased detrusor overactivity (Dasgupta 2006). Sugary fizzy drinks have a high glycaemic index, which worsens control of diabetes and related neuro-muscular functions. These factors are also recognised as potential hazards to general health, which is predictive of urinary incontinence.

\section{4) Constipation and straining}

Some evidence suggests that the chronic straining associated with constipation may be a risk factor in the development of urinary incontinence (Moller 2000), and may increase the latency time of the pudendal nerve (Kiff 1984). This nerve supplies the muscles responsible for pelvic support, which is why it has been suggested that constipation may result in, or worsen, urinary incontinence. Poor diet and lack of fibre in the diet can also lead to constipation.

\section{5) Smoking cessation}

Several trials have suggested that smokers are more likely than non-smokers to report urinary incontinence (Dallosso 2003; Tampakoudis 1995).

\section{6) Physical activity}

Prospective cohort evidence suggests that moderate physical activity decreases the risk of onset of urinary incontinence in middle-aged and older women (Danforth 2007; McGrother 2012; Townsend 2008).

\section{7) Physical forces}

It is likely that weakened pelvic floor support structures and raised intra-abdominal pressure caused by heavy lifting and strenuous activity such as aerobics may affect incontinence. Strenuous activity alone may also lead to incontinence in the short term (Nygaard 2006).

\section{Why it is important to do this review}

This review aimed to evaluate the effects of these types of lifestyle interventions on improving incontinence and related symptoms by assessing the evidence available from randomized controlled trials. Such interventions are cheap to deploy, have few side effects, are broadly acceptable and may improve the overall health of adults with and without urinary incontinence. This review will enable us to better understand the effect such interventions have on urinary incontinence.

\section{O B J E C T I VES}

The objective of the review was to determine the effectiveness of specific lifestyle interventions (i.e. weight loss; dietary changes; fluid intake; reduction in caffeinated, carbonated and alcoholic drinks; avoidance of constipation; stopping smoking; and physical activity) in the management of adult urinary incontinence (UI).

\section{MET HODS}

\section{Criteria for considering studies for this review}

\section{Types of studies}

Randomised trials or quasi-randomised trials (that use some assignment rule such as alternation, or hospital or clinic record number).

\section{Types of participants}

Adults with urinary incontinence, diagnosed either by symptom classification (stress Ulurinary incontinence (SUI); urgency urinary incontinence (UUI); mixed urinary incontinence (MUI)) or by urodynamic investigation (urodynamic stress incontinence (USI); idiopathic detrusor overactivity (IDO)). Due to the small number of studies available, we made a pragmatic decision after the review commenced, to include all studies if some of the participants had UI. An example would include studies primarily concerned with people with overactive bladder (OAB): OAB describes a clinical problem - that encompasses urgency and urgency UI (usually with frequency and nocturia) - from a symptomatic perspective (Abrams 2002). The review excluded studies where all participants explicitly had overactive bladder without UI (socalled 'OAB-dry'). Otherwise we included studies with overactive bladder with the assumption that some participants (regardless of the proportion) had UI (so-called 'OAB-wet'). We also made the post hoc decision to include studies that reported prevalence of UI as an outcome. Here the identified studies were from diabetes trials 
where not all participants had UI at baseline. Given that obesity is amongst the most clearly established risk factors for UI in women (Abrams 2013), we assumed that some study participants had UI at baseline. We excluded studies where all participants were continent at baseline.

\section{Types of interventions}

One arm of the trial had to be allocated to a community-based lifestyle intervention following a standardised (within trial) protocol. Any of the following lifestyle interventions alone or in combination were included: advice given to lose weight, change diet, adapt the amount or type (e.g. caffeine) of fluid intake, and moderate alcohol consumption, as well as advice given to avoid constipation and straining, stop smoking, and be more physically active whilst restricting excessive heavy physical activity.

Comparison interventions included no (active) treatment, other conservative physical therapies such as pelvic floor muscle training (PFMT) or bladder training, or pharmacological therapies.

We did not consider interventions such as leaflet-only lifestyle advice, without a standardised (within trial) protocol, to be eligible active treatments.

\section{Types of outcome measures}

The International Continence Society recommends five outcome categories: the individual's observation (reported symptoms), quantification of symptoms (urine loss), the clinician's observation, and quality of life outcomes, namely, condition-specific, and generic and socioeconomic measures (Mattiasson 1998).

\section{Primary outcomes}

- Individual report of symptom cure/improvement.

- Condition-specific quality of life, e.g. ICIQ-Urinary Incontinence Form (Avery 2004).

- Adverse effects.

\section{Secondary outcomes}

- Quantification of symptoms (e.g. diary, bladder chart):

$\circ$ cure and improvement rates on diary or pad test in the short term (less than 12 months) and longer term (more than 12 months);

- number of incontinent episodes in 24 hours.

- Generic quality of life measures e.g. Short Form 36 (Ware 1993).

- Socio-economic measures:

$\circ$ costs of interventions;

$\circ$ cost-effectiveness of interventions;

- resource implications.

- Non-specified outcomes judged important when performing the review. As the search identified trials in people with diabetes that reported prevalence of UI at follow-up, post hoc decisions were made to include prevalence as an outcome only for the assessment of weight loss interventions.

\section{Main outcomes for 'Summary of findings' table}

Main outcomes for the 'Summary of findings' table were (in order of importance):

- symptom cure based on individual report;

- symptom improvement (including cure) based on individual report;

- condition-specific quality of life;

- adverse effects;

- symptom cure based on quantification of symptoms;

- symptom improvement (including cure) based on quantification of symptoms;

- number of incontinent episodes in 24 hours.

For the assessment of weight loss interventions only, prevalence at follow-up was included in place of the number of incontinent episodes. Main outcomes for weight loss interventions thus were (in order of importance):

- symptom cure based on individual report;

- symptom improvement (including cure) based on individual report;

- condition-specific quality of life;

- adverse effects;

- symptom cure based on quantification of symptoms;

- symptom improvement (including cure) based on quantification of symptoms;

- prevalence of UI at follow-up.

The timeframe chosen for these outcomes was at 12-month followup.

\section{Search methods for identification of studies}

We did not impose any language or other restrictions on the searches.

\section{Electronic searches}

This review drew on the search strategy developed for the Cochrane Incontinence Group. We identified relevant trials from the Cochrane Incontinence Group Specialised Trials Register. For more details of the search methods used to build the Specialised Register please see the Group's module in The Cochrane Library. The register contains trials identified from the Cochrane Central Register of Controlled Trials (CENTRAL), MEDLINE, and MEDLINE in process, and handsearching of journals and conference proceedings. Most of the trials in the Cochrane Incontinence Group Specialised Register are also contained in CENTRAL. The date of the search was 3 July 2013; the results of these searches are fully incorporated into the review. 
We completed an additional search of ClinicalTrials.gov on 28 November 2013 - this search is detailed in Appendix 1. The results of this search have not been fully incorporated into the review we have placed potentially eligible studies into Studies awaiting classification.

We undertook a further updated search of the Specialised Register on 27 October 2014 the results of which we assessed, and added potentially eligible studies to Studies awaiting classification (the Specialised Register now includes searches of ClinicalTrials.gov and WHO ICTRP).

The terms used to search the Incontinence Group Specialised Register were:

$\left(\left(\left\{\right.\right.\right.$ DESIGN.CCT* $\left.{ }^{*}\right\}$

OR $\{$ DESIGN.RCT*\}) AND (\{INTVENT.LIFESTYLE* $\})$ AND \{TOPIC.URINE.INCON*\})

(All searches were of the keyword field of Reference Manager 2012).

\section{Searching other resources}

We searched the references lists of relevant articles.

\section{Data collection and analysis}

\section{Selection of studies}

Two review authors independently screened eligible studies for inclusion. We resolved any disagreements by discussion. We listed excluded trials with reasons for their exclusion.

\section{Data extraction and management}

Two review authors extracted data from published reports independently,and resolved any disagreements by discussion. Where there was insufficient information in the published report, we planned to seek clarification from the trialists, but this was not required.

For studies where not all participants had UI at baseline, we preferred the data from a subgroup of people with UI, if these were reported separately. If such data were not available, we extracted data from the whole study but recorded the proportion of people with UI at baseline where possible.

\section{Assessment of risk of bias in included studies}

Two review authors evaluated all relevant studies independently for their potential risk of bias.

We undertook assessment of methodological quality using the Cochrane 'Risk of bias' tool to include assessment of: random sequence generation; allocation concealment; blinding of participants and personnel; blinding of outcome assessment; incomplete outcome data; selective reporting; and other sources of bias. We resolved any differences of opinion related to the 'Risk of bias' assessment by discussion. We planned sensitivity analysis using only the data from studies having a low risk of bias, but this was not possible due to lack of data.

\section{Measures of treatment effect}

We undertook quantitative synthesis if we identified more than one eligible study. We used a fixed-effect model to calculate pooled estimates of treatment effect across similar trials with their $95 \%$ confidence intervals. We combined dichotomous outcome data using the relative risk (RR) method. We intended to combine continuous outcomes using the Mantel-Haenszel weighted mean difference (WMD) method, but this was not done because the continuous outcome data available were either not reported as means with standard deviations (SD), or were not reported by more than one study. We calculated a mean difference for individual trials where possible.

We grouped trial data according to the type of incontinence when data were available. We planned other subgroup analyses (e.g. age, gender, severity of symptoms, methodological quality), but could not perform these due to insufficient data.

We did not perform quantitative synthesis for adverse events, because the included studies reported adverse events narratively and very few numerical data were available; instead we report the findings by a qualitative summary.

\section{Unit of analysis issues}

We analyzed trials with a parallel group design on the basis of individuals randomized.

The recommended approach for including cross-over trials in a meta-analysis is to perform a paired analysis taking into account the within-person differences (Elbourne 2002). However, the included cross-over trials tended to report all measurements after the active treatment period and all measurements after the control treatment period, and then compared these data as if they came from a parallel group trial. The trials also did not publish the mean and standard deviation values (for the within-person differences) required to perform paired analyses. We therefore presented data from these trials as reported, although this gives rise to a 'unit of analysis' error. These results should therefore be interpreted with caution.

\section{Dealing with missing data}

Where possible, we used data based on explicit intention-to-treat analysis. If this was unclear, we performed available case analysis. We collected data on dropout rates, and noted reasons for withdrawal and dropout reported by the trialists in the 'Characteristics of included studies' table when these appeared to be treatmentrelated. 


\section{Assessment of heterogeneity}

We assessed heterogeneity across studies by visual inspection of plots of the data, the Chi ${ }^{2}$ test for heterogeneity, and the $\mathrm{I}^{2}$ statistic (Higgins 2003). We also explored potential sources of heterogeneity.

\section{Assessment of reporting biases}

We planned to create funnel plots of the intervention effect estimates against their standard errors using Review Manager (RevMan; RevMan 2014), but the number of studies included in the review was not sufficient for us to perform this assessment.

\section{Sensitivity analysis}

To assess the potential impact of widening the inclusion criteria of the review to include studies where not all of the participants had UI at baseline, we considered conducting sensitivity analyses in which we would exclude studies with mixed populations (with and without incontinence) from the meta-analysis of each outcome, however, we could not do this due to the low number of studies available.

\section{Summary of findings table}

We summarised results in 'Summary of findings' tables, following the standard methods described in Chapters 11 and 12 of the Cochrane Handbook for Systematic Reviews of Interventions (Schünemann 2011a; Schünemann 2011b). As the recommendation to generate 'Summary of findings' tables is relatively new and became prominent after the publication of the review protocol, we decided to undertake this exercise and determined main outcomes for these tables during the course of the review. We used no external information in the 'Assumed risk' column of the tables. The overall quality of evidence for each outcome was assessed using the GRADE (Grading of Recommendations Assessment, Development and Evaluation) approach (Guyatt 2008). In GRADE, there are four levels of quality of evidence: high, moderate, low and very low. Randomised studies begin as 'high' quality evidence, but may be rated downwards depending upon performance in one or more of five pre-defined categories: (i) limitation of study design (risk of bias), (ii) inconsistency (heterogeneity), (iii) indirectness, (iv) imprecision, and (v) other considerations (e.g. publication bias).

\section{RES U L T S}

\section{Description of studies}

See: Characteristics of included studies; Characteristics of excluded studies; Characteristics of ongoing studies.

\section{Results of the search}

The electronic searches retrieved a total of 338 records, from which we obtained 60 full text articles we assessed for eligibility. We considered 32 reports of 11 trials eligible for inclusion in the review, and identified one report of an eligible ongoing trial (Moholdt 2011).

Additionally, we completed assessment of 1151 records retrieved from ClinicalTrials.gov (28 November 2013) after the main search was fully incorporated into the review - details of four potentially relevant records are given in the Characteristics of studies awaiting classification table (Baker 2011; Heesakkers 2009; Huang 2012; Markland 2013). A further updated search of the Specialised Register on 27 October 2014 retrieved 101 records; we screened these and added three extra studies to the Studies awaiting classification section (Gozukara 2014; Seckin 2011; Wells 2014). The results of these latter two searches (ClinicalTrials.gov and the Specialised Register) have not been fully incorporated into the review. The flow of literature through the assessment process is shown in the PRISMA flowchart (Figure 1). 
Figure I. PRISMA study flow diagram

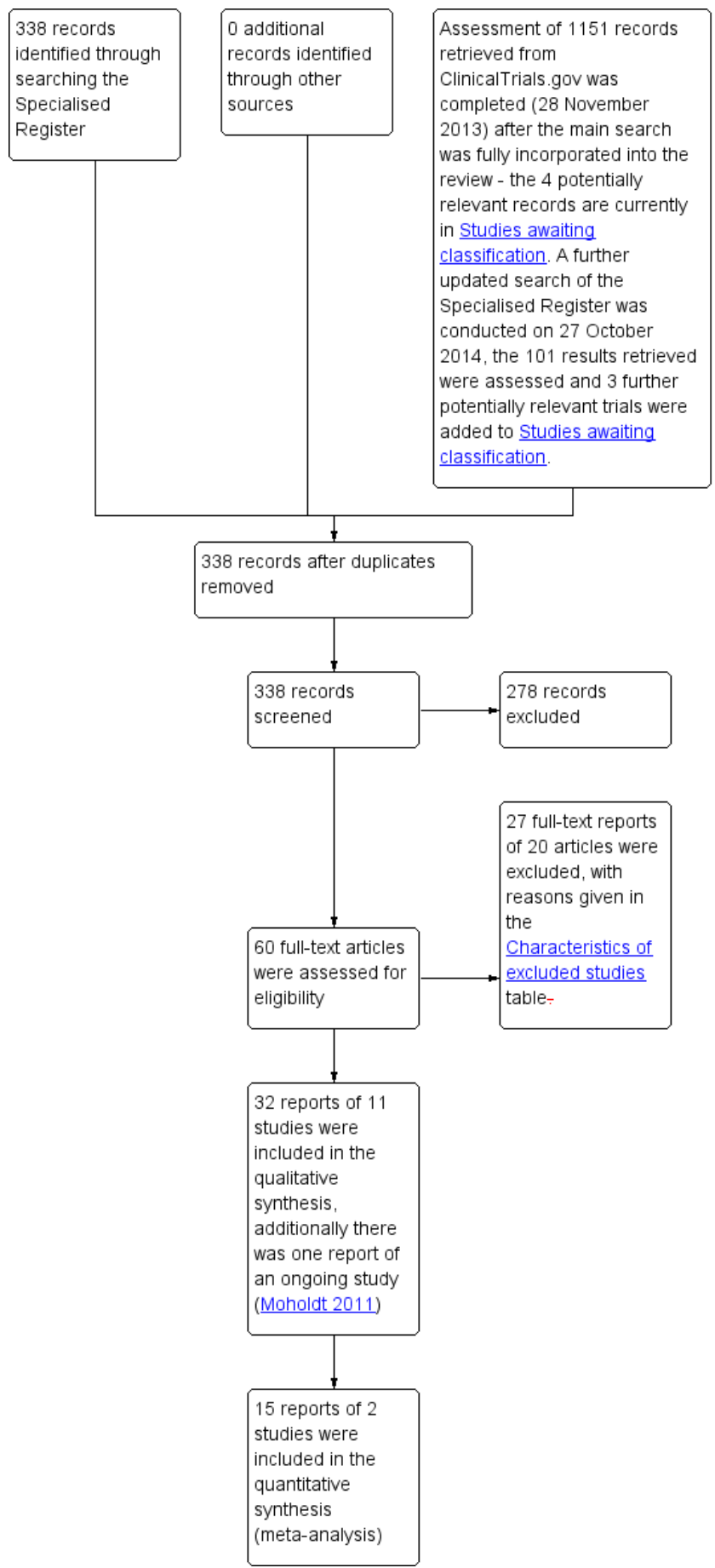

Lifestyle interventions for the treatment of urinary incontinence in adults (Review) 


\section{Included studies}

\section{Design}

The review included a total of 32 reports of 11 trials: five parallel-arm randomized controlled trials (RCTs; Brown 2006b; Dowd 1996; Phelan 2012; Subak 2005; Subak 2009), four randomized cross-over trials (Hashim 2008; Manonai 2006; Swithinbank 2005; Wells 2011), and one quasi-randomised trial that used health record numbers as the basis for assigning people to interventions (Bryant 2002). We also identified one unpublished RCT with limited information (Miller 2007).

\section{Participants}

The included trials involved a total of 5974 participants, who were predominantly female (5954 women and 20 men). The average age (it was unclear if this was a mean or median) of the participants in the included trials ranged from 49 to 58 years, except for two trials with means of 62.7 years (Hashim 2008), and 70.25 years (Dowd 1996).

Sample size varied across trials. The majority of included trials had 60 or fewer participants (seven trials), however, two trials had more than 1000 participants and a further two trials had more than 100 participants Brown 2006b; Phelan 2012; Subak 2009; Swithinbank 2005).

In four trials, all trial participants had UI at baseline:

- Dowd 1996: 58 women with UI;

- Subak 2005: 48 women with SUI (6\%), stress predominant MUI (40\%), UUI (11\%) and urgency predominant MUI (43\%);

- Subak 2009: 338 women with SUI (8\%), stress predominant MUI (25\%), UUI (18\%) and urgency predominant MUI (48\%);

- Swithinbank 2005: 110 women with USI (57\%) and IDO $(43 \%)$

Four trials included adults with OAB, leading to UUI in some of the trial participants:

- Bryant 2002: 9 men and 86 women with symptoms of urgency, frequency and/or UUI; $83 \%$ had UUI at baseline;

- Hashim 2008: 11 men and 13 women with OAB; 29\% had UUI at baseline;

- Miller 2007: 60 women with OAB;

- Wells 2011: 14 women with OAB, with or without UI.

One trial included women with urogenital atrophy, leading to UI in some of the participants:

- Manonai 2006: 42 women with urogenital atrophy; 61\% had SUI and 19\% had UUI at baseline.
The other trials that contributed the largest numbers of participants were sub-studies of large diabetes trials of intensive weight loss programmes, namely the DPP (Diabetes Prevention Program; Brown 2006b), which focused on the prevention of diabetes, and Look AHEAD (Action For Health in Diabetes; Phelan 2012), which evaluated cardiovascular morbidity and mortality among individuals with type 2 diabetes. Not all of the trial participants in these trials had UI at baseline, but reported prevalence of UI at follow-up:

- Brown 2006b: 2191 women in a diabetes trial; no baseline measures of UI;

- Phelan 2012: 2994 women in a diabetes trial; 27\% had weekly UI at baseline.

\section{Interventions}

\section{Weight loss}

Four trials assessed the effect of weight loss programmes on incontinence compared with a control intervention (Brown 2006b; Phelan 2012; Subak 2005; Subak 2009). All weight loss interventions included components of diet and physical activity.

\section{Diet}

The review identified one trial that examined dietary factors by comparing a soy-rich diet with a control diet (Manonai 2006).

\section{Changing volume of fluid intake}

Three trials assessed the effect of changing the volume of fluid intake (Dowd 1996; Hashim 2008; Swithinbank 2005).

\section{Type of fluid intake}

Three trials assessed the effect of reducing caffeinated drinks ( Bryant 2002; Miller 2007; Wells 2011). No relevant trials were identified with respect to alcohol, sweetened fizzy drinks or diet drinks.

\section{Constipation and straining, smoking cessation, physical activity and physical forces}

The review identified no randomized trials addressing the effect of constipation and straining, smoking cessation, physical activity or physical forces on urinary incontinence. 


\section{Outcome}

Quality of reporting of outcomes was generally poor. Not all specified outcomes were reported. Where reported, outcomes were reported using diverse measures, which made the results difficult to interpret. Meta-analysis was performed only for cure and improvement rates and UI prevalence from the weight loss interventions. All other outcomes were summarised narratively.

\section{Excluded studies}

We excluded 27 reports relating to 20 studies after full text screening; see Characteristics of excluded studies. For example, the review excluded studies where lifestyle change was implemented as part of a multi-faceted intervention, e.g. dietary change and constipation management with pelvic floor muscle training, because in such studies we could not separate the effects of lifestyle change from other factors.

\section{Risk of bias in included studies}

The risk of bias of the included trials is summarised in Figure 2 and Figure 3.

Figure 2. Risk of bias graph: review authors' judgements about each risk of bias item presented as percentages across all included studies

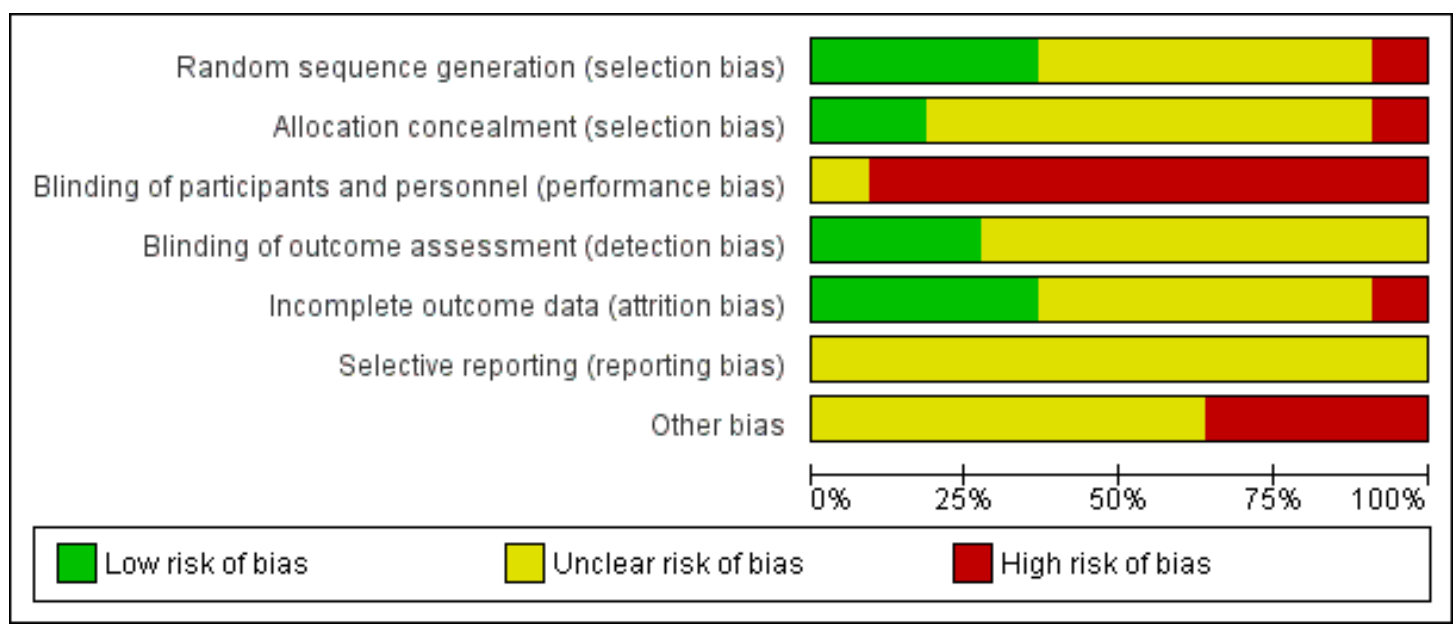


Figure 3. Risk of bias summary: review authors' judgements about each risk of bias item for each included study

\begin{tabular}{|c|c|c|c|c|c|c|c|}
\hline & 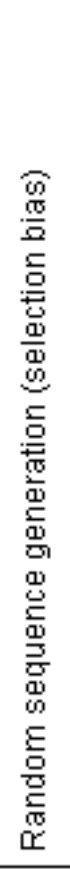 & 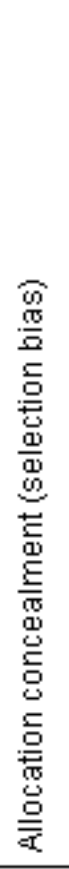 & 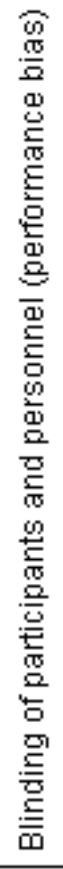 & 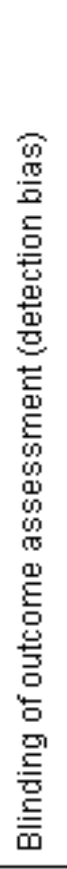 & 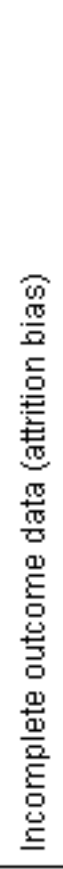 & 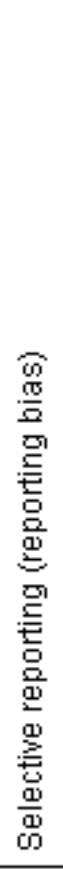 & 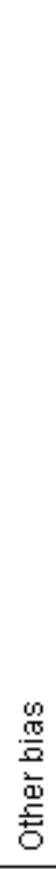 \\
\hline Brown $2006 \mathrm{~b}$ & + & $?$ & - & $?$ & + & $?$ & $?$ \\
\hline Bryant 2002 & - & - & & $?$ & $?$ & $?$ & $?$ \\
\hline Dowd 1996 & $?$ & $?$ & & $?$ & - & $?$ & \\
\hline Hashim 2008 & $?$ & $?$ & & $?$ & + & $?$ & \\
\hline Manonai 2006 & $?$ & $?$ & 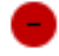 & $?$ & $?$ & $?$ & $?$ \\
\hline Miller 2007 & $?$ & $?$ & $?$ & $?$ & $?$ & $?$ & \\
\hline Phelan 2012 & $?$ & $?$ & & + & $?$ & $?$ & $?$ \\
\hline Subak 2005 & + & + & & + & + & $?$ & $?$ \\
\hline Subak 2009 & + & + & & + & + & $?$ & $?$ \\
\hline Swithinbank 2005 & $?$ & $?$ & & $?$ & $?$ & $?$ & $?$ \\
\hline Wells 2011 & + & $?$ & & $?$ & $?$ & $?$ & \\
\hline
\end{tabular}




\section{Allocation}

Four of the 11 included trials described adequate methods of random sequence generation (Brown 2006b; Subak 2005; Subak 2009; Wells 2011), and of these, allocation was adequately concealed in two (Subak 2005; Subak 2009), but was unclear in the other two (Brown 2006b; Wells 2011). One trial used quasi-randomisation based on health record numbers and was therefore at high risk of selection bias (Bryant 2002). Other trials did not describe the methods used for random sequence generation and allocation concealment and so we judged them to be at unclear risk of bias for this domain.

\section{Blinding}

Blinding of participants and personnel was not feasible due to the nature of interventions; this may have biased self-reported outcomes such as cure, improvement and quality of life. Blinding of outcome assessment should be possible, but was done in only three trials (Phelan 2012; Subak 2005; Subak 2009), and was unclear in the others.

\section{Incomplete outcome data}

The percentage of participants followed up and included in analysis varied across trials as shown below:

- $100 \%$ (Hashim 2008);

- $90 \%$ or more (Phelan 2012);

- between 80\% and 89\% (Brown 2006b; Manonai 2006;

Subak 2005; Subak 2009; Swithinbank 2005);

- between 70\% and 79\% (Bryant 2002; Wells 2011);

- 55\% (Dowd 1996); and

- not reported (Miller 2007).

Of these, four trials were considered to be at low risk of attrition bias (incomplete outcome data) because the trial reports stated that either there were no missing outcome data (Hashim 2008), or described use of imputation (Subak 2009), or confirmation that participants with missing data did not differ from participants with data in terms of demographic and clinical characteristics (Brown 2006b; Subak 2005). One trial (Dowd 1996), in which 26 (45\%) of the 58 participants did not complete diaries and were excluded from analysis, was assessed as having a high risk of attrition bias. Reasons for missing outcome data were not clearly described in the other trials, and it was difficult to determine whether the extent of missing data was likely to induce clinically important bias. We therefore judged them to be at unclear risk of bias for this domain.

\section{Selective reporting}

All trials reported on the outcomes listed in their methods section but, as there was otherwise insufficient information to permit judgement of low or high risk of bias within published reports, we consider them to be at unclear risk of bias for this domain.

\section{Other potential sources of bias}

Two trials assessing fluid intake manipulation (Dowd 1996; Hashim 2008), and caffeine reduction (Miller 2007; Wells 2011), noted that compliance to the trial protocol was relatively poor. Apart from this factor, it was difficult to assess whether any other important risk of bias existed in these and the other trials.

\section{Effects of interventions}

See: Summary of findings for the main comparison Weight loss compared to control for the treatment of urinary incontinence in adults; Summary of findings $\mathbf{2}$ Soy-rich diet compared to control for the treatment of urinary incontinence in adults; Summary of findings 3 Decreasing fluids compared to increasing fluids for the treatment of urinary incontinence in adults; Summary of findings 4 Caffeine reduction compared to control for the treatment of urinary incontinence in adults; Summary of findings 5 Lifestyle weight loss compared to metformin weight loss for the treatment of urinary incontinence in adults

The results of the included studies, and the quality of the body of evidence for each outcome, are summarised in the 'Summary of findings' tables (Summary of findings for the main comparison; Summary of findings 2; Summary of findings 3; Summary of findings 4; and Summary of findings 5).

\section{I) Weight loss by obese or overweight adults versus no active intervention}

\section{Description of studies}

We identified four trials involving a total of 4701 participants that compared intensive lifestyle weight loss interventions with control or no active interventions in relation to incontinence (Brown 2006b; Phelan 2012; Subak 2005; Subak 2009). All participants in two of the included trials had UI (Subak 2005; Subak 2009). The other two trials were sub-studies of large diabetes trials (Brown 2006b; Phelan 2012), DPP and Look AHEAD, respectively, and contributed $4315(92 \%)$ of the trial participants to the analysis. These trials did not recruit participants specifically with UI and therefore not all the participants had it. We extracted outcome data on cure and improvement (based on quantification of symptoms) from a subgroup of people with UI in the Look AHEAD trial $(\mathrm{N}=738$; Phelan 2012), and data on prevalence of UI at follow- 
up from the whole (sub-)study $(\mathrm{N}=2994)$. The trial authors reported the one-year results of a four-year intensive weight loss programme; the trialists planned that follow-up of this trial would run until 2014. The only relevant outcome from the DPP trial was prevalence at follow-up of UI from the whole (sub-)study ( $\mathrm{N}=$ 1321; Brown 2006b); the proportion of people with UI at baseline was unknown (not reported).

All participants in the included trials were female. The weight loss groups were given a reduced-calorie diet and increased physical activity according to a structured and supervised protocol. The comparison groups received:

- no intervention (waiting list; Subak 2005);

- a structured education programme on weight loss (Subak 2009);

- diabetes support and education (Phelan 2012); or

- a placebo drug (Brown 2006b).

Duration of the interventions varied across trials. The intensive intervention phase lasted for:

- three months (Subak 2005);

- six months followed by a further randomisation in the intervention group (not the control group) to motivation-based or skill-based maintenance programmes for an additional 12 months (Subak 2009);

- six months with monthly follow-up thereafter for an average of 2.8 years (Brown 2006b); or

- 12 months (Phelan 2012).

All four trials reported that women allocated to the intervention group achieved a statistically significant decrease in body weight from baseline compared with those in the control group.

\section{Primary outcomes}

Improvement rates based on women's perception (self-report) were reported in one trial (Subak 2009). The results showed that at six months women in the intervention group were more likely to report improvement than those in the control group at six months (163/214 (76\%) versus 49/90 (54\%), risk ratio (RR) 1.4, 95\% confidence interval (CI) 1.14 to 1.71 ; Analysis 1.1), 12 months (298 women in analysis, $75 \%$ versus $68 \%$, RR not estimable, reported $\mathrm{P}$ value 0.2 ) and 18 months (291 women in analysis, $75 \%$ versus $62 \%$, RR not estimable, reported $P$ value 0.02 ) after randomisation (Analysis 1.2). The reported $P$ values suggest that the differences were statistically significant at six months and 18 months. No information was available on self-reported cure.

The intervention group also reported that incontinence had less adverse impact on their lives (median Incontinence Impact Questionnaire scores, 40 women in analysis, 37 versus 89 , P value 0.01 ) and was less distressing (median Urogenital Distress Inventory scores, 40 women in analysis, 104 versus 195 , P value $<0.0001$ ) compared with the control group in one trial that reported these outcomes (Subak 2005; Analysis 1.3).
Adverse effects appeared to be relatively uncommon, with one trial reporting that the intervention had 'few side effects' (Subak 2005).

\section{Secondary outcomes}

Three trials reported cure and improvement rates based on quantification of symptoms (rather than women's perception; Subak 2005; Subak 2009; Phelan 2012; Analysis 1.4; Analysis 1.5; Analysis 1.6; Analysis 1.7). Depending on the trial, length of follow-up and type of incontinence, cure rates for the intervention group ranged from $7 \%$ to $35 \%$ and improvement rates ranged from $37 \%$ to $64 \%$. In the control group cure rates ranged from $0 \%$ to $32 \%$ of women, while improvement ranged from $0 \%$ to $62 \%$. In general the intervention group had higher rates in terms of both cure and improvement compared with the control group when stress and urgency UI symptoms were considered together ('all UI'). For improvement rates, the difference between the groups was statistically significant at three months $(7 / 19(37 \%)$ versus $0 /$ 21 (0\%), RR 16.50, 95\% CI 1.01 to 270.78; Analysis 1.6), six months (88/214 (41\%) versus 20/90 (22\%), RR 1.85, 95\% CI 1.22 to 2.81 ; Analysis 1.6$)$ and 12 months (234/583 (40\%) versus $146 / 449$ (32\%), RR 1.21, 95\% CI 1.02 to 1.44; Analysis 1.6), although the effect was attenuated over time and was no longer statistically significant at 18 months $(91 / 197$ (46\%) versus 36/90 (40\%), RR 1.15 , 95\% CI 0.86 to 1.55 ; Analysis 1.6). The difference for cure rates did not reach statistical significance (Analysis 1.4).

Looking at different types of UI at each outcome time point, the Subak 2009 trial showed a similar pattern with a tendency towards greater improvement in the intervention group than in the control group among the subgroup of women who reported stress symptoms at six, 12 and 18 months ( $P$ values $0.01,0.01$ and 0.92 , respectively) or urgency symptoms at six, 12 and 18 months ( $P$ values $0.04,0.07$ and 0.03 , respectively; Analysis 1.7). In the same trial, cure rates by type of UI also favoured the intervention group for both SUI (P value 0.004 ) and UUI (P value 0.02 ) at six months, but no further follow-up was available (Analysis 1.5).

The prevalence of weekly (or more frequent) UI of any type (stress or urgency) was lower in the intervention group than in the control group in the two sub-studies of diabetes trials with a follow-up of between one and 2.8 years (Analysis 1.8). According to adjusted odds ratios (ORs) reported by trial authors, the intervention was associated with a statistically significant reduction in the odds of having UI by around $20 \%$ to $24 \%$ compared with the control group (in Phelan 2012, adjusted OR 0.80, 95\% CI 0.65 to 0.98 ; in Brown 2006b, adjusted OR 0.76, 95\% CI 0.61 to 0.95). The prevalence of weekly SUI was also lower in the intervention group compared with the control in both trials (in Phelan 2012, adjusted OR 0.73 , 95\% CI 0.55 to 0.96, Analysis 1.9; in Brown 2006b, adjusted OR $0.80,95 \%$ CI 0.64 to 1.01 ) but no such difference was apparent for UUI (Analysis 1.9). The trial authors suggest that the reduction in the prevalence of overall weekly incontinence 
may be due to differences in weekly SUI.

Compared with women in the control group, those in the intervention group had a greater percentage reduction from baseline in weekly incontinence episodes over the period of three to 18 months regardless of type of UI (all, stress or urgency; Analysis 1.10; Analysis 1.11). Differences between the groups for all UI and SUI episodes were reported to be statistically significant at three, six and 12 months but no longer significant at 18 months. The difference for UUI was not statistically significant at any point in time after three months.

General health-related quality of life was measured only in one small trial with 40 participants using SF-36 ( (Subak 2005; Analysis 1.3). The median SF-36 Physical Component Score favoured the intervention group ( 55 versus $47, \mathrm{P}$ value 0.003 ) but there was no significant difference between the groups in the Mental Component Score of the same instrument (48 versus 51, $P$ value 0.09)

\section{2) Dietary changes versus no active intervention}

\section{Description of study}

We identified only one small trial that assessed the effect of dietary factors on UI (Manonai 2006). The trial used a randomized crossover design and compared a soy-rich diet with a control (soy-free) diet in 42 women who experienced at least one of urinary or genital symptoms owing to urogenital atrophy. At baseline around 61\% and $63 \%$ of women in the intervention and control groups, respectively, had SUI episodes and $19 \%$ and $11 \%$, respectively, had UUI episodes. Partcipants underwent two two-week treatment periods in random order with two four-week washout periods before and between treatments. The trial authors found compliance to the diet to be satisfactory on the basis of the elevation of serum levels of daidzein and genistein during the soy-rich diet period. Outcome data were available for 36 women who completed the trial. As data subgrouped by incontinence status were not available, the extracted data were from the whole study.

\section{Primary outcomes}

The trial did not address self-reported cure and improvement rates, condition-specific quality of life and adverse effects.

\section{Secondary outcomes}

The trial did not address cure and improvement rates based on quantification of symptoms, number of UI episodes and generic quality of life. The available data suggest that the percentage of women with UUI episodes in the control group increased from baseline during the control diet period ( $\mathrm{N}=36$, from $11 \%$ to $22 \%$, P value not reported; Analysis 2.1). Correspondingly, symptom scores (mean, SD) of UUI significantly increased during the control diet period $(\mathrm{N}=36$, from $0.14(0.35)$ to $0.25(0.50)$, $\mathrm{P}$ value $<0.05$; Analysis 2.2), although the difference was small.

\section{3) Change in fluid intake versus no treatment}

\section{Description of studies}

We identified three trials that examined altering the level of fluid intake (Dowd 1996; Hashim 2008; Swithinbank 2005).

One RCT allocated 58 women with UI to one of three groups that increased fluid intake by 500 (Dowd 1996). The trial provided a five-week programme with randomisation in the second week. The trial reported that adherence to the fluid manipulation was poor, which made results difficult to interpret.

Another randomized cross-over trial with 84 women with UI reported outcome data for the 69 women (39 with USI and 30 with IDO) who completed the trial (Swithinbank 2005). The trial lasted four weeks. In the first week participants drank normally (week 1, baseline) and in the second week drank normally, but only caffeine-free fluids (week 2, caffeine-free baseline). Participants were then randomized in the order in which they either increased fluids to 3 litres daily, or decreased fluids to $750 \mathrm{ml}$ daily, in the third and fourth weeks while maintaining caffeine restriction (i.e. only drinking caffeine-free fluids). Adherence to fluid intake protocols seemed fair, with a mean fluid intake of $1639 \mathrm{ml}$ for Week 1, $1630 \mathrm{ml}$ for Week 2, $2673 \mathrm{ml}$ for the week of increasing fluids and $872 \mathrm{ml}$ for the week of decreasing fluids.

In another cross-over trial with 24 participants $(11$ men and 13 women) with OAB (Hashim 2008), only seven (29\%) participants had UUI at baseline. Participants were randomized into two groups and asked to either increase or decrease their fluid intake from baseline. As outcome data specific to a subgroup of people with UI were not reported separately, the extracted data applied to the whole study. Group I was asked to drink at $<25 \%$ of baseline for four days, followed by two days' normal drinking, four days' at $<50 \%$, two days' normal drinking, four days at $>25 \%$, two days' normal drinking, and then four days at $>50 \%$. Group II did the reverse. The trial reported that participants had difficulty in either increasing or decreasing fluids by $50 \%$.

\section{Primary outcomes}

One cross-over trial assessed quality of life using the Bristol Female Lower Urinary Tract Symptoms questionnaire (Swithinbank 2005). Quality of life improved when fluid intake was decreased compared with baseline in women with USI $(\mathrm{N}=39$, P value < $0.003)$ or IDO $(\mathrm{N}=30$, P value $<0.003)$ but the women reported no significant difference in the impact of incontinence symptoms on their daily life before and after treatment (no further data were available).

Regarding adverse effects, the same cross-over trial reported that, with decreasing fluids, 'side effects such as constipation and thirst 
were troublesome' (Swithinbank 2005). Another cross-over trial with 24 participants reported that adverse events observed were mild and tolerable: four participants felt thirsty and two had headaches, constipation or concentrated urine when fluid intake was decreased by $50 \%$ from baseline; and one had headache when intake was reduced by $25 \%$ (Hashim 2008).

No information was available regarding self-reported cure or improvement.

\section{Secondary outcomes}

The number of daily incontinent episodes was reported by three trials that used different measures. A four-week cross-over trial stratified results by type of UI at baseline (Swithinbank 2005; Analysis 3.1). Among 39 women with USI, the week of decreasing fluid intake (with caffeine restriction) was associated with a statistically significant reduction in the median number of daily incontinent episodes compared with the week of increasing fluid intake (with caffeine restriction; 0.5 versus 0.7 , P value 0.006 ). Daily incontinent episodes after decreasing fluid intake (with caffeine restriction) were also statistically significantly fewer compared with the baseline week when participants drank normally (week 1, 0.5 versus $1.6, \mathrm{P}$ value 0.006 ), but there was no significant difference when compared with the caffeine-free baseline week in which participants maintained a similar fluid intake from baseline, but substituted caffeine-free drinks for caffeine-containing drinks (week 2, 0.5 versus $0.8, \mathrm{P}$ value 1.000 ). The week of increasing fluid intake (no caffeine) did not differ significantly from the caffeinefree baseline week (week 2, 0.7 versus 0.8 , P value 0.426 ) in terms of daily incontinent episodes. For 30 women with IDO, drinking less fluid (no caffeine) had no statistically significant effect on daily incontinent episodes ( 0.5 versus 0.6 , P value not significant) when compared with the caffeine-free baseline, but drinking more fluid (no caffeine) resulted in a significant worsening (increase) of the symptom $(1.1$ versus $0.6, \mathrm{P}$ value $<0.003)$.

In the other cross-over trial participants were asked to increase or decrease their fluid intake by $25 \%$ and $50 \%$ from baseline in random order (Hashim 2008). There was no statistically significant difference in the mean number of daily incontinent episodes between the baseline period and each of the fluid manipulation periods, although it should be noted that only seven (29\%) of the 24 participants had UUI at baseline (Analysis 3.2).

The Dowd 1996 trial randomized participants to three groups (maintain, increase or decrease fluid), but the authors reported that adherence to the fluid manipulation protocol was poor and that results were inconclusive (Analysis 3.3).

\section{4) Caffeine reduction versus continued caffeine intake}

\section{Description of studies}

We identified three trials that assessed the effects of a reduction in caffeine intake on incontinence (Bryant 2002; Miller 2007; Wells 2011).

In Bryant 2002, 95 participants (86 women, 9 men) with OAB ( $83 \%$ had UUI at baseline) were randomized by use of health record numbers (quasi-randomised) to caffeine reduction education or control (continued caffeine intake). In addition, both groups received bladder training and were followed up for four weeks. Caffeine intake in the intervention group was reduced significantly from baseline compared with the control group (58\% versus $11 \%$, P value < 0 000.1)

Wells 2011 was a randomized cross-over trial in which 14 women with $\mathrm{OAB}$ (with or without UI) underwent two two-week periods of caffeinated or caffeine-free fluids intake with a 14-day washout period between treatments. It was a feasibility trial and identified only in abstract form. Data were available for the 11 women who completed the trial. Two participants did not comply with caffeine substitution.

The third trial, Miller 2007, was an unpublished two-arm RCT that evaluated the effect of restricting 'irritating' beverages (caffeinated or non-caffeinated). In this trial around 60 women with $\mathrm{OAB}$ (it was unclear if some or all participants were incontinent) were asked to substitute 'irritating' beverages with milk or water, but to maintain a similar volume of fluid from baseline. The request to stop drinking irritating beverages was associated with an improvement in OAB symptoms, but the trial author noted that the findings were confounded by a significant reduction in overall fluid intake in the intervention group from baseline (email communication from the trial author to the Cochrane Incontinence Group). No further information was available regarding this trial. The remainder of this section therefore focuses on the first two trials.

In all three trials, outcome data were extracted from the whole study, as data specific to the UI subgroup of the trial population were not reported separately.

\section{Primary outcomes}

The Wells 2011 trial reported condition-specific quality of life using ICIQ Overactive Bladder (ICIQ-OAB) and ICIQ Overactive Bladder Symptoms Quality of Life (ICIQ-OABqol) questionnaires among 11 of the 14 women who completed the trial. Overall, women had lower (better) scores during the period of caffeine substitution (when drinking caffeine-free fluids) compared with the caffeine exposure period, but the difference in total scores for the ICIQ-OABqol was not statistically significant (mean 54 versus 68, P value 0.065; Analysis 4.1). No information was available regarding self-reported cure and improvement, or adverse effects.

\section{Secondary outcomes}

There was no evidence of a difference in incontinence episode frequency between the caffeine reduction and caffeine exposure 
groups. The Bryant 2002 trial reported a mean difference of 0.2 episodes per day (Analysis 4.2: mean difference (MD) - 0.20 , CI 1.02 to 0.62 ), whereas the Wells 2011 trial reported 'no difference' with no numerical data provided. No information was available for cure and improvement rates based on quantification of symptoms or generic quality of life.

\section{5) Reduction in sweetened fizzy or diet drinks versus no treatment}

We found no trials that compared a reduction in sweetened fizzy or diet drinks with no treatment.

\section{6) Reduction in alcohol consumption versus no treatment}

We found no trials that compared a reduction in alcohol consumption with no treatment.

\section{7) Avoiding constipation versus no treatment}

We found no trials that compared avoidance of constipation with no treatment.

\section{8) Smoking cessation versus no treatment}

We found no trials that compared stopping smoking with no treatment.

\section{9) Restricting strenuous physical forces versus no treatment}

We found no trials that compared restricting strenuous physical forces with no treatment.

10) Reducing high levels of, or increasing low levels of, physical activity versus no treatment

We found no trials that compared a reduction in high levels of physical activity, or increasing low levels of physical activity, with no treatment.

\section{II) Any lifestyle interventions, either alone or in combination, versus other lifestyle interventions or pharmacological and other conservative therapies}

One trial was identified that compared a lifestyle weight loss intervention versus metformin. This trial was a sub-study of a large DPP trial for diabetes described above (Brown 2006b), which compared different weight loss programmes: an intensive lifestyle intervention or a pharmacological intervention (metformin). This comparison included 1296 women.

The only relevant outcome for this review was the effect of weight loss on the prevalence of weekly or more frequent UI at a mean follow-up of 2.8 years. The results showed that women allocated to the lifestyle group $(\mathrm{N}=659)$ had a significantly lower prevalence of UI (any UI) compared with those in the comparison group (252/ 659 (38\%) versus $306 / 635$ (48\%), RR $0.79,95 \%$ CI 0.70 to 0.90 ; Analysis 5.1.1). The results hold for the prevalence of both weekly SUI symptoms (206/659 (31\%) versus 252/635 (40\%), RR 0.79, 95\% CI 0.68 to 0.91 ; Analysis 5.1.2), and UUI symptoms (156/ $659(24 \%)$ versus $182 / 635$ (29\%), RR $0.83,95 \%$ CI 0.69 to 0.99 ; Analysis 5.1.3). 


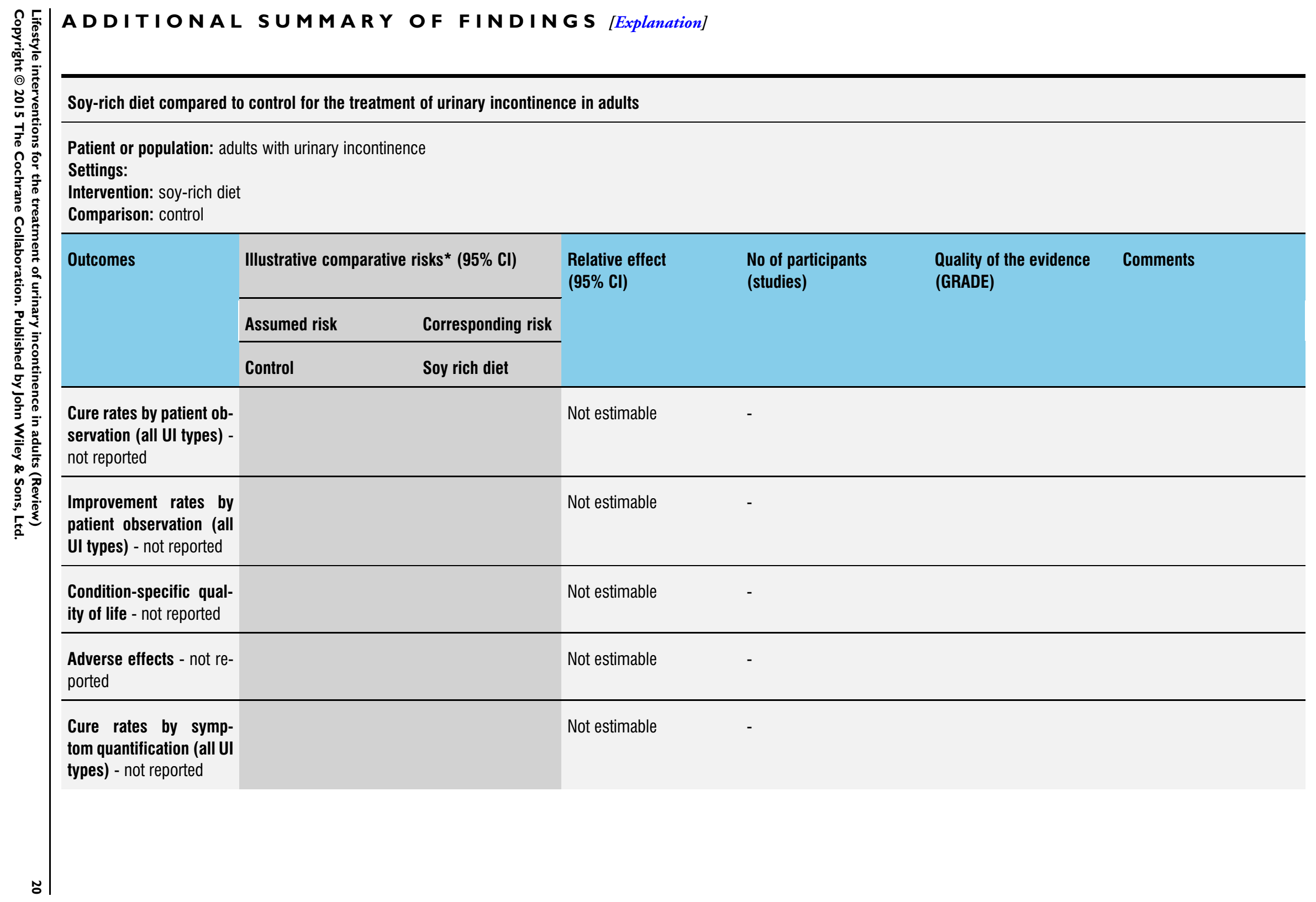


Improvement rates by symptom quantification

(all UI types) - not reported

Incontinent episodes per

week (all UI types) - not

reported

*The basis for the assumed risk (e.g. the median control group risk across studies) is provided in footnotes. The corresponding risk (and its $95 \%$ confidence interval) is based on the assumed risk in the comparison group and the relative effect of the intervention (and its $95 \% \mathrm{Cl}$ ).

Cl: confidence interval; RR: risk ratio; UI: urinary incontinence

GRADE Working Group grades of evidence

High quality: Further research is very unlikely to change our confidence in the estimate of effect.

Moderate quality: Further research is likely to have an important impact on our confidence in the estimate of effect and may change the estimate.

Low quality: Further research is very likely to have an important impact on our confidence in the estimate of effect and is likely to change the estimate.

Very low quality: We are very uncertain about the estimate.

\section{Not estimable}

Not estimable 


\begin{tabular}{|c|c|c|c|c|c|c|}
\hline \multicolumn{7}{|c|}{ Decreasing fluids compared to increasing fluids for the treatment of urinary incontinence in adults } \\
\hline \multicolumn{7}{|c|}{$\begin{array}{l}\text { Patient or population: adults with urinary incontinence } \\
\text { Settings: } \\
\text { Intervention: decreasing fluids } \\
\text { Comparison: increasing fluids }\end{array}$} \\
\hline \multirow[t]{3}{*}{ Outcomes } & \multicolumn{2}{|c|}{ Illustrative comparative risks* $(95 \% \mathrm{CI})$} & \multirow{3}{*}{$\begin{array}{l}\text { Relative effect } \\
(95 \% \mathrm{CI})\end{array}$} & \multirow{3}{*}{$\begin{array}{l}\text { No of participants } \\
\text { (studies) }\end{array}$} & \multirow{3}{*}{$\begin{array}{l}\text { Quality of the evidence } \\
\text { (GRADE) }\end{array}$} & \multirow[t]{3}{*}{ Comments } \\
\hline & Assumed risk & Corresponding risk & & & & \\
\hline & Increasing fluids & Decreasing fluids & & & & \\
\hline $\begin{array}{l}\text { Cure rates by patient ob- } \\
\text { servation (all UI types) - } \\
\text { not reported }\end{array}$ & & & Not estimable & - & & \\
\hline $\begin{array}{l}\text { Improvement rates by } \\
\text { patient observation (all } \\
\text { Ul types) - not reported }\end{array}$ & & & Not estimable & - & & \\
\hline $\begin{array}{l}\text { Condition-specific qual- } \\
\text { ity of life } \\
\text { Follow-up: } 1 \text { weeks }\end{array}$ & See comment & See comment & Not estimable & $\begin{array}{l}69 \\
\left(1 \text { study }^{1}\right)\end{array}$ & $\begin{array}{l}\oplus \bigcirc \bigcirc \bigcirc \\
\text { very low } 2,3,4,5,6\end{array}$ & $\begin{array}{l}\text { Quality of life improved } \\
\text { when fluid intake was de- } \\
\text { creased but the impact of } \\
\text { incontinence on daily life } \\
\text { did not differ significantly } \\
\text { before or after the treatment }\end{array}$ \\
\hline $\begin{array}{l}\text { Adverse effects } \\
\text { Follow-up: } 1 \text { weeks }\end{array}$ & See comment & See comment & Not estimable & $\begin{array}{l}93 \\
\left(2 \text { studies }^{1}\right)\end{array}$ & $\begin{array}{l}\oplus \bigcirc \bigcirc \bigcirc \\
\text { very low } 2,3,5,6,7,8\end{array}$ & $\begin{array}{l}\text { Reported adverse effects } \\
\text { include constipation, thirst, } \\
\text { headache and concen- } \\
\text { trated urine with decreas- } \\
\text { ing fluids }\end{array}$ \\
\hline
\end{tabular}




\begin{tabular}{|c|c|c|c|c|c|c|}
\hline $\begin{array}{l}\text { Cure rates by symp- } \\
\text { tom quantification (all UI } \\
\text { types) - not reported }\end{array}$ & & & Not estimable & - & & \\
\hline $\begin{array}{l}\text { Improvement rates by } \\
\text { symptom quantification } \\
\text { (all UI types) - not re- } \\
\text { ported }\end{array}$ & & & Not estimable & - & & \\
\hline $\begin{array}{l}\text { Incontinent episodes per } \\
\text { week (all UI types) } \\
\text { Follow-up: } 1-4 \text { weeks }\end{array}$ & See comment & See comment & Not estimable & $\begin{array}{l}125 \\
\left(3 \text { studies }^{9}\right)\end{array}$ & $\begin{array}{l}\oplus \bigcirc \bigcirc \bigcirc \\
\text { very low } \\
2,3,5,6,8,10,11\end{array}$ & $\begin{array}{l}\text { Decreasing fluid intake sig- } \\
\text { nificantly reduced inconti- } \\
\text { nent episodes in one study, } \\
\text { no difference was found in } \\
\text { another study and the re- } \\
\text { sults were inconclusive in } \\
\text { the other study }\end{array}$ \\
\hline
\end{tabular}

*The basis for the assumed risk (e.g. the median control group risk across studies) is provided in footnotes. The corresponding risk (and its $95 \%$ confidence interval) is based on the assumed risk in the comparison group and the relative effect of the intervention (and its $95 \% \mathrm{Cl}$ ).

Cl: confidence interval; UI: urinary incontinence

GRADE Working Group grades of evidence

High quality: Further research is very unlikely to change our confidence in the estimate of effect.

Moderate quality: Further research is likely to have an important impact on our confidence in the estimate of effect and may change the estimate.

Low quality: Further research is very likely to have an important impact on our confidence in the estimate of effect and is likely to change the estimate.

Very low quality: We are very uncertain about the estimate.

Randomised cross-over trial

2 Risk of bias: We downgraded the evidence by one level because blinding of participants, personnel and outcome assessors was probably not done and could introduce bias.

${ }^{3}$ Risk of bias: We downgraded the evidence by one level because the authors did not report or provide a description of an allocation concealment method.

${ }^{4}$ Missing outcome data in $18 \%$ of participants.

5 Indirectness: We downgraded the evidence by two levels because of short follow-up $<12$ months in all studies and because study

participants included both continent and incontinent patients in one study (Hashim 2008)

${ }^{6}$ Imprecision: We downgraded the evidence by one level because confidence intervals for relative effect were not estimable. 
월 (Hashim 2008).

${ }^{8}$ Inconsistency: We downgraded the evidence by one level because becuse of heterogenous interventions.

${ }^{9}$ One RCT compared increasing versus decreasing versus maintaining fluid intake (Dowd 1996) and two randomized cross-over trials

comparing increasing versus decreasing fluid intake (Hashim 2008; Swithinbank 2005).

${ }^{10}$ Missing outcome data in 45\% of participants in the RCT (Dowd 1996), 18\% of participants in a cross-over trial (Swithinbank 2005),

whereas the other cross-over trial had no missing outcome data (Hashim 2008).

${ }^{11}$ Low adherence to the protocol was reported in two studies (Dowd 1996; Hashim 2008). 
Caffeine reduction compared to control for the treatment of urinary incontinence in adults

Patient or population: adults with urinary incontinence

Settings:

Intervention: caffeine reduction

Comparison: control

\begin{tabular}{|c|c|c|c|c|c|c|}
\hline \multirow[t]{3}{*}{ Outcomes } & \multicolumn{2}{|c|}{ Illustrative comparative risks* $(95 \% \mathrm{CI})$} & \multirow{3}{*}{$\begin{array}{l}\text { Relative effect } \\
(95 \% \mathrm{Cl})\end{array}$} & \multirow{3}{*}{$\begin{array}{l}\text { No of participants } \\
\text { (studies) }\end{array}$} & \multirow{3}{*}{$\begin{array}{l}\text { Quality of the evidence } \\
\text { (GRADE) }\end{array}$} & \multirow[t]{3}{*}{ Comments } \\
\hline & Assumed risk & Corresponding risk & & & & \\
\hline & Control & Caffeine reduction & & & & \\
\hline $\begin{array}{l}\text { Cure rates by patient ob- } \\
\text { servation (all UI types) - } \\
\text { not reported }\end{array}$ & & & Not estimable & - & & \\
\hline $\begin{array}{l}\text { Improvement rates by } \\
\text { patient observation (all } \\
\text { Ul types) - not reported }\end{array}$ & & & Not estimable & - & & \\
\hline $\begin{array}{l}\text { Condition-specific qual- } \\
\text { ity of life } \\
\text { ICIQ Overactive Bladder } \\
\text { Symptoms Quality of Life. } \\
\text { Scale from: } 25 \text { to } 160 \text {. } \\
\text { Better quality of life indi- } \\
\text { cated by lower values. } \\
\text { Follow-up: } 2 \text { weeks }\end{array}$ & $\begin{array}{l}\text { The mean condition-spe- } \\
\text { cific quality of life in the } \\
\text { control groups was } \\
\mathbf{6 8 . 3 6} \text { points }\end{array}$ & $\begin{array}{l}\text { The mean condition-spe- } \\
\text { cific quality of life in the } \\
\text { intervention groups was } \\
\mathbf{1 4 . 4 5} \text { lower } \\
\text { ( } 95 \% \text { CI not estimable) }\end{array}$ & Not estimable & $\begin{array}{l}11 \\
\left(1 \text { study }^{1}\right)\end{array}$ & $\begin{array}{l}\oplus \bigcirc \bigcirc \bigcirc \\
\text { very low }{ }^{2,3,4,5,6}\end{array}$ & \\
\hline $\begin{array}{l}\text { Adverse effects - not re- } \\
\text { ported }\end{array}$ & & & Not estimable & - & & \\
\hline $\begin{array}{l}\text { Cure rates by symp- } \\
\text { tom quantification (all UI } \\
\text { types) - not reported }\end{array}$ & & & Not estimable & - & & \\
\hline
\end{tabular}


Incontinent episodes per The mean number of in- The mean number of in- Not estimable

higher)

*The basis for the assumed risk (e.g. the median control group risk across studies) is provided in footnotes. The corresponding risk (and its $95 \%$ confidence interval) is based on the assumed risk in the comparison group and the relative effect of the intervention (and its $95 \% \mathrm{Cl}$ ).

Cl: confidence interval

GRADE Working Group grades of evidence

High quality: Further research is very unlikely to change our confidence in the estimate of effect.

Moderate quality: Further research is likely to have an important impact on our confidence in the estimate of effect and may change the estimate.

Low quality: Further research is very likely to have an important impact on our confidence in the estimate of effect and is likely to change the estimate.

Very low quality: We are very uncertain about the estimate.

${ }^{1}$ Randomised cross-over trial; feasibility study.

${ }^{2}$ Risk of bias: We downgraded the evidence by one level because blinding of participants, personnel and outcome assessors was probably not done.

${ }^{3}$ Risk of bias: We downgraded the evidence by one level because the authors did not report or provide a description of an allocation concealment method.

${ }^{4}$ Missing outcome data in $>20 \%$ of participants.

${ }^{5}$ Indirectness: We downgraded the evidence by two levels because of short follow-up $<12$ months and because study participants included both continent and incontinent patients.

${ }^{6}$ Imprecision: We downgraded the evidence by one level because confidence intervals for relative effect were not estimable.

${ }^{7}$ A quasi-randomised controlled trial based on health record numbers.

${ }^{8}$ Risk of bias: We downgraded the evidence by one level because allocation concealment was inadequate (quasi-randomisation based on health record numbers). 


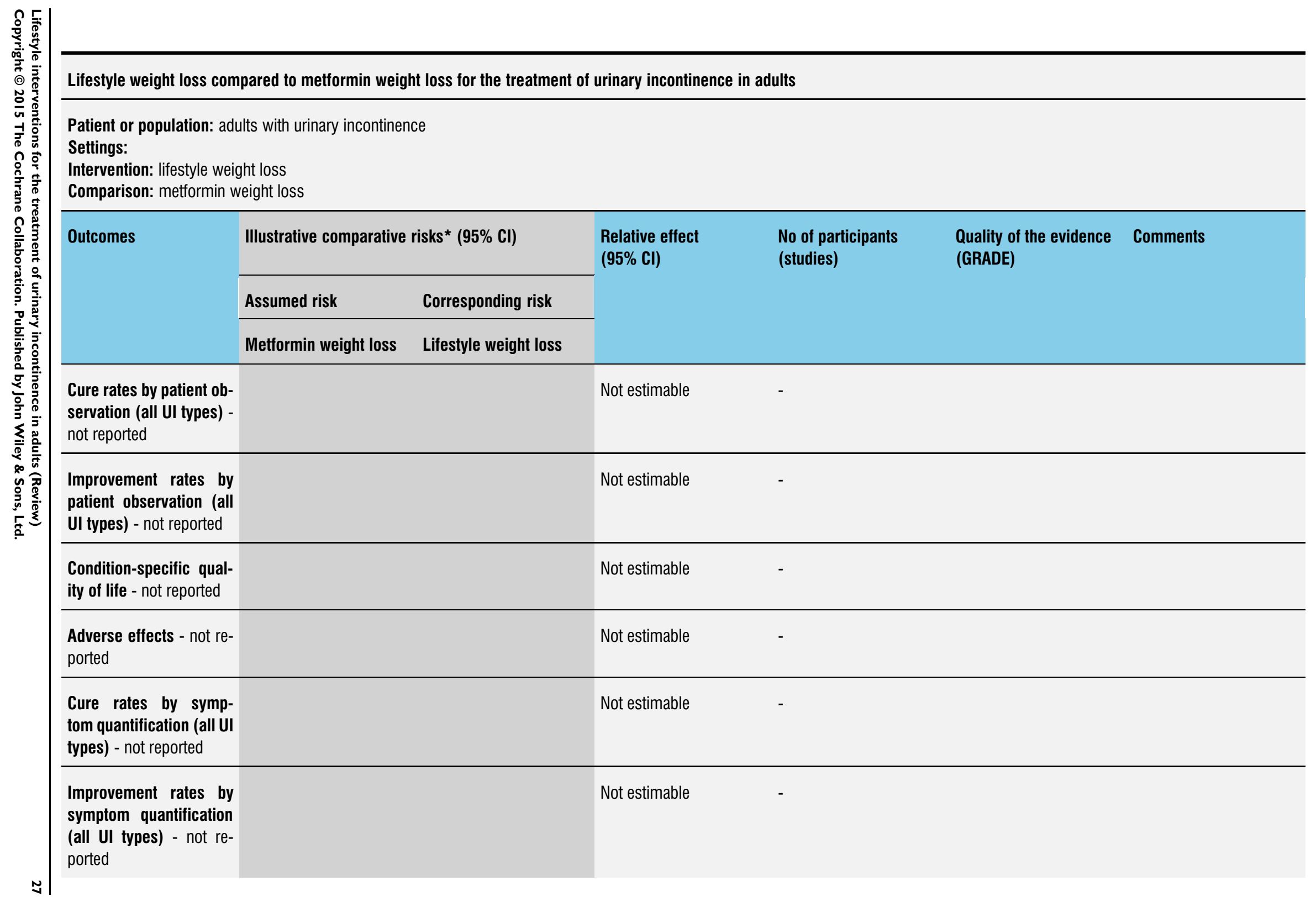




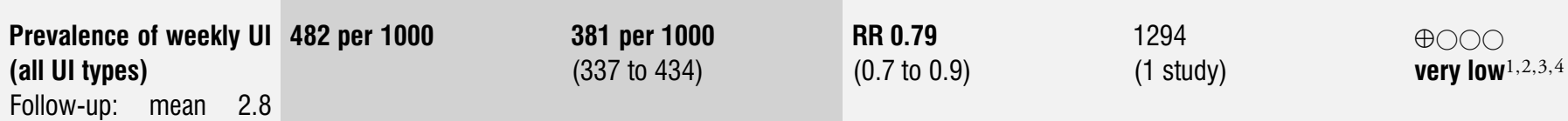

years

*The basis for the assumed risk (e.g. the median control group risk across studies) is provided in footnotes. The corresponding risk (and its $95 \%$ confidence interval) is based on the assumed risk in the comparison group and the relative effect of the intervention (and its $95 \% \mathrm{Cl}$ ).

Cl: confidence interval; RR: risk ratio

GRADE Working Group grades of evidence

High quality: Further research is very unlikely to change our confidence in the estimate of effect.

Moderate quality: Further research is likely to have an important impact on our confidence in the estimate of effect and may change the estimate.

Low quality: Further research is very likely to have an important impact on our confidence in the estimate of effect and is likely to change the estimate.

Very low quality: We are very uncertain about the estimate.

${ }^{1}$ Risk of bias: We downgraded the evidence by one level because blinding of participants, personnel and outcome assessors was not mentioned and may introduce bias.

${ }^{2}$ Risk of bias: We downgraded the evidence by one level because the authors did not report or provide a description of an allocation concealment method.

${ }^{3}$ Missing outcome data in $11 \%$ of participants.

${ }^{4}$ Indirectness: We downgraded the evidence by one level because data come from a sub-study of a trial (Brown 2006) for diabetes that included continent as well as incontinent patients. 


\section{DISCUSSION}

This is the first systematic review to consider the effectiveness of specific lifestyle interventions in the management of adults with urinary incontinence.

\section{Summary of main results}

This review identified eleven trials that reported on the effect of weight loss (four trials), the intake of a soy-rich diet (one trial), change in fluid intake (three trials), reduction in caffeinated drinks (three trials), and lifestyle versus non-lifestyle interventions for weight loss (one trial). No trials were identified that investigated alcohol, sweetened fizzy drinks or diet drinks, constipation and straining, smoking cessation, physical activity or physical forces. Adverse effects appeared to be relatively uncommon for all interventions studied, although, with decreasing fluids, some participants experienced thirst, constipation, concentrated urine or headaches.

\section{Is weight loss by obese or overweight adults more effective than no treatment?}

Four trials investigated whether weight loss by obese or overweight adults was more effective than no treatment and included a total of 4701 women (Brown 2006b; Phelan 2012; Subak 2005; Subak 2009). It is important to note that two trials, which contributed over $90 \%$ of the women to this analysis, were primarily diabetes trials $(\mathrm{N}=1321$ and 2994, respectively; Brown 2006b; Phelan 2012).

There is 'low' quality evidence that, compared with the control interventions, weight loss programmes were associated with higher improvement rates based on women's self-report (primary outcome), and also higher cure and improvement rates based on quantifiable symptoms (secondary outcomes), although there was no information available on self-reported cure (primary outcome). The two diabetes trials also reported prevalence of urinary incontinence and identified a similar trend towards the weight loss groups having a greater reduction in the number of women with weekly incontinence episodes compared with the control groups ('very low' quality evidence). Only the smallest trial with 40 women measured disease-specific quality of life using the Incontinence Impact Questionnaire and the Urogenital Distress Inventory (Subak 2005), which showed statistically significant differences that favoured the weight loss group compared with the control group ('low' quality evidence).

This consistency of effect across a number of measured outcomes gives strength to the evidence. Overall, the differences in both cure and improvement when weight loss is compared to control suggest that weight loss interventions may be of interest to morbidly and moderately obese women and their clinicians. The degree of improvement in UI may be contingent upon the magnitude of the weight loss. A cohort analysis, Wing 2010, associated with one of the included trials (called the PRIDE study, $\mathrm{N}=338$ at baseline; Subak 2009) showed that women who lost $5 \%$ to $10 \%$ of their body weight (regardless of randomized treatment assignment) were two to four times more likely to achieve at least a $70 \%$ reduction in the number of total (i.e. stress or urgency) incontinence episodes per week compared with those who gained weight at follow-ups at six months (adjusted OR 3.7, 95\% CI 1.6 to 8.2), at 12 months (adjusted OR 3.7, 95\% CI 1.7 to 8.3) and at 18 months (adjusted OR $2.4,95 \%$ CI 1.1 to 5.1 ). Weight losses greater than $10 \% \mathrm{did}$ not result in greater improvements in incontinence outcomes (at 6 months, adjusted OR 3.8, 95\% CI 1.5 to 9.6; at 12 months, adjusted OR 4.1, 95\% CI 2.1 to 7.9 ; at 18 months, adjusted OR $3.3,95 \%$ CI 1.7 to 6.4$)$.

There is little evidence available concerning the potential mechanisms involved in the weight loss effect. There was inconsistency in the type of intervention provided that included various combinations of diet and physical activity. It was also unclear whether the dietary mechanism involved reduced calorie intake, or other change in the quality of the diet, or both. Some of the potential benefits of weight loss could also have been attributed to better glycaemic control rather than weight loss alone, in view of the substantial numbers of diabetics involved in the trials. Such results may not be entirely relevant to all people with obesity, although there was independent evidence for a weight loss effect in nondiabetics.

As might be expected, the benefit of the weight loss intervention diminished over time. This is clear from the forest plots for cure and improvement rates by quantification of symptoms and the number of incontinence episodes per week, which show that the point estimates move closer to the line of no effect from three months, through to 18 months. Maintenance of effect is rarely seen in long-term incontinence trials carried out years after intervention (Agur 2008; Glazener 2005), and therefore sustainability of weight loss and its long-term effect on incontinence would require further research.

\section{Is dietary change more effective than no change?}

One small trial investigated whether dietary change is more effective than no change (Manonai 2006); it included 42 women comparing a soy-rich diet with a soy-free diet. The only available outcome data for UI frequency found no evidence of a difference between the two diets ('very low' quality evidence). Other data were insufficient to draw any conclusions about the effect of the content of the diet on UI.

\section{Is changing the volume of fluid intake more effective than no change in the volume of fluid intake?}

Three trials investigated whether changing the volume of fluid intake is more effective than no change in the volume of fluid intake; these included 181 women and 11 men (Dowd 1996; Hashim 2008; Swithinbank 2005). Only one cross-over trial used 
disease-specific quality of life as the primary outcome and reported improvement in scores for the Bristol Female Lower Urinary Tract Symptoms questionnaire following decreased fluid intake (Swithinbank 2005). One trial reported poor adherence to the intervention protocol, which led to inconclusive results (Dowd 1996). Each trial used a different protocol detailing fluid manipulation and none of the trials reported improvement or cure. We ranked the quality of findings as 'very low'.

\section{Is caffeine reduction more effective than no change in caffeine consumption?}

Three trials investigated whether caffeine reduction is more effective than no change in caffeine consumption and included a total of 160 women and nine men (Bryant 2002; Miller 2007; Wells 2011). One trial was reported exclusively via an author email (Miller 2007), and was insufficiently detailed for us to draw firm conclusions. Across the trials, there was inconsistency in outcomes used, limited data and insufficient reporting to enable an analysis of whether caffeine reduction is better than no change in consumption. The limited and 'very low' quality data available on disease-specific quality of life (ICIQ-OABqol) and incontinence episode frequency found no evidence of a difference between the groups.

\section{Is any lifestyle intervention more effective than another intervention?}

One trial investigated whether one lifestyle intervention is more effective than any another intervention and included 1296 women (Brown 2006b); this was a sub-study of a large diabetes trial that compared two weight loss programmes - an intensive lifestyle intervention or a pharmacological intervention (metformin). The only available outcome data were on the effect of weight loss on prevalence of weekly UI (a secondary outcome of 'very low' evidence quality). The results showed that women had a lower prevalence of weekly UI in the lifestyle group than in the metformin group at a mean of 2.8 years follow-up and this difference between the groups was statistically significant, favouring the lifestyle intervention.

\section{Overall completeness and applicability of evidence}

The majority of included trials had small sample sizes, with 60 or fewer participants, and short follow-up (i.e. less than 12 months). Five of the included trials were parallel-arm RCTs (Brown 2006b; Dowd 1996; Subak 2005; Subak 2009; Phelan 2012). The remainder included four randomized cross-over trials (Hashim 2008; Manonai 2006; Swithinbank 2005; Wells 2011), and one quasiRCT (allocation made using health record numbers; Bryant 2002). We also included one unpublished trial, with limited information, from an author email (Miller 2007).
Participants in the trials included in this review were predominantly female, with the average age (unclear if this was mean or median) ranging from 49 to 58 years, except for two trials with means of 62.7 years, Hashim 2008, and 70.25 years, Dowd 1996. The trial participants were also those resident in the community. Therefore, the applicability of findings to men and older age groups, and particularly frail elderly people in care home settings, is uncertain.

Random sequence allocation was adequately generated and concealed in only two trials (Subak 2005; Subak 2009); in other trials it was either inadequate or not described in sufficient detail. This may have introduced selection bias.

The percentage of participants followed up and included in analysis varied across the included trials. Only four trials had either no missing outcome data, imputed missing data, or stated that missing data were balanced across groups (Brown 2006b; Hashim 2008; Subak 2005; Subak 2009), while in one trial nearly half of the participants were excluded from analysis due to missing data (Dowd 1996). In the other trials, the numbers of and reasons for missing outcome data were not clearly described, which led to uncertainty about the degree of attrition bias present in these trials. Reported outcome data were heterogenous in a number of ways and this limited our ability to make comparisons across trials. For example, within each category of lifestyle intervention (weight loss, diet quality, fluid restriction and caffeine restriction), the trials used no outcomes consistently. There was no single outcome common to all trials, and even outcomes that were conceptually similar were measured in different ways. No primary outcome data were available for six of the trials included in the review (Brown 2006b; Bryant 2002; Dowd 1996; Manonai 2006; Miller 2007; Phelan 2012). In particular, quality-of-life outcomes were very poorly recorded. The importance of the inclusion of quality-of-life outcomes should not be underestimated, as they are likely to be the most keenly valued by patients themselves. More recent trials are likely to include quality-of-life measures, as they are increasingly identified as key outcomes, and use of recognised instruments for measuring them, such as the International Consultation on Incontinence Questionnaire (ICIQ), are becoming more widely used.

\section{Quality of the evidence}

We assessed the levels of evidence for each outcome measured at 12 months after the commencement of the treatment using the GRADE approach (Summary of findings for the main comparison; Summary of findings 2; Summary of findings 3; Summary of findings 4; and Summary of findings 5). Overall, the GRADE level of evidence for all outcomes was either 'low' or 'very low' across the different interventions. The main factors for downgrading the evidence included risk of bias (lack of blinding and unclear allocation concealment), indirect evidence (less than 12 months of follow-up) and imprecise results due to a small sam- 
ple size with wide confidence intervals, or a lack of information (e.g. standard deviation) required to estimate confidence intervals. Evidence from studies where only some of the participants were incontinent was also downgraded for indirectness as described below.

Quality of outcome reporting was generally poor. We judged methodological quality (risk of bias) from the trial reports, and so our judgements may reflect the quality of reporting, rather than the actual methodological quality of the trials.

\section{Potential biases in the review process}

Due to the limited number of trials we identified that included only adults with UI, we made a post hoc decision to include data from trials where not all participants were incontinent when they entered the trial: the populations in these trials primarily had: overactive bladder (Hashim 2008; Miller 2007; Wells 2011); urgency and frequency (Bryant 2002); urogenital atrophy (Manonai 2006), or diabetes (Brown 2006b; Phelan 2012). Baseline incontinence ranged from 27\% of the trial participants in Phelan 2012 to $83 \%$ in Bryant 2002, or was not reported but assumed (Brown 2006b). We extracted outcome data from the whole study for all trials except Phelan 2012, which provided subgrouped data specific to incontinence status.

We made another post hoc decision to include an outcome on the prevalence of UI at follow-up; this outcome was identified from the two weight loss trials in people with diabetes (Brown 2006b; Phelan 2012). Our literature search was systematic and designed to pick up any mention of UI, urinary leakage or overactive bladder in the title, abstract and controlled vocabulary. A more indepth search required to identify studies for all clinical conditions was, however, not feasible within the limited resources available. This may have introduced reporting bias, as a large or beneficial intervention effect on UI may be more likely to be reported in abstracts of published reports than data showing little or no effect, and so be more likely to be identified by our search. If this is the case, including prevalence data could have exaggerated intervention effects. The applicability of evidence for managing people with urinary incontinence may also be limited, as the extent to which the weight loss programmes served as prevention, rather than treatment, of urinary incontinence is unclear.

Although every effort was made to adhere to the review protocol to minimise bias, these post hoc decisions resulted in changes to the inclusion criteria of the review. As data from those studies with mixed populations (with and without incontinence) often constituted the only information available for some of the interventions assessed in the review, we chose to include these data to provide relevant, albeit indirect, evidence. We exercised caution when interpreting these findings, by downgrading the quality of the body of evidence for the outcomes based on the studies with mixed populations (with and without incontinence) by one level on the ground of indirectness.
The review also encountered a problem associated with cross-over trials that did not report data in a standard way which would take into account the within-person differences (paired analysis). Instead, the included trials tended to report all measurements after completion of the treatment period and compared these data, as if they were a parallel group; some included trials also reported all measurements before and after intervention and compared these data within each treatment phase. The information required to perform paired analyses was not available from the published reports, which meant not only that the data from similar trials could not be incorporated into a meta-analysis, but also that the reported data presented a 'unit of analysis' error. These results should therefore be interpreted with caution.

The addition of the assessment of evidence quality using the GRADE approach and 'Summary of findings' tables was a relatively new development in the systematic review methods at the time of this review. While these methods were not specified in the protocol, we nevertheless attempted to incorporate them into the present review. Efforts were made to minimise bias in determining outcomes to be included in the tables and quality ratings for each outcome through careful discussion among the review authors. However, these steps may have been influenced by knowledge of the results of the research and may therefore carry some risk of bias.

\section{Agreements and disagreements with other studies or reviews}

We are unaware of other systematic reviews on this topic. However, a summary of the evidence in men and in women, including that from non-randomised studies, is provided in the 5th Edition of the International Consultation on Incontinence (Moore 2013).

\section{A U THORS'CONCLUSIONS}

\section{Implications for practice}

The available data show that evidence for weight loss as a treatment to reduce urinary incontinence (UI) among morbidly and moderately obese women is building, and might be worth considering as an initial treatment prior to other standard treatments such as pelvic floor muscle training and surgery. However, there is insufficient evidence to inform practice reliably about the effectiveness of lifestyle interventions in general.

\section{Implications for research}

The evidence for lifestyle changes for UI is strongest for the effects of weight loss programmes, which should receive research priority. Weight loss interventions involving diet and fluid manipulation 
require more well designed trials that using representative samples of cases. Priority should also be given to investigating dietary mechanisms for weight loss effects, such as calorie reduction, specific food or drink items and nutrient content as well as the role of physical activity. Where specific evidence of effectiveness exists, as in weight loss, lifestyle interventions should be further evaluated as first-line treatments.

The review identified a complete lack of randomized trials for lifestyle factors that are generally supposed to increase incontinence, such as the intake of alcohol, sweetened fizzy or diet drinks, smoking, physical forces, or clinical constipation and straining. The widespread use of such lifestyle advice to moderate these factors in the hope of reducing UI, and the observational evidence we identified, suggest a need for further research in these areas.

There is a need for separate consideration of the components of multi-faceted lifestyle interventions in trials. Combining a number of individual interventions, whose efficacy has not been evaluated independently, in trials makes it impossible to determine which factors affect change. Ideally, the initial research focus should be on those areas where evidence is building (e.g. weight loss) or where healthcare advice often promotes lifestyle interventions in the absence of evidence (e.g. caffeine consumption). The results of such trials could then feed into a multi-faceted lifestyle intervention trial that would reflect common practice and be rooted in a sound evidence base.

It is expected that more recent trials are likely to have fewer methodological problems. Ongoing improvements in the quality of reporting, and incorporation of consistent use of CONSORT (Consolidated Standards of Reporting Trials, http://www.consortstatement.org/), should impact on the inclusion of trials in subsequent systematic reviews, ensuring that the most robust evidence contributes to clinical recommendations.

\section{R E F E R E N C E S}

\section{References to studies included in this review}

\section{Brown 2006b \{published data only\}}

* Brown JS, Wing R, Barrett-Connor E, Nyberg LM, Kusek

JW, Orchard TJ, et al. Lifestyle intervention is associated with lower prevalence of urinary incontinence: the Diabetes Prevention Program. Diabetes Care 2006;29(2):385-90. [: sr-incont21588]

Diabetes Prevention Program Research Group. The Diabetes Prevention Program (DPP): description of lifestyle intervention. Diabetes Care 2002;25(12):2165-71. [: sr-incont45301]

Diabetes Prevention Program Research Group. The Diabetes Prevention Program: design and methods for a clinical trial in the prevention of type 2 diabetes. Diabetes Care 1999;22(4):623-34. [: sr-incont45300]

Knowler WC, Barrett-Connor E, Fowler SE, Hamman RF, Lachin JM, Walker EA, et al. Reduction in the incidence of type 2 diabetes with lifestyle intervention or metformin. New England Journal of Medicine 2002;346(6):393-403. [: sr-incont45299]

\section{Bryant 2002 \{published data only\}}

Bryant CM, Dowell CJ, Fairbrother G. A randomised trial of the effects of caffeine upon frequency, urgency and urge incontinence (Abstract number 96). Neurourology and Urodynamics. 2000; Vol. 19(4), issue 4:501-2. [: sr-incont9985]

* Bryant CM, Dowell CJ, Fairbrother G. Caffeine reduction education to improve urinary symptoms. British Journal of Nursing 2002; Vol. 11, issue 8:560-5. [: sr-incont14625] Bryant CM, Dowell CJ, Fairbrother G. Final results of a randomised trial of a caffeine reduction intervention and descriptive analysis of caffeine behaviours (Abstract number 303). Proceedings of the International Continence Society
(ICS), 31st Annual Meeting; 2001 Sept 18-21: Seoul, Korea. 2001. [: sr-incont14382]

Dowd 1996 \{published data only\}

Dowd TT, Campbell JM, Jones JA. Fluid intake and urinary incontinence in older community-dwelling women. Journal of Community Health Nursing 1996;13(3):179-86. [: sr-incont4875]

Hashim 2008 \{published data only\}

Hashim H, Abrams P. How should OAB patients manipulate their fluid input? (Poster abstract 1187). Journal of Urology 2007;177(4 Suppl S):391-2. [: sr-incont31881] ${ }^{*}$ Hashim H, Abrams P. How should patients with an overactive bladder manipulate their fluid intake?. BJU International 2008;102(1):62-6. [: sr-incont27614] Sivanandam A, Bhandari M. How should patients with an overactive bladder manipulate their fluid intake? [comment]. BJU International 2008;102(7):903; author reply 903-4. [: sr-incont27443]

Manonai 2006 \{published data only\} Manonai J, Songchitsomboon S, Chanda K, Hong JH, Komindr S. The effect of a soy-rich diet on urogenital atrophy: a randomized, cross-over trial. Maturitas 2006;54 (2):135-40. [: sr-incont21878]

Miller 2007 \{unpublished data only\} Miller JM. Overactive bladder and potentially "irritating" beverage intake: a randomized controlled trial. http:// www.nursing.umich.edu/faculty/miller janis.html (accessed 10 Dec 2007) 2007. [: sr-incont29636]

Phelan 2012 \{published data only\} Phelan S, Kanaya AM, Subak LL, Hogan PE, Espeland MA, Wing RR, et al. Prevalence and risk factors for urinary incontinence in overweight and obese diabetic women: 
action for health in diabetes (Look AHEAD) study. Diabetes Care 2009;32(8):1391-7. [: sr-incont32095]

* Phelan S, Kanaya AM, Subak LL, Hogan PE, Espeland MA, Wing RR, et al. Weight loss prevents urinary incontinence in women with type 2 diabetes: results from the Look AHEAD trial. Journal of Urology 2012;187(3): 939-44. [: sr-incont44588]

Ryan DH, Espeland MA, Foster GD, Haffner SM, Hubbard VS, Johnson KC, et al. Look AHEAD (Action for Health in Diabetes): design and methods for a clinical trial of weight loss for the prevention of cardiovascular disease in type 2 diabetes. Controlled Clinical Trials 2003;24(5):610-28. [: sr-incont45302]

\section{Subak 2005 \{published data only\}}

Subak LL, Whitcomb E, Shen H, Saxton J, Vittinghoff E, Brown JS. Weight loss: a novel and effective treatment for urinary incontinence. Journal of Urology 2005;174(1): 190-5. [: sr-incont20655]

Subak 2009 \{published data only\} Grady D, Subak L, Kusek J, Nyberg L. PRIDE program to reduce incontinence by diet and exercise. www.controlled-trials.com (accessed 17 January 2005) and http://clinicaltrials.gov/show/NCT00091988 (accessed 28 November 2013) 2004. [: sr-incont19516; : sr-incont49826]

Huang AJ, Stewart AL, Hernandez AL, Shen H, Subak LL, for the Program to Reduce Incontinence by Diet and Exercise. Sexual function among overweight and obese women with urinary incontinence in a randomized controlled trial of an intensive behavioral weight loss intervention. Journal of Urology 2009;181(5):2235-42. [: sr-incont31149]

Huang AJ, Subak LL, Wing R, West DS, Hernandez AL, Macer J, et al. An intensive behavioral weight loss intervention and hot flushes in women. Archives of Internal Medicine 2010;170(13):1161-7. [: sr-incont40225] Myers DL, Sung VW, Richter HE, Creasman J, Subak LL. Prolapse symptoms in overweight and obese women before and after weight loss. Female Pelvic Medicine o Reconstructive Surgery 2012;18(1):55-9. [: sr-incont44558] Pinto AM, Kuppermann M, Nakagawa S, Vittinghoff E, Wing RR, Kusek JW, et al. Comparison and correlates of three preference-based health-related quality-of-life measures among overweight and obese women with urinary incontinence. Quality of Life Research 2011;20(10): 1655-62. [: sr-incont44597]

Pinto AM, Subak LL, Nakagawa S, Vittinghoff E, Wing RR, Kusek JW, et al. The effect of weight loss on changes in health-related quality of life among overweight and obese women with urinary incontinence. Quality of Life Research 2012;21(10):1685-94. [: sr-incont45862]

* Subak L, Wing R, West D, Franklin F, Vittinghoff $\mathrm{E}, \mathrm{Creasman} \mathrm{JM}$, et al. Weight loss to treat urinary incontinence in overweight and obese women. New England Journal of Medicine 2009;360(5):481-90. [: sr-incont29651]

Subak LL, Marinilli Pinto A, Wing RR, Nakagawa S, Kusek
JW, Herman WH, et al. Decrease in urinary incontinence management costs in women enrolled in a clinical trial of weight loss to treat urinary incontinence. Obstetrics \& Gynecology 2012;120(2 Pt 1):277-83. [: sr-incont45146] Subak LL, Wing R, Smith West D, Franklin F, Vittinghoff E, Creasman J, et al. A behavioral weight loss program significantly reduces urinary incontinence episodes in overweight and obese women (Abstract 1). Journal of Pelvic Medicine \& Surgery 2007;13(5):223-4. [: sr-incont31081] West DS, Gorin AA, Subak LL, Foster G, Bragg C, Hecht $\mathrm{J}$, et al. A motivation-focused weight loss maintenance program is an effective alternative to a skill-based approach. International Journal of Obesity 2011;35(2):259-69. [: sr-incont40994]

Wing RR, Creasman JM, West DS, Richter HE, Myers $\mathrm{D}$, Burgio KL, et al. Improving urinary incontinence in overweight and obese women through modest weight loss. Obstetrics \& Gynecology 2010;116(2 Pt 1):284-92. [: sr-incont39918]

Wing RR, West DS, Grady D, Creasman JM, Richter HE, Myers D, et al. Effect of weight loss on urinary incontinence in overweight and obese women: results at 12 and 18 months. Journal of Urology 2010;184(3):1005-10. [: sr-incont 40041$]$

\section{Swithinbank 2005 \{published data only\}}

* Swithinbank L, Hashim H, Abrams P. The effect of fluid intake on urinary symptoms in women. Journal of Urology 2005;174(1):187-9. [: sr-incont20656]

Swithinbank LV, Rogers CA, Yang Q, Shepherd AM, Abrams P. Does the amount and type of fluid intake effect urinary symptoms in women? (Abstract number 104). Neurourology and Urodynamics. 1999; Vol. 18(4), issue 4: 371-2. [: sr-incont9946]

\section{Wells 2011 \{published data only\}}

Wells M, Green S, Jamieson K, Markham T, Rogers P, Getliffe K, et al. An investigation of the effect of drinking caffeinated versus decaffeinated fluids on symptoms of overactive bladder syndrome: a feasibility trial (Abstract 700). Proceedings of the 41st Annual Meeting of the International Continence Society (ICS); 2011 Aug 29-Sept 2; Glasgow, Scotland. 2011. [: sr-incont42229]

\section{References to studies excluded from this review}

\section{BE-DRI \{published data only\}}

Mueller ER, Litman H, Zimmern PE, Norton P, Goode P. Impact of fluid management on fluid intake and urge incontinence in the BE-DRI trial for OAB in women [Abstract 1530]. Journal of Urology 2009;181(4 Suppl): 547-8.

The Urinary Incontinence Treatment Network (UITN). Design of the Behavior Enhances Drug Reduction of Incontinence (BE-DRI) study. Contemporary Clinical Trials 2007;28(1):48-58. [: SR-INCONT22573]

Zimmern P, Litman H, Mueller E, Norton P, Goode P. Impact of fluid management on fluid intake and urge incontinence in the BE-DRI trial for OAB in women 
(Abstract: Podium \#30). Neurourology and Urodynamics 2009;28(2):163.

* Zimmern P, Litman HJ, Mueller E, Norton P, Goode P, for the Urinary Incontinence Treatment Network. Effect of fluid management on fluid intake and urge incontinence in a trial for overactive bladder in women. BJU International 2010;105(12):1680-5. [: SR-INCONT39953]

Bird 2005 \{published data only\}

Bird ET, Parker BD, Kim HS, Coffield KS. Caffeine ingestion and lower urinary tract symptoms in healthy volunteers. Neurourology and Urodynamics 2005;24(7): 611-5.

Brown 2007 \{published data only\}

Brown CT, Emberton M. Self-management for men with lower urinary tract symptoms. Current Urology Reports 2009; 10(4):261-6.

* Brown CT, Yap T, Cromwell DA, Rixon L, Steed L, Mulligan K, et al. Self management for men with lower urinary tract symptoms: randomised controlled trial. $B M J$ 2007;334(7583):25-8.

Yap TL, Brown C, Cromwell DA, Van Der Meulen J, Emberton M. The impact of self-management of lower urinary tract symptoms on frequency-volume chart measures. BJU International 2009;104(8):1104-8.

Dougherty 2002 \{published data only\}

Dougherty MC, Dwyer JW, Pendergast JF, Boyington AR, Tomlinson BU, Coward RT. A randomized trial of behavioral management for continence with older rural women. Research in Nursing \& Health 2002;25(1):3-13. [: SR-INCONT12933]

Dumoulin 2011 \{published data only\}

Dumoulin C, Sran M, Lieblich P, Wilson P. Physiotherapy significantly reduces leakage in postmenopausal women with osteoporosis and urinary incontinence: result of a parallel randomised controlled trial (Abstract 130). Neurourology and Urodynamics 2011;30(6):985-6.

Glazener 2001 \{published data only\}

Glazener CM, Herbison GP, MacArthur C, Grant A, Wilson PD. Randomised controlled trial of conservative management of postnatal urinary and faecal incontinence: six year follow up. BMJ 2005;330(7487):337-40. Glazener CM, Herbison GP, Wilson PD, MacArthur $\mathrm{C}$, Lang GD, Gee H, et al. Conservative management of persistent postnatal urinary and faecal incontinence: randomised controlled trial. BMJ. England, 2001; Vol. 323, issue 7313:593-6. [: SR-INCONT 12122]

* Glazener CM, Herbison GP, Wilson PD, MacArthur C, Lang GD, Gee H, et al. Conservative management of persistent postnatal urinary and faecal incontinence: randomised controlled trial [Extended electronic version]. eBMJ. England, 2001; Vol. 323:1-5. [: SR-INCONT12123]

Herschorn 2003 \{published data only\} Herschorn S, Becker D, Miller B, Thompson M, Forte $\mathrm{L}$. The impact of a simple health education intervention in overactive bladder patients (Abstract). Proceedings of the International Continence Society (ICS), 33rd Annual Meeting; 2003 Oct 5-9; Florence Italy. 2003:352-3.

Herschorn 2004 \{published data only\}

Herschorn S, Becker D, Miller E, Thompson M, Forte L. Impact of a health education intervention in overactive bladder patients. Canadian Journal of Urology 2004;11(6): 2430-7. [: SR-INCONT20194]

\section{Hofbauer 1990 \{published data only\}}

Hofbauer J, Preisinger F, Nurnberger N. [The value of physical therapy in genuine female stress incontinence]. [German] [Der Stellenwert der Physikotherapie bei der weiblichen genuinen Stress-inkontinenz]. Zeitschrift Fur Urologie Und Nephrologie 1990;83(5):249-54. [: SR-INCONT350]

Kim 2011a \{published data only\}

Kim H, Yoshida H, Suzuki T. The effects of multidimensional exercise treatment on communitydwelling elderly Japanese women with stress, urge, and mixed urinary incontinence: a randomized controlled trial. International Journal of Nursing Studies 2011;48(10): 1165-72. [: SR-INCONT42657]

Kim 2011b \{published data only\}

Kim H, Yoshida H, Suzuki T. Effects of exercise treatment with or without heat and steam generating sheet on urine loss in community-dwelling Japanese elderly women with urinary incontinence. Geriatrics and Gerontology International 2011;11(4):452-9. [: SR-INCONT42661]

Kincade 2007a \{published data only\}

Kincade JE, Dougherty MC, Carlson JR, Wells EC, Hunter GS, Busby-Whitehead J. Factors related to urinary incontinence in community-dwelling women. Urologic Nursing 2007;27(4):307-17. [: SR-INCONT23858]

Kincade 2007b \{published data only\}

Kincade JE, Dougherty MC, Carlson JR, Hunter GS, Busby-Whitehead J. Randomized clinical trial of efficacy of self-monitoring techniques to treat urinary incontinence in women. Neurourology and Urodynamics 2007;26(4): 507-11. [: SR-INCONT23537]

Li 2001 \{published data only\}

Li FZ, Harmer P, McAuley E, Duncan TE, Duncan SC, Chaumeton N, et al. An evaluation of the effects of Tai Chi exercise on physical function among older persons: a randomized controlled trial. Annals of Behavioral Medicine 2001;23(2):139-46.

Parker 2005 \{published data only\}

Parker B, Bird E, Coffield S. Randomized prospective study of caffeine's effect on lower urinary tract symptoms in healthy human subjects (Poster 7). Neurourology and Urodynamics 2005;24(2):167-8.

Ree 2007 \{published data only\} Ree ML, Nygaard I, Bo K. Muscular fatigue in the pelvic floor muscles after strenuous physical activity. Acta Obstetricia et Gynecologica Scandinavica 2007;86(7):870-6.

Schauss 2006 \{published data only\}

Schauss DA, Spiller DG. Reducing the symptoms of overactive bladder and urinary incontinence: results of a 
two-month randomized, double-blind, placebo-controlled clinical trial (Abstract 300). Proceedings of the International Continence Society (ICS), 36th Annual Meeting; 2006 Nov 27-Dec 1; Christchurch, New Zealand. 2006.

Tomlinson 1999 \{published data only\}

Tomlinson BU, Dougherty MC, Pendergast JF, Boyington AR, Coffman MA, Pickens SM. Dietary caffeine, fluid intake and urinary incontinence in older rural women. International Urogynecology Journal and Pelvic Floor Dysfunction 1999;10(1):22-8.

Van Hespen 2006 \{published data only\} Van Hespen ATH, Tak ECPM, Van Dommelen P, HopmanRock M. Evaluation of the urinary incontinence training programme, INCondition, for women living in homes for the elderly. Nederlands Tijdschrift voor Fysiotherapie 2006; 116(6):136-42.

\section{Wagg 2007 \{published data only\}}

Wagg AR, Barron D, Kirby M, Stott D Corlett K. A randomised partially controlled trial to assess the impact of self-help vs. structured help from a continence nurse specialist in women with undiagnosed urinary problems in primary care. International Journal of Clinical Practice 2007; 61(11):1863-73. [: SR-INCONT23948]

\section{References to studies awaiting assessment}

\section{Baker 2011 \{published data only\}}

Baker J. Mindfulness-Based Stress Reduction Techniques and Yoga for treatment of urinary urge incontinence (MBSR-Yoga) (Trials registry number: NCT01470560). ClinicalTrials.gov (http://clinicaltrials.gov/show/ NCT01470560) 2011. [: sr-incont49230]

\section{Gozukara 2014 \{published data only\}} Gozukara YM, Akalan G, Tok EC, Aytan H, Ertunc D. The improvement in pelvic floor symptoms with weight loss in obese women does not correlate with the changes in pelvic anatomy. International Urogynecology Journal 2014;25(9): 1219-25. [: sr-incont62552]

Heesakkers 2009 \{published data only\}

Heesakkers J. Prospective intervention study of drink advice in overactive bladder syndrome $(\mathrm{OAB})$ (Trials registry number: NCT00982241). ClinicalTrials.gov (http:// clinicaltrials.gov/show/NCT00982241) 2009 (accessed 2 December 2013). [: sr-incont49231]

Huang 2012 \{published data only\}

Huang A. Lessening Incontinence by Learning Yoga (LILY) (Trials registry number: NCT01672190). ClinicalTrials.gov (http://clinicaltrials.gov/show/NCT01672190) 2012 (accessed 28 November 2013). [: NCT01672190; : TrialID.LILY.; : sr-incont49228]

Huang AJ, Jenny HE, Chesney MA, Schembri M, Subak LL. A group-based yoga therapy intervention for urinary incontinence in women: a pilot randomized trial. Female Pelvic Medicine \& Reconstructive Surgery 2014; 20(3):147-54. [: NCT01672190; : TrialID.LILY.; : sr-incont60608]
Markland 2013 \{published data only\}

Markland AD, Shanks JL. Vitamin D supplementation in older adults with urinary incontinence (Trial registry number: NCT01971801). ClinicalTrials.gov (http:// clinicaltrials.gov/show/NCT01971801) 2013 (accessed 28 November 2013). [: sr-incont49229]

Seckin 2011 \{published data only\} Seckin B, Kulaksizoglu H, Cakmakci E. The effects of pelvic floor muscle targeted Pilates versus regular aerobic exercise on urinary incontinence (Abstract UP-03.170). Urology 2011;78(3 Suppl 1):S400-1. [: sr-incont61934]

Wells 2014 \{published data only\} Wells MJ, Jamieson K, Markham TC, Green SM, Fader MJ. The effect of caffeinated versus decaffeinated drinks on overactive bladder: a double-blind, randomized, crossover study. Journal of Wound, Ostomy, \& Continence Nursing 2014;41(4):371-8. [: sr-incont62569]

\section{References to ongoing studies}

\section{Moholdt 2011 \{published data only\}}

Moholdt TT, Salvesen K, Ingul CB, Vik T, Oken E, Morkved S. Exercise Training in Pregnancy for obese women (ETIP): study protocol for a randomised controlled trial. Trials [Electronic Resource] 2011;12:154. [: sr-incont41703]

\section{Additional references}

\section{Abrams 2002}

Abrams P, Cardozo L, Fall M, Griffiths D, Rosier P, Ulmsten $\mathrm{U}$, et al. The standardisation of terminology of lower urinary tract function: report from the Standardisation Sub-committee of the International Continence Society. American Journal of Ostetrics and Gynecology 2002;187(1): $116-26$.

Abrams 2005

Abrams P, Cardozo L, Khoury S, Wein A. Incontinence: 3rd International Consultation on Incontinence, 2004, Volume 1: Basics and Evaluation. 2005. France: Health Publication Ltd, 2005.

Abrams 2013

Milsom I, Altman D, Cartwright R, Lapitan MC, Nelson $\mathrm{R}$, Sillén $\mathrm{U}$, et al. Epidemiology of urinary incontinence (UI) and other lower urinary tract symptoms (LUTS), pelvic organ prolapse (POP) and anal incontinence (AI) (Comitttee 1). In: Abrams P, Cardozo L, Khoury S, Wein A editor(s). Incontinence: 5th International Consultation on Incontinence. Recommendations of the International Scientific Committee: evaluation and treatment of urinary incontinence, pelvic organ prolapse and faecal incontinence; $2012 \mathrm{Feb} 23-25$; Paris. Belgium: International Consultation on Urological Diseases (ICUD), 2013:15-107.

Agur 2008

Agur WI, Steggles P, Waterfield M, Freeman RM. The longterm effectiveness of antenatal pelvic floor muscle training: eight-year follow up of a randomised controlled trial. British journal of obstetrics and gynaecology 2008;115(8):985-990. 
Avery 2004

Avery K, Donovan J, Peters T, Shaw C, Gotoh M, Abrams P. ICIQ: a brief and robust measure for evaluating the symptoms and impact of urinary incontinence. Neurourology and Urodynamics 2004;23(4):322-30.

Baumgart 2015

Baumgart M, Snyder HM, Carrillo MC, Fazio S, Kim H, Johns $\mathrm{H}$. Summary of the evidence on modifiable risk factors for cognitive decline and dementia: a population based perspective. Alzheimer's \& Dementia 2015;11: 718-726.

Brown 2006a

Brown JS, Wing R, Barrett-Connor E, et al. Lifestyle intervention is associated with lower prevalence of urinary incontinence. Diabetes Care 2006;29:385-90.

Cartwright 2007

Cartwright R, Srikrishna S, Cardozo L, Gonzalez J. Does Diet Coke cause overactive bladder? A 4-way crossover trial, investigating the effect of carbonated soft drinks on overactive bladder symptoms in normal volunteers (Abstract 19). Neurourology and Urodynamics 2007;26(5):626-7.

Chowdhury 2012

Chowdhury R, Stevens S, Gorman D, Pan A, Warnakula S, Chowdhury S, Ward H, Johnson L, Crowe F, Hu FB, Franco $\mathrm{OH}$. Association between fish consumption, longchain omega 3 fatty acids and risk of cerebrovascular disease: a systematic review and meta-analysis. BMJ (Clinical Research ed) 2012;345:e6698.

Creighton 1990

Creighton SM, Stanton SL. Caffeine: does it affect your bladder?. British Journal of Urology 1990;66(6):613-4.

\section{Dallosso 2003}

Dallosso HM, McGrother CW, Matthews RJ, Donaldson MMK, and the Leicestershire MRC Incontinence Study Team. The association of diet and other lifestyle factors with overactive bladder and stress incontinence: a longitudinal study in women. BJU International 2003;92:69-77.

\section{Dallosso 2004a}

Dallosso HM, Matthew R, McGrother CM, Donaldson MMK and the Leicestershire MRC Incontinence Study Team. Diet as a risk factor for the development of stress urinary incontinence: a longitudinal study in women. European Journal of Clinical Nutrition 2004a;58(6):920-6.

\section{Dallosso 2004b}

Dallosso HM, Matthews RJ, McGrother CW, Donaldson MMK, Shaw $\mathrm{C}$ and the Leicestershire MRC Incontinence Study Team. The association of diet and other lifestyle factors with the onset of overactive bladder: a longitudinal study in men. Public Health Nutrition 2004b;7(7):885-91.

\section{Dallosso 2004c}

Dallosso HM, McGrother CM, Matthew R, Donaldson MMK and the Leicestershire MRC Incontinence Study Team. Nutrient composition of the diet and the development of overactive bladder: a longitudinal study in women. Neurourology and Urodynamics 2004;23(3): 204-10.

\section{Danforth 2007}

Danforth KN, Shah AD, Townsend MK, Lifford KL, Curhan GC, Resnick NM, et al. Physical activity and urinary incontinence among healthy, older women. Obstetrics and Gynecology 2007;109:721-7.

\section{Dasgupta 2006}

Dasgupta J, Elliott RA, Doshani A, Tincello DG. Enhancement of rat bladder contraction by artificial sweeteners via increased extracellular Ca2+ influx. Toxicology and Applied Pharmacology 2006;217(2):216-24.

\section{Dumoulin 2010}

Dumoulin C, Hay-Smith J. Pelvic floor muscle training versus no treatment, or inactive control treatments, for urinary incontinence in women. Cochrane Database of Systematic Reviews 2010, Issue 1. [DOI: 10.1002/ 14651858.CD005654.pub2; : CD005654]

Elbourne 2002

Elbourne DR, Altman DG, Higgins JP, Curtin F, Worthington HV, Vail A. Meta-analyses involving crossover trials: methodological issues. International Journal of Epidemiology 2002;31(1):140-9.

\section{Fader 2007}

Fader M, Cottenden AM, Getliffe K. Absorbent products for light urinary incontinence in women. Cochrane Database of Systematic Reviews 2007, Issue 2. [DOI: 10.1002/ 14651858.CD001406.pub2; : CD001406]

\section{Fader 2008}

Fader M, Cottenden AM, Getliffe K. Absorbent products for moderate-heavy urinary and/or faecal incontinence in women and men. Cochrane Database of Systematic Reviews 2008, Issue 4. [DOI: 10.1002/14651858.CD007408; : CD007408]

\section{Folstein 1975}

Folstein MF, Folstein SE, McHugh PR. "Mini-mental state". A practical method for grading the cognitive state of patients for the clinician. Journal of Psychiatric Research 1975;12(3):189-98.

\section{Glazener 2005}

Glazener CMA, Herbison GP, MacArthur C, Grant A, Wilson DP. Randomised controlled trial of conservative management of postnatal urinary and faecal incontinence: six year follow up. BMJ 2005;330(7487):337-9.

\section{Guyatt 2008}

Guyatt GH, Oxman AD, Kunz R, Vist GE, Falck-Ytter Y, Schünemann HJ, et al. What is "quality of evidence" and why is it important to clinicians?. BMJ 2008;336(7651): 995-8.

\section{Hannestad 2004}

Hannestad YS, Rortveit G, Daltveit AK, Hunskaar S. Are smoking and other lifestyle factors associated with female urinary incontinence? The Norwegian EPINCONT Study. BJOG: An International Journal of Obstetrics and Gynaecology 2004;110(3):247-54. 


\section{He 2006}

He FJ, Nowson CA, MacGregor GA. Fruit and vegetable consumption and stroke: meta-analysis of cohort studies. Lancet 2006;367(9507):320-326.

Herbison 2002

Herbison GP, Dean N. Weighted vaginal cones for urinary incontinence. Cochrane Database of Systematic Reviews 2002, Issue 1. [DOI: 10.1002/14651858.CD002114; : CD002114]

Higgins 2003

Higgins JPT, Thompson SG, Deeks JJ, Altman DG. Measuring inconsistency in meta-analyses. BMJ 2003;327: 557-60.

\section{Hunskaar 2008}

Hunskaar S. A systematic review of overweight and obesity as risk factors and targets for clinical intervention for urinary incontinence in women. Neurourology and Urodynamics 2008;27(8):749-57.

\section{James 1988}

James JE, Paull I, Cameron-Traub E, Miners JO, Lelo A, Birkett DJ. Biochemical validation of self-reported caffeine consumption during caffeine fading. Journal of Behavioral Medicine 1988;11(1):15-30.

\section{Kiff 1984}

Kiff ES, Barnes PR, Swash M. Evidence of pudendal neuropathy in patients with perineal descent and chronic straining at stool. Gut 1984;25(11):1279-82.

\section{Lipp 2011}

Lipp A, Shaw C, Glavind K. Mechanical devices for urinary incontinence in women. Cochrane Database of Systematic Reviews 2011, Issue 7. [DOI: 10.1002/ 14651858.CD001756.pub5; : CD001756]

\section{Maserejian 2010}

Maserejian NN, Giovannucci EL, McVary KT, McGrother C, McKinlay JB. Dietary macronutrient and energy intake and urinary incontinence in women. American Journal of Epidemiology 2010;171(10):1116-25.

\section{Mattiasson 1998}

Mattiasson A, Djurhuus JC, Fonda D, Lose G, Nordling J, Stöhrer M. Standardization of outcome studies in patients with lower urinary tract dysfunction: a report on general principles from the Standardisation Committee of the International Continence Society. Neurourology and Urodynamics 1998;17(3):249-53.

\section{McGrother 2004}

McGrother CW, Donaldson MMK, Shaw C, Matthews RJ, Hayward TA, Dallosso HM, et al. Storage symptoms of the bladder: prevalence, incidence and need for services in the UK. BJU International 2004;93(6):763-9.

\section{McGrother 2007}

McGrother C, Donaldson M, Wagg A, Matharu G, Williams K, Watson J, et al. Continence. In: Stevens ARJ, Mant J, Simpson S editor(s). Health Care Needs Assessment: the epidemiologically based needs assessment reviews. 3rd Edition. Abingdon: Radcliffe Medical Press Ltd, 2007: 69-175.

\section{McGrother 2012}

McGrother CW, Donaldson MMK, Thompson J, Wagg A, Tincello DG, Manktelow BN. Etiology of overactive bladder: a diet and lifestyle model for diabetes and obesity in older women. Neurourology and Urodynamics 2012;31: 487-95.

\section{Moller 2000}

Moller L, Lose G, Jorgensen T. Risk factors for lower urinary tract symptoms in women 40-60 years of age. Obstetrics and Gynecology 2000;96:446.

\section{Moon 1997}

Moon TD, Hagen L, Heisey DM. Urinary symptomatology in younger men. Urology 1997;50(5):700-3.

\section{Moore 2013}

Moore K, Dumoulin C, Bradley C, Burgio K, Chambers T, Hagen $S$, et al. Adult conservative management (Chapter 12). In: Abrams P, Cardozo L, Khoury S, Wein A editor(s). Incontinence: 5th International Consultation on Incontinence. Recommendations of the International Scientific Committee: evaluation and treatment of urinary incontinence, pelvic organ prolapse and faecal incontinence2012 Feb 23-25; Paris. Belgium: International Consultation on Urological Diseases (ICUD), 2013:1101-227.

Nabi 2006

Nabi G, Cody JD, Ellis G, Hay-Smith J, Herbison GP. Anticholinergic drugs versus placebo for overactive bladder syndrome in adults. Cochrane Database of Systematic Reviews 2006, Issue 4. [DOI: 10.1002/ 14651858.CD003781.pub2; : CD003781]

\section{Nygaard 2006}

Nygaard I, Girts T, Fultz NH, Kinchen K, Pohl G, Sternfeld B. Is urinary incontinence a barrier to exercise in women?. Obstetrics and Gynecology 2005;106(2):307-314.

\section{Ogah 2009}

Ogah J, Cody JD, Rogerson L. Minimally invasive synthetic suburethral sling operations for stress urinary incontinence in women. Cochrane Database of Systematic Reviews 2009, Issue 4. [DOI: 10.1002/14651858.CD006375.pub2; : CD006375]

\section{Ortega 2012}

Ortega RM, Rodriguez-Rodriguez E, Lopez-Sobaler AM. Effects of omega 3 fatty acids supplementation in behavior and non-neurodegenerative neuro-psychiatric disorders. British Journal of Nutrition 2012;107:S261-S270.

Reference Manager 2012

Thomson Reuters. Reference Manager Professional Edition Version 12. New York: Thomson Reuters. New York: Thomson Reuters, 2012.

\section{RevMan 2014}

The Nordic Cochrane Centre, The Cochrane Collaboration. Review Manager (RevMan). 5.3. Copenhagen: The Nordic Cochrane Centre, The Cochrane Collaboration, 2014.

\section{Schünemann 2011a}

Schünemann HJ, Oxman AD, Higgins JPT, Vist GE, Glasziou P, Guyatt GH. Chapter 11: Presenting results 
and 'Summary of findings' tables. In: Higgins JPT, Green S (editors). Cochrane Handbook for Systematic Reviews of Interventions Version 5.1.0 [updated March 2011]. The Cochrane Collaboration 2011. Available from www.cochrane-handbook.org. The Cochrane Collaboration, Available from www.cochranehandbook.org..

\section{Schünemann 2011b}

Schünemann HJ, Oxman AD, Vist GE, Higgins JPT, Deeks JJ, Glasziou P, et al. Chapter 12: Interpreting results and drawing conclusions. In: Higgins JPT, Green S (editors). Cochrane Handbook for Systematic Reviews of Interventions Version 5.1.0 [updated March 2011]. The Cochrane Collaboration 2011. Available from www.cochrane-handbook.org. The Cochrane Collaboration.

\section{Skerrett 2010}

Skerrett PJ, Willett WC. Essentials of healthy eating: a guide. Journal of Midwifery \& Women's Health 2010;55(6): 492-501.

\section{Subak 2002}

Subak LL, Johnson C, Whitcomb E, et al. Does weight loss improve incontinence in moderately obese women? . International Urogynecology Journal and Pelvic Floor Dysfunction 2002;13(1):40-3.

\section{Subak 2005a}

Subak LL, Whitcomb E, Shen H, Saxton J, Vittinghoff E, Brown JS. Weight Loss: a novel and effective treatment for urinary incontinence. Journal of Urology 2005;174:190-5.

\section{Subak 2009a}

Subak LL, Richter HE, Hunskaar S. Obesity and urinary incontinence: epidemiology and clinical research update. Journal of Urology 2009;182(6 Suppl):S2-7. [: SR-INCONT39545]

\section{Subak 2009b}

Subak LL, Wing R, West DS, Franklin F, Vittinghoff E, Creasman JM, et al. PRIDE Investigators. Weight loss to treat urinary incontinence in overweight and obese women. New England Journal of Medicine 2009;360(5):481-90.

\section{Tampakoudis 1995}

Tampakoudis P, Tantanassis T, Grimbizis G, Papaletsos $\mathrm{M}$, Mantalenakis $\mathrm{S}$. Cigarette smoking and urinary incontinence in women? A new calculative method of estimating the exposure to smoke. European Journal of Obstetrics, Gynecology, and Reproductive Biology 1995;63(1): 27-30.

\section{Townsend 2008}

Townsend MK, Curhan GC, Resnick NM, Grodstein F. Body mass index, waist circumference, and incident urinary incontinence in older women. Obesity 2008;16:881-6.

\section{Turner 2004}

Turner DA, Shaw C, McGrother CW, Dallosso HM, Cooper NJ. The cost of clinically xignificant urinary storage symptoms for community dwelling adults in the UK. BJU International 2004;93(9):1246-52.

\section{Wallace 2004}

Wallace SA, Roe B, Williams K, Palmer M. Bladder training for urinary incontinence in adults. Cochrane Database of Systematic Reviews 2004, Issue 1. [DOI: 10.1002/ 14651858.CD001308.pub2; : CD001308]

\section{Ware 1993}

Ware JE, Snow KK, Kosinski M, Gandek B. SF-36® Health Survey Manual and Interpretation Guide. Boston, MA: New England Medical Center, The Health Institute, 1993.

\section{Wing 2010}

Wing RR, Creasman JM, West DS, Richter HE, Myers $\mathrm{D}$, Burgio $\mathrm{KL}$, et al. Improving urinary incontinence in overweight and obese women through modest weight loss. Obstetrics and Gynecology 2010;116(2 Pt 1):284-92.

* Indicates the major publication for the study 


\section{CHARACTERISTICS OF STUDIES}

\section{Characteristics of included studies [ordered by study ID]}

\section{Brown 2006b}

Methods

Participants
Design: A sub-study of the Diabetes Prevention Program (DPP), an RCT with overweight non-diabetic individuals, randomly allocated to the intensive lifestyle weight loss programme (Group I), metformin (Group II) or placebo (Group III). For the purpose of this sub-study, men were excluded from analysis

Study centre: 27 centres in the USA

Recruitment period: 1996-1999

Power calculation: performed for the original DPP trial

Number of (female) participants randomized: total $=2191$

Number of (female) participants followed up: total = 1957; Group I = 660; Group II = 636; Group III = 661

Withdrawals/dropouts/lost to follow-up: total $=234(11 \%)$ women with missing UI data were excluded from analysis

Gender: female

Mean age, years (SD): Group I: 49.3 (10.6); Group II: 49.9 (9.6); Group III: 49.5 (9.7)

BMI mean (SD): Group I: 34.7 (6.9); Group II: 34.8 (6.9); Group III: 35.1 (7.0)

Ethnicity:

Group I: white = 343; African American = 138; Hispanic = 103; Native American = 51; Asian $=25$

Group II: white = 333; African American = 148; Hispanic = 97; Native American = 45; Asian $=13$

Group III: white = 355; African American = 144; Hispanic = 94; Native American = 51;

Asian $=17$

Education: not stated

Employment status: not stated

Severity of symptoms: not stated

Prior incontinence surgery: not stated

Inclusion criteria: age at least 25 years, $\mathrm{BMI} \geq 24 \mathrm{~kg} / \mathrm{m}^{2}$, a fasting plasma glucose level $95-125 \mathrm{mg} / \mathrm{dl}$, and a $2-\mathrm{h}$ post challenge glucose level $140-199 \mathrm{mg} / \mathrm{dl}$

Exclusion criteria: people taking medications that could affect glucose tolerance or who had serious medical illness

Diagnostic groups: not stated
Group I: intensive lifestyle intervention. The goals were at least $7 \%$ weight loss and at least 150 minutes of moderate-intensity physical activity per week. A 16-lesson curriculum covering diet, exercise, and behaviour modification, taught by case managers during the first 24 weeks after enrolment, was "flexible, culturally sensitive, and individualized". Subsequent individual sessions (usually monthly) and group sessions with the case managers were also provided to reinforce the behavioural changes

Treatment duration: 24 weeks with monthly follow-up thereafter

Length of follow-up: average 2.8 (range 1.8-4.6) years

Training provided by: case managers, with training in nutrition, exercise or behaviour modification, on a one-to-one basis

Group II: metformin $850 \mathrm{mg}$ twice daily with standard lifestyle intervention 
Brown 2006b (Continued)

Group III: placebo twice daily with standard lifestyle intervention

The standard lifestyle intervention included written information and an individual meeting (20-30 minutes) that emphasized a healthy diet, reduced weight, increased activity levels and smoking cessation, at baseline and annually

Co-interventions: not stated

Compliance: Mean change in weight, $\mathrm{kg}(\mathrm{SD})$ : Group I = -3.4 (8.2); Group II = -1.5 (7. 6); Group III = +0.5 (6.7); P value $<0.001$

Outcomes

Weekly prevalence of UI by type (stress, urge or any UI) based on participant's report at the end-of-trial visit

Notes

The primary aim of the DPP trial was to evaluate whether an intensive lifestyle intervention with improved diet and increased physical activity or metformin therapy among overweight pre-diabetic men and women would prevent or delay the onset of type 2 diabetes. Not all participants had UI at baseline. The objective of the analysis included in this review was to assess whether these interventions were associated with a lower prevalence of incontinence in women, because weight loss may decrease incontinence, whereas increased physical activity may worsen incontinence, and incontinence may also be a barrier to exercise

Funding: The DPP trial was supported by the following: The Diabetes Prevention Program, National Institutes of Health/National Institute of Diabetes and Digestive and Kidney Diseases, the National Institute of Child Health and Human Development, the National Institute on Aging, the Office of Research on Minority Health and Health Disparities, the Office of Women's Health, the Indian Health Service, the Centers for Disease Control and Prevention, the General Clinical Research Program, the National Center for Research Resources, the American Diabetes Association, Bristol-Myers Squibb, Lipha Pharmaceuticals, and Parke-Davis. LifeScan, Health O Meter, Hoechst Marion Roussel, Merck-Medco Managed Care, Merck, Nike Sports Marketing, and Slim Fast Foods. Quaker Oats donated materials, equipment, or medicines for concomitant conditions. McKesson ioServices, Matthews Media Group, and the Henry M Jackson Foundation provided support services under subcontract with the Co-ordinating Center

Risk of bias

Bias

Authors' judgement

Support for judgement

Random sequence generation (selection Low risk bias)

Quote: "Adaptive randomisation stratified by clinical centre"

\begin{tabular}{|c|c|c|}
\hline Allocation concealment (selection bias) & Unclear risk & Not mentioned \\
\hline $\begin{array}{l}\text { Blinding of participants and personnel } \\
\text { (performance bias) } \\
\text { All outcomes }\end{array}$ & High risk & $\begin{array}{l}\text { Assignments to metformin and placebo } \\
\text { were blinded but the lifestyle intervention } \\
\text { was not }\end{array}$ \\
\hline
\end{tabular}

Blinding of outcome assessment (detection Unclear risk bias)

All outcomes

Lifestyle interventions for the treatment of urinary incontinence in adults (Review)

Copyright @ 2015 The Cochrane Collaboration. Published by John Wiley \& Sons, Ltd. 
Brown 2006b (Continued)

\begin{tabular}{|c|c|c|}
\hline $\begin{array}{l}\text { Incomplete outcome data (attrition bias) } \\
\text { All outcomes }\end{array}$ & Low risk & $\begin{array}{l}\text { Of the } 2191 \text { women enrolled in the } 3 \text { arms } \\
\text { of the DPP, } 234(11 \%) \text { women with miss- } \\
\text { ing UI data were excluded from the analy- } \\
\text { sis. The study stated that "women missing } \\
\text { data on urinary incontinence did not differ } \\
\text { in incident diabetes, mean weight change, } \\
\text { or mean change in physical activity over- } \\
\text { all or within treatment groups compared } \\
\text { with women with completed urinary in- } \\
\text { continence data" }\end{array}$ \\
\hline
\end{tabular}

Selective reporting (reporting bias) Unclear risk

Insufficient information provided. The main outcome for this analysis was prevalence of incontinence

Other bias

Unclear risk

The DPP trial was closed early after 2.9 years when lifestyle changes and metformin treatment had each reduced the incidence of diabetes

Bryant 2002

Methods

Design: quasi-RCT. Participants were randomized by health record numbers and allocated to caffeine reduction education (Group I) or control (Group II)

Study centre: 2 nurse-led continence clinics, Sydney, Australia

Recruitment period: not stated

Power calculation: performed

Funding: not stated

Participants

Number of participants randomized: total $=95$; Group I = 48; Group II $=47$

Number of participants followed up: total $=74$; Group I = 36; Group II = 38

Withdrawals/dropouts/lost to follow-up: total $=21(22 \%)$; Group I = 12; Group II = 9. Reasons: failure to return to follow-up $(n=14)$; anxiety or family problem $(n=4)$; hospital admission $(\mathrm{n}=2)$; intercurrent illness $(\mathrm{n}=1)$

Gender (number and \% female): Group I = 45 (94\%); Group II = $41(87 \%)$

Mean age, years (SD): Group I = 56 (18); Group II = 58 (16)

Mean body weight, $\mathrm{kg}(\mathrm{SD})$ : Group I = 69 (17); Group II = 68 (20)

Ethnicity: not stated

Education: not stated

Employment status: not stated

Severity of symptoms: mean number of leakage episodes per 24 hours (SD): Group I = 2.8 (3.2); Group II = 3.1 (3.9)

Prior incontinence surgery: not stated

Inclusion criteria: adults with symptoms of urgency, frequency and/or urge incontinence, and who routinely ingested caffeine at levels of $100 \mathrm{mg}$ or more every 24 hours

Exclusion criteria: significant cognitive impairment, pregnancy or symptoms of urinary tract infection

Diagnostic groups: $83 \%$ of the sample had urge UI, while $17 \%$ reported no UI at baseline

Lifestyle interventions for the treatment of urinary incontinence in adults (Review)

Copyright @ 2015 The Cochrane Collaboration. Published by John Wiley \& Sons, Ltd. 
Bryant 2002 (Continued)

(only frequency and urgency)

Outcomes

Number of incontinent episodes in 24 hours

Notes

Risk of bias

\begin{tabular}{|c|c|c|}
\hline Bias & Authors' judgement & Support for judgement \\
\hline $\begin{array}{l}\text { Random sequence generation (selection } \\
\text { bias) }\end{array}$ & High risk & $\begin{array}{l}\text { Quote: "Patients were randomized by } \\
\text { health record number to two groups" }\end{array}$ \\
\hline Allocation concealment (selection bias) & High risk & $\begin{array}{l}\text { Quote: "Patients were randomized by } \\
\text { health record number to two groups" }\end{array}$ \\
\hline $\begin{array}{l}\text { Blinding of participants and personnel } \\
\text { (performance bias) } \\
\text { All outcomes }\end{array}$ & High risk & Not mentioned but unlikely \\
\hline
\end{tabular}

Blinding of outcome assessment (detection Unclear risk

Not mentioned

bias)

All outcomes

Incomplete outcome data (attrition bias) Unclear risk All outcomes
Interventions

Group I: educational intervention (with bladder training) to reduce caffeine intake to $<100 \mathrm{mg}$ a day. The intervention consisted of a thorough review (with participants) of their caffeine intake history, urinary symptoms and time/volume/caffeine charts for 3 randomly selected 24-hour periods, followed by a planned caffeine reduction intervention using a caffeine fading method (James 1988). This method decreases caffeine intake by one drink each day until the desired maximum intake of $100 \mathrm{mg}$ caffeine a day is reached and the caffeinated drinks have been replaced by other fluids

Treatment duration: participants were seen weekly for 4 weeks

Length of follow-up: no follow-up after 4-week programme

Training provided by: not stated

Group II: continued usual daily caffeine intake of $>100 \mathrm{mg}$ every 24 hours. Also received bladder training

Co-interventions: not stated

Compliance: mean caffeine intake reduction per 24 hours, (SD):

Group I: 58\%; Group II: $11 \%$; P value $<0.0001$

\begin{tabular}{ll}
\hline Interventions & Group I: educational intervention (with bladder training) to reduce caffeine intake to \\
$<100 \mathrm{mg}$ a day. The intervention consisted of a thorough review (with participants) of \\
their caffeine intake history, urinary symptoms and time/volume/caffeine charts for 3 \\
randomly selected 24 -hour periods, followed by a planned caffeine reduction interven- \\
tion using a caffeine fading method (James 1988). This method decreases caffeine intake \\
by one drink each day until the desired maximum intake of 100 mg caffeine a day is \\
reached and the caffeinated drinks have been replaced by other fluids \\
Treatment duration: participants were seen weekly for 4 weeks \\
Length of follow-up: no follow-up after 4-week programme \\
Training provided by: not stated \\
Group II: continued usual daily caffeine intake of $>100$ mg every 24 hours. Also received \\
bladder training \\
Co-interventions: not stated \\
Compliance: mean caffeine intake reduction per 24 hours, (SD): \\
Group I: $58 \%$; Group II: $11 \%$; P value $<0.0001$
\end{tabular}


Bryant 2002 (Continued)

Selective reporting (reporting bias) Unclear risk

Other bias

Unclear risk
Insufficient information. Reported outcomes specified in the method section

Insufficient information provided

\section{Dowd 1996}

Methods

Participants
Design: RCT. Participants were assigned randomly to increased fluid intake (Group I), decreased fluid intake (Group II) or maintained fluid intake (Group III)

Study centre: USA

Recruitment period: not stated

Power calculation: not stated

\begin{tabular}{|c|c|}
\hline Participants & $\begin{array}{l}\text { III = } 20 \\
\text { Number of participants followed up: total = 32; Group I = 14; Group II = 10; Group } \\
\text { III = } 8 \\
\text { Withdrawals/dropouts/lost to follow-up: total = } 26 \text { ( } 45 \%) \text {; Group I = 6; Group II = 8; } \\
\text { Group III = 12. Reason: diaries were not sufficiently completed } \\
\text { Gender: female } \\
\text { Mean age, years (range): } 70.25 \text { ( } 52-89) \\
\text { BMI: } 19 / 32 \text { participants with data had normal or below normal weight; } 8 / 32 \text { participants } \\
\text { were obese } \\
\text { Ethnicity: not stated } \\
\text { Education: not stated } \\
\text { Employment status: not stated } \\
\text { Severity of symptoms (mean daily UI episodes per day): } 0.6 \text { (n = 32) } \\
\text { Prior incontinence surgery: not stated } \\
\text { Inclusion criteria: women over } 50 \text { years of age who had had UI for } 6 \text { months or more, } \\
\text { were independent in self-care, scored over } 20 \text { on the Mini-Mental State Examination } \\
\text { (Folstein } 1975 \text { ) and were English speaking } \\
\text { Exclusion criteria: not stated } \\
\text { Diagnostic groups: not stated }\end{array}$ \\
\hline
\end{tabular}

Interventions
The first week served as the baseline, after which participants were assigned to 1 of the 3 groups. Participants were instructed in the detailed recording of intake using the same measuring cups and glasses for the duration of the study and were instructed to keep intake and output diaries for 5 weeks

Group I: increased fluid intake by $500 \mathrm{ml}$, total intake not to exceed $2400 \mathrm{ml}$ per day Group II: decreased intake by $300 \mathrm{ml}$, total intake not to be less than $1000 \mathrm{ml}$ per day Group III: maintained fluid intake at baseline level

Treatment duration: 5 weeks (randomisation in second week)

Length of follow-up: a 3-month telephone follow-up ( $n=29)$ was undertaken for the entire cohort; no data were available for each randomized group

Treatment provided by: registered nurses who were given in-service training on UI and oriented to the study procedures. They provided new data-collection sheets and responded to questions on a weekly basis

Co-interventions: not stated 
Compliance (mean daily fluid intake): Group I = fluid intake was increased until week 3 when they returned closer to the baseline level; Group II = intake was less than baseline through the first 4 weeks but increased in week 5; Group III = increased intake by approximately $170 \mathrm{ml}$ in week 5; this suggests generally low compliance across the groups

\begin{tabular}{ll}
\hline Outcomes & Number of incontinent episodes in 24 hours \\
\hline Notes & $\begin{array}{l}\text { The secondary aim of the study was to assess whether there was any relationship between } \\
\text { caffeine intake and incontinence episodes } \\
\text { Funding: Kidney Foundation of Summit County in Akron, Ohio, USA }\end{array}$ \\
\hline
\end{tabular}

\section{Risk of bias}

\begin{tabular}{|c|c|c|}
\hline Bias & Authors' judgement & Support for judgement \\
\hline $\begin{array}{l}\text { Random sequence generation (selection } \\
\text { bias) }\end{array}$ & Unclear risk & $\begin{array}{l}\text { Quote: "The women were assigned ran- } \\
\text { domly" }\end{array}$ \\
\hline Allocation concealment (selection bias) & Unclear risk & Not mentioned \\
\hline $\begin{array}{l}\text { Blinding of participants and personnel } \\
\text { (performance bias) } \\
\text { All outcomes }\end{array}$ & High risk & Not mentioned but unlikely \\
\hline $\begin{array}{l}\text { Blinding of outcome assessment (detection } \\
\text { bias) } \\
\text { All outcomes }\end{array}$ & Unclear risk & Not mentioned \\
\hline $\begin{array}{l}\text { Incomplete outcome data (attrition bias) } \\
\text { All outcomes }\end{array}$ & High risk & $\begin{array}{l}\text { Data were presented for } 32 / 58(55 \%) \text { of } \\
\text { the women randomized who maintained } \\
\text { the diaries for the entire study }\end{array}$ \\
\hline Selective reporting (reporting bias) & Unclear risk & $\begin{array}{l}\text { Insufficient information provided. The } \\
\text { only outcome reported was the number of } \\
\text { incontinence episodes, but this was accord- } \\
\text { ing to the study aim }\end{array}$ \\
\hline Other bias & High risk & $\begin{array}{l}\text { The study reported that adherence to the } \\
\text { fluid manipulation was poor and made re- } \\
\text { sults difficult to interpret }\end{array}$ \\
\hline
\end{tabular}



randomized

Number of participants followed up: 24

Withdrawals/dropouts/lost to follow-up: none

Gender: male $=11$; female $=13$

Age (years): mean 62.7, median (range) $62.5(42,80)$

BMI: not stated

Ethnicity: not stated

Education: not stated

Employment status: not stated

Severity of symptoms: not stated

Prior incontinence surgery: not stated

Inclusion criteria: adult men and women ( $\geq 18$ years old) with symptoms of OAB. Enrolled after a 4-day screening period (to establish baseline values) using frequency/ volume charts (FVC), completed daily, if they had a mean of 8 or more voids and 1 or more urgency and/or urgency incontinence episodes in 24 hours. Participants were identified from a database that included those who were contacted and/or participated in previous trials. They were initially screened by telephone to see if they would agree to take part in the trial and were eligible for it

Exclusion criteria: participants were excluded from any part of the study if their increase/ decrease resulted in them drinking $>3 \mathrm{~L}$ or $<1 \mathrm{~L}$ of fluid, as drinking $3 \mathrm{~L}$ would be excessive and drinking $<1 \mathrm{~L}$ would cause symptoms of dehydration, e.g. headaches and constipation. People were also excluded if they were pregnant or breast-feeding; had haematuria, bacteriuria, pyuria, proteinuria, glucosuria or ketosuria on urine dipstick testing; had a residual volume of $>150 \mathrm{~mL}$, as assessed by a bladder scan; had uncontrolled hypertension, suspicion or evidence of clinically relevant cardiac failure, renal disease or hepatic disease; were diagnosed with or suspected of having diabetes insipidus/ primary polydipsia or diabetes mellitus; had neurogenic dysfunction of the lower urinary tract; were known alcohol or drug abusers; were scheduled to be admitted to hospital for inpatient surgery during the trial; had any history of clinically relevant psychiatric disorders within the last 24 months preceding enrolment in the trial; had a history of not complying with medical regimens or were not compliant with protocol requirements or unable to keep a diary or perform the required volume measurements on their own; had significant pelvic organ prolapse (Stage III or IV) or had significant stress UI

Diagnostic groups: OAB $=24(100 \%)$. Only $7(29 \%)$ participants had 1 or more urge UI episode at baseline

4-day screening period with FVC to establish baseline drinking habits, prior to randomisation to Group I or II

Group I:

4 days drinking $25 \%$ less than baseline followed by 2 days normal drinking (i.e. a 
Hashim 2008 (Continued)

washout); followed by

4 days drinking $50 \%$ less than baseline followed by 2 days normal drinking; followed by 4 days drinking $25 \%$ more than baseline followed by 2 days normal drinking; followed by

4 days drinking $50 \%$ more than baseline

Group II:

4 days drinking $25 \%$ more than baseline followed by 2 days normal drinking; followed by

4 days drinking 50\% more than baseline followed by 2 days normal drinking; followed by

4 days drinking $25 \%$ less than baseline followed by 2 days normal drinking; followed by 4 days drinking $50 \%$ less than baseline

Participants who drank $>3 \mathrm{~L}$ or $<1 \mathrm{~L}$ were excluded. Patients completed a 4-day FVC in each part of the study, and the ICIQ-OAB questionnaire at the end of each 4-day period, to assess their quality of life for that period

Significance was analyzed by comparing each intervention group to the overall baseline of the study group $(n=24)$. The number of participants differed in each period so this is presented for reference

Treatment duration: 4 weeks

Co-intervention: not stated

Compliance: all 24 participants participated in the period with a $25 \%$ reduction, but not all participated in the other parts of the study because they did not fulfil the criteria, i.e. their input was $<1 \mathrm{~L}$ or $>3 \mathrm{~L}$ when the fluid intake was manipulated. The mean fluid output was approximately $289 \mathrm{ml}$ higher than the fluid intake. When participants were asked to drink $25 \%$ more than their normal fluid input they only managed to drink $17 \%$ more, and when asked to drink 50\% more they managed $23 \%$ more, when comparing the respective groups with baseline. When asked to drink $50 \%$ less, participants managed to drink $32 \%$ less than the baseline. The $25 \%$ reduction was adhered to quite well

Outcomes

Condition-specific quality of life

Adverse effects

Number of incontinent episodes in 24 hours

Notes

Funding: Bristol Urological Institute PA Research Fund

Risk of bias

Bias

Random sequence generation (selection Unclear risk bias)
Unclear risk

Blinding of participants and personnel High risk (performance bias)

All outcomes
Support for judgement

Quote: "randomized into one of the two groups"

Not mentioned

Not mentioned but unlikely 


\section{Hashim 2008 (Continued)}

\begin{tabular}{l|ll|l}
\hline $\begin{array}{l}\text { Blinding of outcome assessment (detection } \\
\text { bias) } \\
\text { All outcomes }\end{array}$ & Unclear risk & Not mentioned \\
\hline $\begin{array}{l}\text { Incomplete outcome data (attrition bias) } \\
\text { All outcomes }\end{array}$ & Low risk & No missing outcomes \\
\hline Selective reporting (reporting bias) & Unclear risk & High risk & $\begin{array}{l}\text { Insufficient information available. } \\
\text { study described what was measured by fre- } \\
\text { quency/volume charts in the method sec- } \\
\text { tion }\end{array}$ \\
\hline Other bias & & $\begin{array}{l}\text { The study reported that participants had } \\
\text { difficulty in adhering to the study protocol } \\
\text { when they were asked either to increase or } \\
\text { decrease fluids by } 50 \%\end{array}$ \\
\hline
\end{tabular}

Manonai 2006

Methods

Participants
Design: cross-over trial with $2 \times 12$-week diet periods and $2 \times 4$-week washout periods before and between treatments. Participants were randomly allocated to the order in which they followed an isocaloric soy-rich diet or a control diet

Study centre: Mahidol University, Bangkok, Thailand

Recruitment period: not stated

Power calculation: not stated

Number of participants randomized: 42

Number of participants followed up: 36

Withdrawals/dropouts/lost to follow-up $=6$. Reasons: 5 withdrew from the study because of their inability to comply with the study; 1 lost to pelvic examination follow-up

Gender: female

Mean age, years: 52.5 (SD 5.11; range 40-59)

BMI: not stated

Ethnicity: not stated

Education: not stated

Employment status: not stated

Severity of symptoms: not stated

Prior incontinence surgery: not stated

Inclusion criteria: healthy women whose periods had ceased at least 3 months previously, who were 45-70 years of age, not using hormone therapy and did not regularly consume a vegetarian diet. All women had experienced at least one type of urinary or genital symptoms owing to urogenital atrophy

Exclusion criteria: presence or history of sex hormone-dependent malignancies; presence or history of liver or renal disorders; and pathology of urogenital tract

Diagnostic groups: before soy-rich diet, $61 \%$ had SUI and 19\% had UUI; and before control diet $63 \%$ had SUI and $11 \%$ had UUI. Some women may have had symptoms of both SUI and UUI. Other women had frequency, urgency or other vaginal symptoms, e.g. vaginal dryness, but no UI 
Manonai 2006 (Continued)

Interventions
During both study periods, participants consumed self-selected diets with low-fat and
low-cholesterol foods. Subjects were advised to maintain their physical activity consis-
tently throughout the study and were instructed to avoid all additional soy products,
herbal or vitamin and mineral supplements. They were also instructed to keep an accu-
rate 3-day food record
Intervention period I: isocaloriic soy-rich diet: Participants consumed $25 \mathrm{~g}$ soy protein
in various forms containing $>50 \mathrm{mg}$ per day of isoflavones, which was substituted for an
equivalent amount of animal protein. All soy foods for the study were provided monthly
Intervention period II: control diet
Treatment duration: $2 \mathrm{x} 12$-week diet periods with $2 \mathrm{x}$-week washout periods before
and between treatments
Treatment provided by: the same nutritionist throughout the study
Co-intervention: not stated
Compliance: good compliance was shown by the significant elevation of serum levels of
daidzein and genistein during the soy-rich diet period

Outcomes

Number of women with incontinent episodes

Incontinence symptom scores

Notes

Funding: Thai Health Promotion Foundation

\section{Risk of bias}

\begin{tabular}{l|l|l}
\hline Bias & Authors' judgement & Support for judgement \\
\hline $\begin{array}{l}\text { Random sequence generation (selection } \\
\text { bias) }\end{array}$ & Unclear risk & $\begin{array}{l}\text { Quote: "The subjects were randomized } \\
\text { into two groups" }\end{array}$ \\
\hline $\begin{array}{l}\text { Allocation concealment (selection bias) } \\
\text { Blinding of participants and personnel } \\
\text { (performance bias) } \\
\text { All outcomes }\end{array}$ & Unclear risk & No information available \\
\hline $\begin{array}{l}\text { Blinding of outcome assessment (detection } \\
\text { bias) } \\
\text { All outcomes }\end{array}$ & Unclear risk & Not mentioned but unlikely \\
\hline $\begin{array}{l}\text { Incomplete outcome data (attrition bias) } \\
\text { All outcomes }\end{array}$ & Unclear risk & $\begin{array}{l}\text { Pelvic examination and vaginal pH test } \\
\text { were performed by the same examiner who } \\
\text { was blinded, but these outcomes were not } \\
\text { relevant to this review. No mention of } \\
\text { blinded assessment for the outcomes spec- } \\
\text { ified in the review }\end{array}$ \\
\hline
\end{tabular}

Lifestyle interventions for the treatment of urinary incontinence in adults (Review)

Copyright @ 2015 The Cochrane Collaboration. Published by John Wiley \& Sons, Ltd. 
Manonai 2006 (Continued)

\begin{tabular}{|c|c|c|}
\hline Selective reporting (reporting bias) & Unclear risk & $\begin{array}{l}\text { Insufficient information available. Re- } \\
\text { ported outcomes were specified in the } \\
\text { methods section }\end{array}$ \\
\hline Other bias & Unclear risk & Insufficient information available \\
\hline
\end{tabular}

Miller 2007

\begin{tabular}{|c|c|}
\hline Methods & $\begin{array}{l}\text { Design: RCT with } 2 \text { groups } \\
\text { Study centre: University of Michigan School of Nursing, USA } \\
\text { Study period: } 01 \text { January 2007-31 December } 2007\end{array}$ \\
\hline Participants & $\begin{array}{l}\text { Number of participants: Group I = around 30; Group II = around } 30 \\
\text { Gender: female } \\
\text { Diagnostic groups: OAB (unclear if wet or dry) }\end{array}$ \\
\hline Interventions & $\begin{array}{l}\text { Group I: reduced intake of 'irritating' beverages (caffeine or non-caffeine). Participants } \\
\text { were instructed to maintain the overall volume of fluid intake by replacing the 'irritating' } \\
\text { beverages with water or milk } \\
\text { Group II: control (no details provided) } \\
\text { Treatment duration: unclear }\end{array}$ \\
\hline Outcomes & $\begin{array}{l}\text { The study found a significant reduction in OAB symptoms (not defined) in the interven- } \\
\text { tion group. However, the author noted that findings were confounded by a significant } \\
\text { reduction in overall fluid intake in the intervention group from baseline (by an average of } \\
8 \text { fluid oz (around } 230 \mathrm{ml} \text { ) per } 24 \text { hours). The author also notes that caffeine reduction } \\
\text { was not associated with the OAB symptom reduction }\end{array}$ \\
\hline Notes & $\begin{array}{l}\text { Unpublished trial. All information was obtained from an author email to the Cochrane } \\
\text { Incontinence Group search co-ordinator ( } 26 \text { January 2009) } \\
\text { Funding: Pfizer, GA6120A8 Detrol Competitive Grant }\end{array}$ \\
\hline
\end{tabular}

Risk of bias

\begin{tabular}{|c|c|c|}
\hline Bias & Authors' judgement & Support for judgement \\
\hline $\begin{array}{l}\text { Random sequence generation (selection } \\
\text { bias) }\end{array}$ & Unclear risk & Insufficient information available \\
\hline Allocation concealment (selection bias) & Unclear risk & Insufficient information available \\
\hline $\begin{array}{l}\text { Blinding of participants and personnel } \\
\text { (performance bias) } \\
\text { All outcomes }\end{array}$ & Unclear risk & Insufficient information available \\
\hline $\begin{array}{l}\text { Blinding of outcome assessment (detection } \\
\text { bias) } \\
\text { All outcomes }\end{array}$ & Unclear risk & Insufficient information available \\
\hline
\end{tabular}


Miller 2007 (Continued)

\begin{tabular}{l|l|l}
\hline $\begin{array}{l}\text { Incomplete outcome data (attrition bias) } \\
\text { All outcomes }\end{array}$ & Unclear risk & Insufficient information available \\
\hline Selective reporting (reporting bias) & Unclear risk & Insufficient information available \\
\hline Other bias & High risk & $\begin{array}{l}\text { The study author noted non-adherence to } \\
\text { the protocol among study participants }\end{array}$ \\
\hline
\end{tabular}

\section{Phelan 2012}

Methods

Participants
Design: a sub-study of the Look AHEAD (Action for Health in Diabetes) trial, an RCT with overweight or obese individuals with type 2 diabetes, randomly allocated to intensive lifestyle weight loss intervention (Group I) or a diabetes support and education control condition (Group II). For the purpose of this sub-study, men were excluded from analysis

Study centre: 16 centres, USA

Recruitment period: from 2001. Planned follow-up until 2014

Power calculation: performed

Number of (female) participants randomized in Look AHEAD trial: 3063. Of these, 69 who did not complete baseline incontinence assessment were excluded from this substudy

Number of randomized participants in this sub-study: Group I = 1495; Group II = 1499

Number of participants followed up: Group I = 1385; Group II = 1354

Withdrawals/dropouts/lost to follow-up: Group I = 110; Group II = 145. Study completers were more likely to be white $(\mathrm{P}$ value $=0.01)$ and to be never smokers $(\mathrm{P}$ value $=$ $0.02)$ than non-completers, but no other significant differences were observed

Gender: female

Mean age, years (SD): Group I: 57.8 (6.7); Group II: 58.1 (6.9)

Mean BMI (SD): Group I: 36.3 (6.2); Group II: 36.7 (6.0)

Ethnicity:

Group I: non-Hispanic white 56\%, African-American 20\%, Hispanic 15\%, Native American/Alaskan native 6\%, Other 3\%;

Group II: non-Hispanic white 55\%, African-American 20\%, Hispanic 15\%, Native American/Alaskan native 7\%, Other 3\%

Education: not stated

Employment status: not stated

Severity of symptoms: not stated

Prior incontinence surgery: not stated

Inclusion criteria: overweight and obese individuals (men and women) with type 2 diabetes, 45-76 years of age with a BMI of $\geq 25 \mathrm{~kg} / \mathrm{m}^{2}\left(>27 \mathrm{~kg} / \mathrm{m}^{2}\right.$ if currently taking insulin)

Exclusion criteria: $\geq$ HbAlc $11 \%$, blood pressure $\geq 160 / 100 \mathrm{mmHg}$, triglycerides $\geq$ $600 \mathrm{mg} / \mathrm{dl}$, inadequate control of comorbid conditions, factors that may limit adherence to the intervention, and underlying disease likely to limit life span and/or affect safety of the interventions

Diagnositic groups: at baseline $27 \%$ of participants reported weekly (or more frequent) urinary incontinence. The reference group was 'less than weekly'. Predominant type 
Phelan 2012 (Continued)

of UI was coded based on whether a participant reported a higher frequency of stress or urgency episodes. About 13\% in each group reported predominant SUI and 10\% reported predominant UUI. Only $2 \%$ of women were classified as having MUI (defined as frequency of SUI = frequency of UUI)

Interventions

Group I: intensive lifestyle intervention designed to promote an average of $7 \%$ or greater weight loss at 1 year. Participants were encouraged to consume a low calorie and low fat, portion controlled diet that included liquid meal replacements, and to achieve at least 175 minutes of physical activity weekly. The participants were seen weekly for the first 6 months and 3 times monthly for the next 6 months for a total of 44 sessions (Phase I, months 1-12)

Treatment duration: the intensive intervention occurred in the first 4 years of the study period (e.g. Phase II, months 13-48; Phase III, months 49+)

Length of follow-up: for the purpose of this sub-study, outcomes were assessed after 1 year of intervention

Training provided by: lifestyle counsellor

Group II: diabetes support and education: participants were invited to 3 group sessions during the year which focused on diet, physical activity or social support

Co-interventions: not reported

Compliance: Mean weight lost at 1 year, kg (SD): Group I: 7.7 (7.0); Group II: 0.7 (5. $0)$; P value $<0.0001$

Outcomes

Improvement (decrease of at least 2 episodes per week) and resolution (cure) in women who had weekly or more frequent incontinence episodes at baseline, assessed by validated self-report questions after 1 year of intervention

Prevalence of UI (that occurred at least weekly) assessed by validated self-report questions after 1 year of intervention

Notes

The primary objective of the LOOK AHEAD trial was to assess the intervention effects on cardiovascular morbidity and mortality

Funding: the Department of Health and Human Services. The following organizations have committed to make major contributions to Look AHEAD: FedEx Corp; Health Management Resources; LifeScan, Inc, a Johnson and Johnson Company; Optifast ${ }^{\circledR}$ of Nestle HealthCare Nutrition, Inc; Hoffmann-La Roche Inc; Abbott Nutrition; and Slim-Fast Brand of Unilever North America

\section{Risk of bias}

Bias

Random sequence generation (selection Unclear risk bias)
Authors' judgement

Allocation concealment (selection bias)
Unclear risk

\section{Support for judgement}

Quote: "Partiicpants were randomly assigned within centers to the ILI [intensive lifestyle intervention] or the DSE [diabetes support and education] conditions with equal probability". "Randomisation is stratified by clinical center and blocked with random block sizes"

No information available 
Phelan 2012 (Continued)

Blinding of participants and personnel High risk (performance bias)

All outcomes

Blinding of outcome assessment (detection Low risk bias)

All outcomes

Incomplete outcome data (attrition bias) Unclear risk

All outcomes
Blinding of patient and personnel not mentioned but unlikely

Quote: "All measures were completed at baseline and 1 year by assessors who were masked to participant treatment group."

Of the 3063 women enrolled in the Look AHEAD trial, 69 (2\%) women with no UI data at baseline were excluded from this sub-study. The 1-year follow-up rate was $93 \%(1385 / 1495)$ in the intervention group and $90 \%(1354 / 1499)$ for the control group. Survey completers were more likely to be white and non-smokers. The implication for the incontinence outcome is unknown

\begin{tabular}{lll}
\hline Selective reporting (reporting bias) & Unclear risk & Insufficient information available \\
\hline Other bias & Unclear risk & Insufficient information available \\
\hline
\end{tabular}

Subak 2005

Methods

Design: RCT stratified by type of incontinence (either stress only and stress-predominate MUI or urge only and urge-predominate MUI), then randomly allocated to immediate (Group I) or delayed (Group II) enrolment in the weight reduction programme Study centre: University of California, USA

Recruitment period: January 1999-March 2000

Power calculation: performed

Participants

Number of participants randomized: total $=48$; Group I = 24; Group II = 24

Number of participants followed up: total $=40$; Group I = 19; Group II = 21

Withdrawals/dropouts/lost to follow-up: total = 8; Group I = 5 (2 loss to follow-up for unknown reasons, 1 medical exclusion, 2 missing primary outcome data); Group II = 3

(2 lost to follow-up for unknown reasons, 1 withdrew from study due to death of spouse) Gender: female

Median age, years (IQR): Group I = 50.5 (46-54); Group II = 57.5 (50-62); P value = 0.006

Median BMI (IQR): Group I = 34 (32-40); Group II = 36 (32-38)

Ethnicity:

Group I: white $=18$; other 2; Group II: white $=17$; other $=3$

Education: not stated

Employment status: not stated

Severity of symptoms (number of women with 'severe' incontinence defined as $>10$ episodes per week): Group I = 19; Group II = 20

Prior incontinence surgery (number of women): Group I = 1; Group II = 3

Lifestyle interventions for the treatment of urinary incontinence in adults (Review)

Copyright @ 2015 The Cochrane Collaboration. Published by John Wiley \& Sons, Ltd. 
Inclusion criteria: a consecutive sample of women 18 to 80 years old with BMI between $25-45 \mathrm{~kg} / \mathrm{m}^{2}$, UI for at least 3 months and at least 4 incontinent episodes in a 7-day urinary diary. Prior incontinence therapies (including surgery) were not exclusions from study eligibility

Exclusion criteria: pregnancy, urinary tract infection, significant medical condition, pelvic cancer, neurological condition possibly associated with incontinence, interstitial cystitis or potential inability to complete the study

Diagnostic groups:

Group I: stress alone = 3; stress-predominate MUI = 9; urge alone = 3; urge-predominate MUI $=9$ Group II: stress alone $=0$; stress-predominate $\mathrm{MUI}=10$; urge alone $=2$; urgepredominate $\mathrm{MUI}=11$

Interventions

Outcomes
Group I: a 3-month intensive group-based medical and behavioural weight loss programme. Participants were placed on a standard low calorie liquid diet $(800 \mathrm{kcals}$ per day or less), encouraged to increase physical activity gradually until they were exercising 60 minutes daily, and were taught standard cognitive and behavioural skills to assist in modifying eating and exercise habits. Participants met weekly in group sessions led by a nutritionist, exercise physiologist or behavioral therapist and followed a structured protocol

Treatment duration: 3 months

Length of follow-up: 3 and 6 months after completion of the 3-month programme for the entire cohort; no data were available for each randomized group

Training provided by: nutritionist, exercise physiologist or behavioural therapist

Group II: a waiting list control group had no intervention for 3 months and then entered the weight reduction programme

Co-interventions: participants currently using incontinence therapy were included in the study, but were asked to not change treatment during study

Compliance: median \% weight improvement, (IQR): Group I: 16 (9-20); Group II: 0 $(-2-2)$

Condition-specific quality of life

Adverse effects

Cure rates based on quantification of symptoms (defined as number of women with a $100 \%$ reduction in weekly UI episodes recorded by 7-day diary)

Improvement (including cure) rates based on quantification of symptoms (defined as number of women with a $75 \%-100 \%$ reduction in weekly UI episodes recorded by 7 day diary)

Number of incontinent episodes per week

Generic quality of life

Notes

Funding: Mount Zion Health Services Inc and University of California

\section{Risk of bias}

\section{Bias}

Random sequence generation (selection Low risk bias)
Authors' judgement

Support for judgement

Quote: “The randomization codes were prepared by computer generated random numbers" 
Subak 2005 (Continued)

\begin{tabular}{|c|c|c|}
\hline Allocation concealment (selection bias) & Low risk & $\begin{array}{l}\text { Quote: "sealed, opaque envelopes num- } \\
\text { bered consecutively" }\end{array}$ \\
\hline $\begin{array}{l}\text { Blinding of participants and personnel } \\
\text { (performance bias) } \\
\text { All outcomes }\end{array}$ & High risk & Quote: "Participants could not be blinded" \\
\hline $\begin{array}{l}\text { Blinding of outcome assessment (detection } \\
\text { bias) } \\
\text { All outcomes }\end{array}$ & Low risk & $\begin{array}{l}\text { Quote: “... research investigators assess- } \\
\text { ing outcomes and statistical analysts were } \\
\text { blinded" }\end{array}$ \\
\hline $\begin{array}{l}\text { Incomplete outcome data (attrition bias) } \\
\text { All outcomes }\end{array}$ & Low risk & $\begin{array}{l}\text { The analysis was "by intent to treat". The } \\
\text { study states that the " } 40 \text { women }(83 \%) \text { who } \\
\text { completed the first } 3 \text { months of the trial } \\
\text { were similar in demographic and clinical } \\
\text { characteristics to the } 8 \text { women ( } 17 \%) \text { who } \\
\text { did not complete the first } 3 \text { months of the } \\
\text { trial" }\end{array}$ \\
\hline Selective reporting (reporting bias) & Unclear risk & Insufficient information available \\
\hline Other bias & Unclear risk & $\begin{array}{l}\text { Imbalance in age at baseline due to chance } \\
\text { (P value }=0.006) \text {, the effect(s) on outcome } \\
\text { are unknown }\end{array}$ \\
\hline
\end{tabular}

Subak 2009

Methods

Design: RCT stratified by clinical centre, then randomly allocated by $2: 1$ ratio to 6month weight loss programme (Group I) or 4-session education programme (Group II) Study centre: multiple centres in Alabama, USA (PRIDE study)

Recruitment period: 2004-2006

Power calculation: performed

Participants

Number of participants randomized: total = 338; Group I = 226; Group II = 112

Number of participants with data on incontinence at 6 months: total $=304$; Group I = 214; Group II = 90

Withdrawals/dropouts/lost by 6 months: total = 34; Group I = 12 ( 5 discontinued; 3 were unwilling to follow the program, 1 had a medical reason and 1 had schedule conflicts; 7 did not fill diary); Group II = 22 ( 15 discontinued; 10 were unwilling to follow the programme, 3 had family problems, 1 was disappointed by the group assignment and 1 had schedule conflicts; 7 did not fill diary)

Number of participants with data on incontinence at 12 months: total = 294; Group I = 207; Group II = 87

Number of participants with data on incontinence at 18 months: total = 287; Group I = 197; Group II = 90

Gender: female

Mean age, years (SD): Group I = 53 (11); Group II = 53 (10)

Mean BMI (SD): Group I = 36 (6); Group II = 36 (5)

Lifestyle interventions for the treatment of urinary incontinence in adults (Review)

Copyright @ 2015 The Cochrane Collaboration. Published by John Wiley \& Sons, Ltd. 
Ethnicity:

Group I: white $=171$; black $=47$; other $=8$; Group II: white $=91$; black $=17$; other $=4$ Education (beyond high school): Group I = 200; Group II = 93

Employment status: not stated

Severity of symptoms: not stated

Prior incontinence surgery: none (see exclusion criteria)

Inclusion criteria: women at least 30 years of age, BMI of 25-50, and at baseline reported 10 or more UI episodes in a 7-day diary of voiding. Previous medical therapy for incontinence or obesity did not affect eligibility

Exclusion criteria: use of medical therapy for incontinence or weight loss within the previous month, current urinary tract infection or $\geq 4$ or more urinary tract infections in the previous year, a history of incontinence of neurologic or functional origin (due to factors not involving the lower urinary tract, such as chronic impairment of physical or cognitive functioning), previous surgery for incontinence or urethral surgery, major medical or genitourinary tract conditions, pregnancy or parturition in the previous 6 months, type 1 or type 2 diabetes mellitus requiring medical therapy that increased the risk of hypoglycemia, and uncontrolled hypertension

Diagnostic groups:

Group I: stress alone $=8$; stress-predominant (at least $2 / 3$ of the total number of episodes were stress episodes) $=36$; urge alone $=33$; urge-predominant (at least $2 / 3$ of the total number of episodes were urge episodes) $=71 \mathrm{MUI}$ with no predominant type $=78$;

Group II: stress alone $=10$; stress-predominant $=21$; urge alone $=8$; urge-predominant $=37$; MUI with no predominant type $=36$ with instructions for improving bladder control (including pelvic floor muscle training) . Incontinence was not discussed further with either group

Group I: weight loss programme designed to produce an average loss of $7 \%$ to $9 \%$ of initial body weight within the first 6 months of the program, modelled after that used in 2 large clinical trials: the Look AHEAD (Action for Health in Diabetes), and the DPP (Diabetes Prevention Program). Participants met weekly for 6 months in groups of 10-15 for 1-hour sessions that were led by experts in nutrition, exercise, and behaviour change and were based on a structured protocol. Given a standard reduced-calorie diet (1200-1500 kcal per day), with a goal of providing no more than $30 \%$ of the calories from fat. To improve adherence, the participants were provided with sample meal plans and were given vouchers for a meal-replacement product (Slim-Fast) to be used for 2 meals a day during months 1-4 and for 1 meal a day thereafter. Encouraged to increase physical activity (brisk walking or activities of similar intensity) gradually until active for at least 200 minutes each week. Behavioural skills, including self-monitoring, stimulus control, and problem-solving, were emphasized

Treatment duration: 6 months

Follow-up (weight loss maintenance): On completion of the 6-month programme, participants underwent a second randomisation to a motivationally focused maintenance programme or a standard skills based maintenance approach and were followed for further 12 months

Training provided by: experts in nutrition, exercise, and behaviour change

Group II: structured education programme (control): 4 education sessions at months $1,2,3$, and 4. During these 1-hour group sessions, which included 10-15 women, general information was presented about weight loss, physical activity, and healthful 
Subak 2009 (Continued)

eating habits, according to a structured protocol

Co-intervention: see exclusion criteria

Compliance (mean weight, $\mathrm{kg}(\mathrm{SD})$ ):

Group I: baseline = 98 (17); 6 months = 90 (17); Group II: baseline = 95 (16); 6 months $=94(17)$

Compliance (weight \% change $(95 \% \mathrm{CI})$ ):

Group I: 6 months $=-8.0(-9.0$ to --7.0$) ; 12$ months $=-7.5(-8.6$ to --6.4$) ; 18$ months $=-5.5(-6.7$ to --4.3$)$; Group II: 6 months $=-1.6(-2.7$ to --0.4$) ; 12$ months $=-1.7(-3$.

2 to -0.2$) ; 18$ months $=-1.6(-3.4$ to -0.7$)$

Outcomes

Improvement rates based on participant's report (women reported that overall leakage was better or much better)

Cure rates based on quantification of symptoms (defined as number of women reporting a $100 \%$ reduction in weekly UI episodes recorded by 7 -day voiding diary)

Improvement rates based on quantification of symptoms (defined as number of women with a 70\%-100\% reduction in weekly UI episodes recorded by 7 -day voiding diary)

Change in the number of incontinent episodes per week

Notes

Funding:the National Institute of Diabetes and Digestive and Kidney Diseases and the Office of Research on Women's Health

Risk of bias

Bias

Authors' judgement

Support for judgement

Random sequence generation (selection Low risk bias)

Quote: "Randomization was performed with the use of randomly permuted blocks of three or six, stratified according to clinical center"

Allocation concealment (selection bias) Low risk

Quote: “... random assignment [was] concealed in tamper-proof envelopes”

Blinding of participants and personnel High risk (performance bias)

Quote: "The participants were aware of All outcomes

Blinding of outcome assessment (detection Low risk bias)

All outcomes

Quote: “... the staff members who collected the outcome data were not" aware of their treatment assignment

Incomplete outcome data (attrition bias) Low risk All outcomes

Quote: "Baseline variables, including age, race, parity, BMI, type of incontinence, frequency of incontinence episodes, and pad weight were not significantly associated with the retention of participants at 6 months". Also, multiple imputation methods were used for missing data

The study stated that "Participants who

Lifestyle interventions for the treatment of urinary incontinence in adults (Review)

Copyright (c) 2015 The Cochrane Collaboration. Published by John Wiley \& Sons, Ltd. 
Subak 2009 (Continued)

dropped out of the study had a higher number of baseline UI episodes than completers ... but dropouts in the intervention and control groups did not differ" (Wing 2010b)

Selective reporting (reporting bias) Unclear risk

Insufficient information available. Reported outcomes were specified in the methods section

\begin{tabular}{lll}
\hline Other bias & Unclear risk & Insufficient information available \\
\hline
\end{tabular}

Swithinbank 2005

Methods

Participants
Design: cross-over trial with random allocation to the order in which participants increased or decreased decaffeinated fluids in weeks 3 or 4

Study centre: Bristol Urological Institute, Southmead Hospital, Bristol, UK

Recruitment period: not stated

Power calculation: performed

Number of participants randomized: 110 women were approached to enter the study, 26 refused, the remaining 84 were included in the study (by incontinence type: USI = 48 ; IDO = 36)

Number of participants followed up: total = 69; USI group = 39; IDO group 30

Withdrawals/dropouts/lost to follow-up: total $=15$; USI group $=9(19 \%)$; IDO group $=6(17 \%)$. No reasons provided

Gender: female

Median age, years (range): 54.8 (31-76)

BMI: not stated

Ethnicity: not stated

Education: not stated

Employment status: not stated

Severity of symptoms: not stated

Prior incontinence surgery: not stated

Inclusion criteria: women with USI or IDO: women in the IDO group had been referred for investigation of symptoms of frequency, urgency and urgency incontinence, and women with USI had been referred because of leakage secondary to coughing and exercise; the USI group was naive to surgery

Exclusion criteria: urinary tract infection, hepatic, cardiac or renal disease, diabetes mellitus; those on anti-depressants, anticholinergics or diuretics

Diagnostic groups: $\mathrm{USI}=48 ; \mathrm{IDO}=36$
Treatment duration: 4 weeks

Week 1: participants drank normally (baseline)

Week 2: all participants drank normally, but only caffeine-free fluids

Weeks 3 and 4: participants were randomized to either increasing caffeine-free fluids to $3 \mathrm{~L}$ ( 20 cups) per day for a week followed by a week of reducing caffeine-free fluids to $750 \mathrm{ml}$ (5 cups) per day, or vice versa. Results from the weeks with increased and decreased fluids were compared. Urine osmolality was measured at weekly clinic visit to 
Swithinbank 2005 (Continued)

\begin{tabular}{|c|c|c|}
\hline & \multicolumn{2}{|c|}{$\begin{array}{l}\text { Detailed urinary diaries that included information concerning episodes of urgency and } \\
\text { leakage were kept for each day of the 4-week study period. A reason for randomising } \\
\text { the order of increased or decreased fluid intake was to counter the placebo effect (e.g. a } \\
\text { bladder training effect) of keeping urinary diaries } \\
\text { Co-interventions: not stated } \\
\text { Compliance (mean fluid intake per day, ml; all women with USI or IDO): week } 1 \text { = } \\
1639 \text { ml; week } 2 \text { with caffeine-free fluids = } 1630 \mathrm{ml} \text {; week increasing fluid = } 2673 \mathrm{ml} \text {; } \\
\text { week decreasing fluid: } 872 \mathrm{ml}\end{array}$} \\
\hline Outcomes & \multicolumn{2}{|c|}{$\begin{array}{l}\text { Condition-specific quality of life } \\
\text { Adverse effects } \\
\text { Number of incontinent episodes in } 24 \text { hours }\end{array}$} \\
\hline Notes & \multicolumn{2}{|l|}{ Funding: not stated } \\
\hline \multicolumn{3}{|l|}{ Risk of bias } \\
\hline Bias & Authors' judgement & Support for judgement \\
\hline $\begin{array}{l}\text { Random sequence generation (selection } \\
\text { bias) }\end{array}$ & Unclear risk & $\begin{array}{l}\text { Quote: "randomized in the order in which } \\
\text { [participants] increased and decreased flu- } \\
\text { ids" }\end{array}$ \\
\hline Allocation concealment (selection bias) & Unclear risk & Not mentioned \\
\hline $\begin{array}{l}\text { Blinding of participants and personnel } \\
\text { (performance bias) } \\
\text { All outcomes }\end{array}$ & High risk & Not mentioned but unlikely \\
\hline $\begin{array}{l}\text { Blinding of outcome assessment (detection } \\
\text { bias) } \\
\text { All outcomes }\end{array}$ & Unclear risk & Not mentioned \\
\hline $\begin{array}{l}\text { Incomplete outcome data (attrition bias) } \\
\text { All outcomes }\end{array}$ & Unclear risk & $\begin{array}{l}\text { Data not available for } 15(18 \%) \text { of } 84 \text { par- } \\
\text { ticipants enrolled. Reasons for this were not } \\
\text { provided }\end{array}$ \\
\hline Selective reporting (reporting bias) & Unclear risk & $\begin{array}{l}\text { Insufficient information available. Re- } \\
\text { ported outcomes were specified in the } \\
\text { methods section }\end{array}$ \\
\hline Other bias & Unclear risk & Insufficient information available \\
\hline
\end{tabular}


Methods

Participants
Design: cross-over trial with random allocation to the order in which participants consumed caffeinated or caffeine-free fluids (feasibility study)

Study centre: single centre, UK

Recruitment period: not reported

Power calculation: not reported

umber of participants randomized: total $=14$

Number of participants followed up: 11

Withdrawals/dropouts/lost to follow-up: 3 withdrawals

Gender: female

Mean age, years (range): 52.1 (27-79)

BMI: not reported

Ethnicity: not reported

Education: not reported

Employment status: not reported

Severity of symptoms: not reported

Prior incontinence surgery: not reported

Inclusion criteria: women aged $>18$ years with newly diagnosed $\mathrm{OAB}$, experiencing $>7$ voids per day and $>2$ episodes per night, self-rated urgency and/or UUI with or without stress incontinent symptoms, and consuming $>2$ caffeinated drinks per day (minimum $60 \mathrm{mg}$ caffeine per 24 hours)

Exclusion criteria: stress incontinence only, smoking, taking oestrogen and/or medications containing caffeine or interfere with caffeine metabolism, postvoid residual $<100$ $\mathrm{ml}$, history of frequent ( $>3 / 6$ months) [sic] urinary tract infections, pregnant, or unable to undertake a bladder diary

Diagnositic groups: OAB with or without UI

Interventions

Outcomes
All participants underwent $2 \times 2$-week periods of caffeinated and caffeine-free fluid intake with the 2 periods separated by a 14-day washout period. Before starting their assigned period, participants took part in a run-In period of caffeine withdrawal, during which they were requested to reduce their caffeine intake by substituting one cup of caffeinated tea or coffee with decaffeinated every other day

Co-interventions: not reported

Compliance: " 2 participants did not comply with caffeine substitution" based on caffeine levels from saliva samples

ICIQ-OAB; ICIQ-OABqol

Number of incontinent episodes (3-day bladder diary)

Notes

Available as abstract only

Funding: not reported

\section{Risk of bias}

Bias

Random sequence generation (selection Low risk bias)
Support for judgement

Quote: “... randomized ... via random number generator" 
Wells 2011

\begin{tabular}{|c|c|c|}
\hline Allocation concealment (selection bias) & Unclear risk & No information available \\
\hline $\begin{array}{l}\text { Blinding of participants and personnel } \\
\text { (performance bias) } \\
\text { All outcomes }\end{array}$ & High risk & Not mentioned but unlikely \\
\hline $\begin{array}{l}\text { Blinding of outcome assessment (detection } \\
\text { bias) } \\
\text { All outcomes }\end{array}$ & Unclear risk & No information available \\
\hline $\begin{array}{l}\text { Incomplete outcome data (attrition bias) } \\
\text { All outcomes }\end{array}$ & Unclear risk & $\begin{array}{l}14 \text { randomized and } 11 \text { completed the fol- } \\
\text { low-up }(79 \%) \text {. No further details }\end{array}$ \\
\hline Selective reporting (reporting bias) & Unclear risk & Insufficient information \\
\hline Other bias & High risk & $\begin{array}{l}2 \text { participants did not comply with caffeine } \\
\text { substitution }\end{array}$ \\
\hline
\end{tabular}

\section{Abbreviations}

BMI: body mass index

DPP: Diabetes Prevention Program

FVC: frequency volume charts

HbA1c: glycated haemoglobin

ICIQ-OAB: Internatioanal Consultation on Incontinence Questionnaire Overactive Bladder

ICIA-OABqol:Internatioanal Consultation on Incontinence Questionnaire Overactive Bladder Symptoms Quality of Life

IDO: idiopathic detrusor overactivity

MUI: mixed urinary incontinence

OAB: overactive bladder

oz: (fluid) ounce

RCT: randomized controlled trial

SD: standard deviation

SUI: stress urinary incontinence

UI: urinary incontinence

USI: urodynamic stress incontinence

UUI: urgency urinary incontinence

\section{Characteristics of excluded studies [ordered by study ID]}

\begin{tabular}{l|l}
\hline Study & Reason for exclusion \\
\hline BE-DRI & $\begin{array}{l}\text { Anticholinergic medications plus behavioural training versus anticholinergic medications alone. Behavioural } \\
\text { training included specific fluid management as well as pelvic floor muscle control and exercises, urge suppression, } \\
\text { and delayed voiding. Study conducted by the Urinary Incontinence Treatment Network (UITN). Complex } \\
\text { interventions for which we could not separate the effect of lifestyle interventions }\end{array}$
\end{tabular}


(Continued) Bird 2005
Not a relevant population. Healthy volunteers $(\mathrm{N}=80)$. Caffeine tablet versus placebo. Outcome: perceived
change in LUTS

Brown 2007 Self-management plus standard care versus standard care. Self-management included lifestyle (fluid, caffeine, alcohol), bladder training and toileting. Complex intervention meant we could not separate the effect of lifestyle interventions

Dougherty 2002 BMC versus control. BMC = lifestyle change, if needed; if lifestyle not needed, bladder training (BT); if BT not effective, PFMT + biofeedback (BF). Complex intervention meant we could not separate the effect of lifestyle interventions

Dumoulin 2011 Physiotherapy versus control. Physiotherapy treatment combined 1) PFMT and other exercises with 2) dietary recommendations/changes and constipation management. We could not separate the effect of (2) from (1)

Glazener $2001 \quad$ Not a relevant intervention. PFMT (for all UI) plus bladder training (for urge UI) versus control

Herschorn 2003 Tolterodine plus health education intervention versus tolterodine alone. $\mathrm{N}=84$. Abstract only, so no details of health education intervention available. Possibly related to Herschorn 2004

Herschorn 2004 Health education intervention plus tolterodine versus tolterodine alone. Participants received a behavioural modification information sheet with multiple components including: 1) fluid intake regulation, 2) caffeine limitation, 3) scheduled toileting, 4) bladder stretching, 5) PFMT, and 6) urge suppression. We could not separate the effect of 1) and 2) from the rest

Hofbauer 1990 Not a relevant intervention. Electrical stimulation (ES) + 'gymnastic' versus 'gymnastic' versus ES versus sham ES. German publication

Kim 2011a Multidimensional exercise treatment, consisting of stretching, PFMT and fitness exercises. Community-dwelling elderly Japanese women with SUI, UUI or MUI. We could not separate the effect of non-PFMT exercise

Kim 2011b Exercise treatment with or without heat and steam generating sheet (HSGS). Exercise consisted of stretching, PFMT and fitness exercises. A 4-arm trial comparing: 1) exercise + HSGS, 2) exercise only, 3) HSGS only, and 4) education. Community-dwelling elderly Japanese women with stress, urge or mixed UI. We could not separate the effect of non-PFMT exercise

Kincade 2007a Described the characteristics of women participating in 2 clinical trials and explored the relationships between demographic characteristics, caffeine and fluid intake, quality of life, and severity of urine loss. No usable data

Kincade 2007b Self-monitoring including: 1) caffeine, 2) fluid intake, 3) PFMT, 4) voiding frequency, 5) constipation. We could not separate the effect of lifestyle change

Li 2001 The study did not focus on UI, but assessed the effects of Tai Chi on physical function. The only incontinencerelated outcome was use of toilet, as part of a composite measure of "eating, dressing, bathing or using the toilet"

Parker 2005

Not a relevant population. Healthy volunteers $(\mathrm{N}=64)$. Caffeine tablet versus placebo. Outcome: LUTS. Abstract only. Probably related to Bird 2005

Lifestyle interventions for the treatment of urinary incontinence in adults (Review)

Copyright @ 2015 The Cochrane Collaboration. Published by John Wiley \& Sons, Ltd. 
(Continued)

\begin{tabular}{l|l} 
Ree 2007 & $\begin{array}{l}\text { The study did not focus on UI, but examined whether strenuous physical activity could produce pelvic floor } \\
\text { muscle fatigue among young nulliparous women with stress UI. No outcome data on UI }\end{array}$ \\
\hline Schauss 2006 & $\begin{array}{l}\text { Not a relevant intervention. 'UroLogic' versus placebo. UroLogic is a nutritional supplement containing Equi- } \\
\text { setum arvense and Crataeva murvale }\end{array}$ \\
\hline Tomlinson 1999 & $\begin{array}{l}\text { Complex intervention for which we could not separate the effect of lifestyle change. BMC versus control. The } \\
\text { three phases of BMC were: } 1 \text { ) self-monitoring including fluid management and caffeine reduction; } 2) \text { bladder } \\
\text { training; and 3) pelvic muscle exercise with biofeedback. } 218 \text { women were randomized into treatment or control. } \\
\text { Analysis focused on 41 women who were randomized into the treatment and completed the first phase of BMC. } \\
\text { No data were available for the control group }\end{array}$ \\
\hline Van Hespen 2006 & $\begin{array}{l}\text { Not a relevant population. RCT of the UI training programme, INCOndition, including training of pelvic floor } \\
\text { muscles, bladder function and mobility, for women living in homes for the elderly. German with English abstract }\end{array}$ \\
\hline Wagg 2007 & $\begin{array}{l}\text { Lifestyle leaflet versus structured help in clinic (including BT and PFMT). Leaflet-only interventions, without } \\
\text { a standardised (within trial) protocol, are not eligible }\end{array}$ \\
\hline
\end{tabular}

\author{
Abbreviations \\ BF: biofeedback \\ BMC: behavioural management for continence \\ BT: bladder training \\ ES: electrical stimulation \\ LUTS: lower urinary tract symptoms \\ MUI: mixed urinary incontinence \\ PFMT: pelvic floor muscle training \\ RCT: randomized controlled trial \\ SUI: stress urinary incontinence \\ UI: urinary incontinence \\ UUI: urgency urinary incontinence
}

Characteristics of studies awaiting assessment [ordered by study ID]

\title{
Baker 2011
}

\begin{tabular}{ll}
\hline Methods & RCT \\
\hline Participants & Women with urgency incontinence \\
\hline Interventions & Mindfulness-based stress reduction technique and yoga (MBSR-yoga) versus sham yoga \\
\hline Outcomes & Change from baseline in mean number of urge incontinent episodes from pre treatment to post treatment \\
\hline Notes & $\begin{array}{l}\text { Estimated enrolment: } 30 \\
\text { Study start date: February } 2011\end{array}$
\end{tabular}

Lifestyle interventions for the treatment of urinary incontinence in adults (Review)

Copyright @ 2015 The Cochrane Collaboration. Published by John Wiley \& Sons, Ltd. 
Baker 2011 (Continued)

Primary completion date: May 2012 (final data collection date for primary outcome measure)

\section{Gozukara 2014}

\begin{tabular}{ll}
\hline Methods & RCT \\
\hline Participants & Overweight/obese women with UI recorded in a 3-day diary \\
\hline Interventions & Behavioural weight loss versus structured education programme \\
\hline Outcomes & $\begin{array}{l}\text { Change in voiding diary from baseline to } 6 \text { months in voiding diary parameters; Pelvic Floor Distress Inventory and } \\
\text { POP-Q }\end{array}$ \\
\hline Notes & $\begin{array}{l}\text { Enrolment: } 158 \\
\text { Study start date: June } 2008\end{array}$
\end{tabular}

Heesakkers 2009

\begin{tabular}{ll}
\hline Methods & RCT \\
\hline Participants & Patients with OAB \\
\hline Interventions & Low versus normal versus high fluid intake \\
\hline Outcomes & Urine osmolality; PPIUS (Perception of Intensity of Urgency Scale) urge-score \\
\hline Notes & $\begin{array}{l}\text { Enrollment: 0 } \\
\text { Study start date: July 2009 } \\
\text { Primary completion date: December 2010 (final data collection date for primary outcome measure) }\end{array}$ \\
\hline
\end{tabular}

\section{Huang 2012}

\begin{tabular}{ll}
\hline Methods & RCT \\
\hline Participants & Women with UI or OAB \\
\hline Interventions & Yoga therapy versus control \\
\hline Outcomes & Change in the number of incontinence episodes over 7 days from pre treatment to post treatment \\
\hline Notes & $\begin{array}{l}\text { Enrollment: } 20 \\
\text { Study start date: August 2012 } \\
\text { Study completion date: December } 2012\end{array}$ \\
\hline
\end{tabular}


Markland 2013

\begin{tabular}{ll}
\hline Methods & RCT \\
\hline Participants & Older women with UI \\
\hline Interventions & Vitamin D supplementation versus placebo \\
\hline Outcomes & $\begin{array}{l}\text { Change in the number of incontinent episodes on a 7-day bladder diary from the baseline evaluation to the final visit } \\
\text { at } 12 \text {-weeks }\end{array}$ \\
\hline Notes & $\begin{array}{l}\text { Estimated enrollment: } 100 \\
\text { Study start date: January } 2014 \\
\text { Estimated study completion date: November } 2015\end{array}$ \\
\hline
\end{tabular}

\begin{tabular}{ll}
\hline Seckin 2011 & \\
\hline Methods & RCT \\
\hline Participants & Individuals with incontinence due to stress or OAB \\
\hline Interventions & Aerobic pelvic floor muscle exercise versus targeted Pilates exercise group \\
\hline Outcomes & Change in SEAPI quality of life score from baseline \\
\hline Notes & $\begin{array}{l}\text { Enrolment: } 80 \\
\text { Poster only, minimal detail available }\end{array}$ \\
\hline
\end{tabular}

\section{Wells 2014}

\begin{tabular}{ll}
\hline Methods & Randomised cross-over trial \\
\hline Participants & Women with newly diagnosed OAB and history of caffeine consumption \\
\hline Interventions & $\begin{array}{l}\text { Group A: 14-day caffeinated drink period followed by a 14-day decaffeinated drink period } \\
\text { Group B: 14-day decaffeinated drink period followed by a 14-day caffeinated drink period (with a 14-day run-in } \\
\text { period and 14-day wash-out period between group entry }\end{array}$ \\
\hline Outcomes & Episodes of urgency and frequency, volume per void and incontinence recorded in a 3-day diary \\
\hline Notes & Enrolment: 11 \\
\hline
\end{tabular}

\section{Abbreviations}

OAB: overactive bladder

POP-Q: Pelvic Organ Prolapse Quantification System

RCT: randomized controlled trial

SEAPI: stress-related leak (S), emptying ability (E), anatomy $(\mathrm{A})$, protection $(\mathrm{P})$, inhibition $(\mathrm{I})$

UI: urinary incontinence 
Characteristics of ongoing studies [ordered by study ID]

\section{Moholdt 2011}

\begin{tabular}{ll}
\hline Trial name or title & Exercise Training in Pregnancy (ETIP) for obese women \\
\hline Methods & $\begin{array}{l}\text { Design: randomised controlled trial with 2 parallel arms (intervention versus control) } \\
\text { Study centre: the Norwegian University of Science and Technology and the St Olav's Hospital, Trondheim } \\
\text { University Hospital }\end{array}$ \\
\hline Participants & 150 previously sedentary, pregnant women with a pre-pregnancy BMI at or above $30 \mathrm{~kg} / \mathrm{m}^{2}$ \\
\hline Interventions & $\begin{array}{l}\text { Intervention: organised exercise training } 3 \text { times per week } \\
\text { Control: standard antenatal care }\end{array}$ \\
\hline Outcomes & $\begin{array}{l}\text { The main outcome measure will be weight gain from baseline to delivery } \\
\text { Secondary outcomes include incontinence }\end{array}$ \\
\hline Starting date & September 2010. Recruitment anticipated until the end of 2012 \\
\hline Contact information & $\begin{array}{l}\text { Trine T Moholdt, Department of Publich Health and General Practice, Norwegian University of Science and } \\
\text { Technology, Trondheim, Norway. Email: trine.moholdt@ntnu.no }\end{array}$ \\
\hline Notes & \\
\hline
\end{tabular}

\section{Abbreviation}

BMI: body mass index 
DATA ANDANALYSES

\section{Comparison 1. Weight loss versus no active intervention}

\begin{tabular}{|c|c|c|c|c|}
\hline Outcome or subgroup title & $\begin{array}{l}\text { No. of } \\
\text { studies }\end{array}$ & $\begin{array}{c}\text { No. of } \\
\text { participants }\end{array}$ & Statistical method & Effect size \\
\hline $\begin{array}{l}1 \text { Improvement rates based on } \\
\text { women's perception (all types } \\
\text { UI) }\end{array}$ & 1 & & Risk Ratio (M-H, Fixed, 95\% CI) & Totals not selected \\
\hline 1.1 At 6 months & 1 & & Risk Ratio (M-H, Fixed, 95\% CI) & $0.0[0.0,0.0]$ \\
\hline $\begin{array}{l}2 \text { Improvement rates based on } \\
\text { women's perception (all types } \\
\text { UI) }\end{array}$ & & & Other data & No numeric data \\
\hline $\begin{array}{l}3 \text { Quality of life and symptom } \\
\text { scores }\end{array}$ & & & Other data & No numeric data \\
\hline $\begin{array}{l}4 \text { Cure rates based on } \\
\text { quantification of symptoms (all } \\
\text { types UI) }\end{array}$ & 3 & & Risk Ratio (M-H, Fixed, 95\% CI) & Totals not selected \\
\hline 4.1 At 3 months & 1 & & Risk Ratio (M-H, Fixed, 95\% CI) & $0.0[0.0,0.0]$ \\
\hline 4.2 At 6 months & 1 & & Risk Ratio (M-H, Fixed, 95\% CI) & $0.0[0.0,0.0]$ \\
\hline 4.3 At 12 months & 1 & & Risk Ratio (M-H, Fixed, 95\% CI) & $0.0[0.0,0.0]$ \\
\hline $\begin{array}{l}5 \text { Cure rates based on } \\
\text { quantification of symptoms (by } \\
\text { type of UI) }\end{array}$ & & & Other data & No numeric data \\
\hline $\begin{array}{l}6 \text { Improvement rates based on } \\
\text { quantification of symptoms (all } \\
\text { types UI) }\end{array}$ & 3 & & Risk Ratio (M-H, Fixed, 95\% CI) & Subtotals only \\
\hline 6.1 At 3 months & 1 & 40 & Risk Ratio (M-H, Fixed, 95\% CI) & $16.5[1.01,270.78]$ \\
\hline 6.2 At 6 months & 1 & 304 & Risk Ratio (M-H, Fixed, 95\% CI) & $1.85[1.22,2.81]$ \\
\hline 6.3 At 12 months & 2 & 1032 & Risk Ratio (M-H, Fixed, 95\% CI) & $1.21[1.02,1.44]$ \\
\hline 6.4 At 18 months & 1 & 287 & Risk Ratio (M-H, Fixed, 95\% CI) & $1.15[0.86,1.55]$ \\
\hline $\begin{array}{l}7 \text { Improvement rates based on } \\
\text { quantification of symptoms (by } \\
\text { type of UI) }\end{array}$ & & & Other data & No numeric data \\
\hline $\begin{array}{l}8 \text { Prevalence of weekly urinary } \\
\text { incontinence after intervention } \\
\text { (all types UI) }\end{array}$ & 2 & & Risk Ratio (M-H, Fixed, 95\% CI) & Totals not selected \\
\hline 8.1 At 12 months & 1 & & Risk Ratio (M-H, Fixed, 95\% CI) & $0.0[0.0,0.0]$ \\
\hline 8.2 At 2.8 years & 1 & & Risk Ratio (M-H, Fixed, 95\% CI) & $0.0[0.0,0.0]$ \\
\hline $\begin{array}{l}9 \text { Prevalence of weekly urinary } \\
\text { incontinence after intervention } \\
\text { (by type of UI) }\end{array}$ & & & Other data & No numeric data \\
\hline $\begin{array}{l}10 \text { Incontinent episodes per week } \\
\text { (\% change from baseline; all UI } \\
\text { types) }\end{array}$ & 1 & & Mean Difference (IV, Fixed, 95\% CI) & Totals not selected \\
\hline 10.1 At 6 months & 1 & & Mean Difference (IV, Fixed, 95\% CI) & $0.0[0.0,0.0]$ \\
\hline 10.2 At 12 months & 1 & & Mean Difference (IV, Fixed, 95\% CI) & $0.0[0.0,0.0]$ \\
\hline 10.3 At 18 months & 1 & & Mean Difference (IV, Fixed, 95\% CI) & $0.0[0.0,0.0]$ \\
\hline
\end{tabular}




\section{Comparison 2. Soy-rich diet versus control}

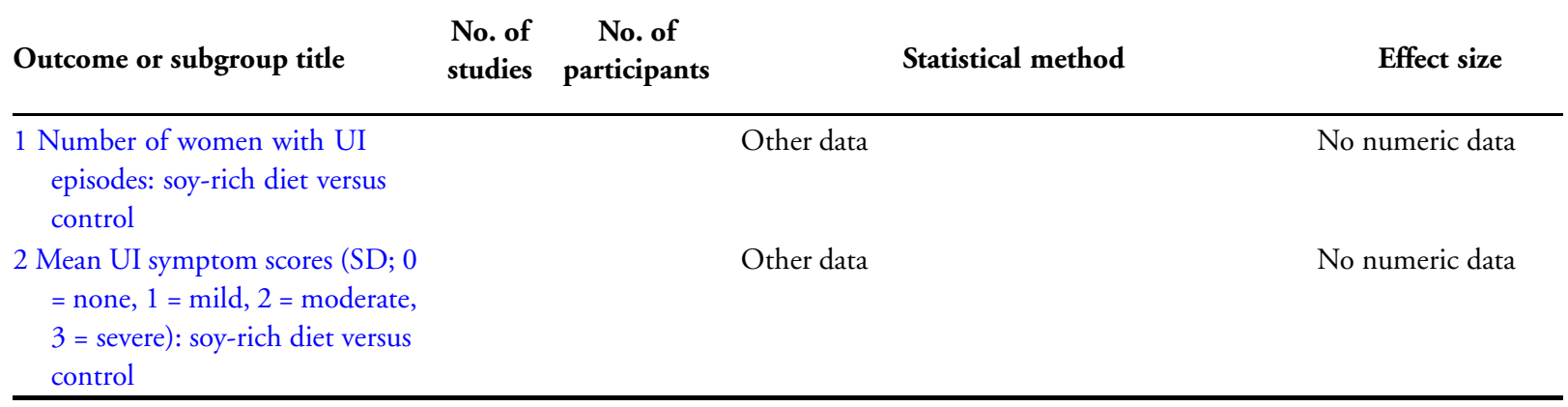

\section{Comparison 3. Increase in fluid intake versus decrease in fluid intake}

\begin{tabular}{|c|c|c|c|c|}
\hline Outcome or subgroup title & $\begin{array}{l}\text { No. of } \\
\text { studies }\end{array}$ & $\begin{array}{c}\text { No. of } \\
\text { participants }\end{array}$ & Statistical method & Effect size \\
\hline $\begin{array}{l}1 \text { Median number of daily UI } \\
\text { episodes (IQR) }\end{array}$ & & & Other data & No numeric data \\
\hline $\begin{array}{l}2 \text { Median number of daily UI } \\
\text { episodes (range) }\end{array}$ & & & Other data & No numeric data \\
\hline $\begin{array}{l}3 \text { Mean number of daily UI } \\
\text { episodes (any UI) }\end{array}$ & & & Other data & No numeric data \\
\hline
\end{tabular}

\section{Comparison 4. Caffeine reduction versus control}

\begin{tabular}{|c|c|c|c|c|}
\hline Outcome or subgroup title & $\begin{array}{l}\text { No. of } \\
\text { studies }\end{array}$ & $\begin{array}{c}\text { No. of } \\
\text { participants }\end{array}$ & Statistical method & Effect size \\
\hline 1 Mean quality of life scores & & & Other data & No numeric data \\
\hline $\begin{array}{l}2 \text { Mean number of UI episodes } \\
\text { per } 24 \text { hours (SD) }\end{array}$ & 1 & & Mean Difference (IV, Fixed, 95\% CI) & Totals not selected \\
\hline
\end{tabular}




\begin{tabular}{lcccc} 
Outcome or subgroup title & $\begin{array}{c}\text { No. of } \\
\text { studies }\end{array}$ & $\begin{array}{c}\text { No. of } \\
\text { participants }\end{array}$ & Statistical method & Effect size \\
\hline $\begin{array}{l}\text { 1 Prevalence of weekly UI after } \\
\text { intervention }\end{array}$ & 1 & Risk Ratio (M-H, Fixed, 95\% CI) & Totals not selected \\
1.1 All UI types at 2.8 years & 1 & Risk Ratio (M-H, Fixed, 95\% CI) & $0.0[0.0,0.0]$ \\
1.2 Stress UI at 2.8 years & 1 & Risk Ratio (M-H, Fixed, 95\% CI) & $0.0[0.0,0.0]$ \\
1.3 Urgency UI at 2.8 years & 1 & Risk Ratio (M-H, Fixed, 95\% CI) & $0.0[0.0,0.0]$ \\
\hline
\end{tabular}

\section{Analysis I.I. Comparison I Weight loss versus no active intervention, Outcome I Improvement rates based on women's perception (all types UI).}

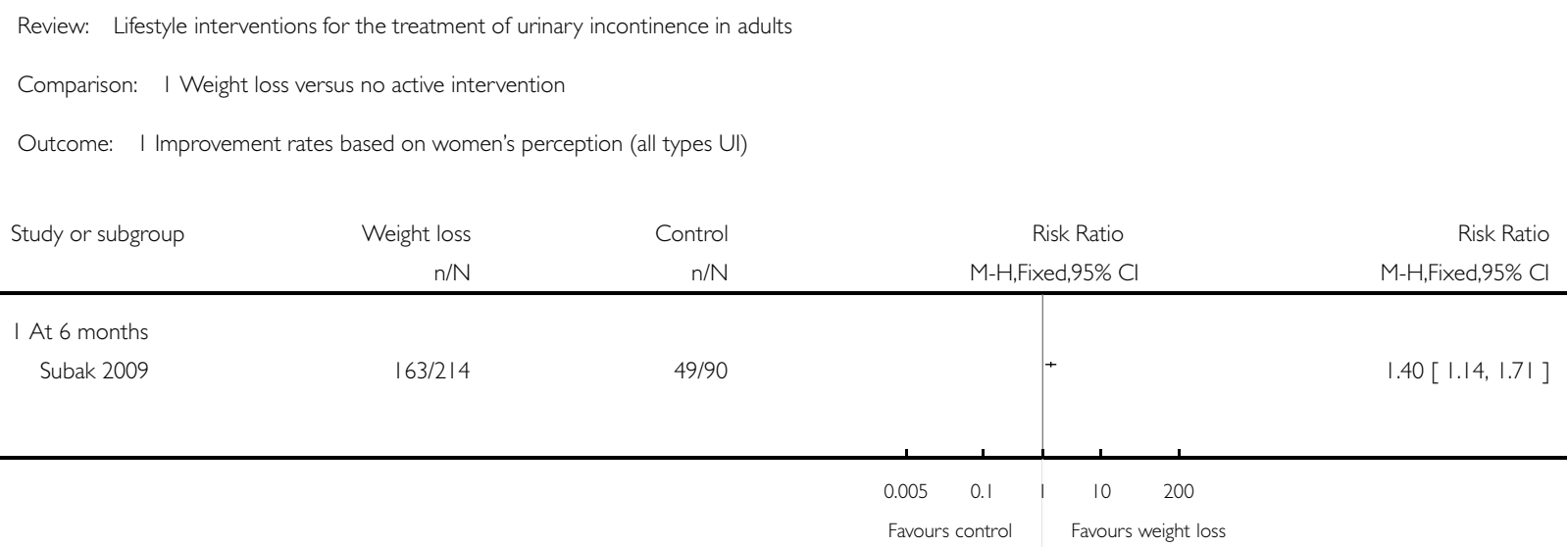

\section{Analysis I.2. Comparison I Weight loss versus no active intervention, Outcome 2 Improvement rates based on women's perception (all types UI).}

Improvement rates based on women's perception (all types UI)

\begin{tabular}{|c|c|c|c|c|c|c|c|c|}
\hline Study & Outcome & $\begin{array}{l}\text { Weight loss } \\
\text { (number } \\
\text { improved) }\end{array}$ & $\begin{array}{l}\text { Weight loss } \\
\text { (t otal } \mathrm{N})\end{array}$ & $\begin{array}{l}\text { Weight loss } \\
(\%)\end{array}$ & $\begin{array}{l}\text { Control } \\
\text { (number } \\
\text { improved) }\end{array}$ & $\begin{array}{l}\text { Control } \\
(\mathrm{t} \text { otal } \mathrm{N})\end{array}$ & $\begin{array}{l}\text { Control } \\
(\%)\end{array}$ & $\begin{array}{l}\text { Reported } P \\
\text { value }\end{array}$ \\
\hline Subak 2009 & $\begin{array}{l}\text { At } \quad 12 \\
\text { months }(\mathrm{N}= \\
298)\end{array}$ & $\begin{array}{l}\text { Not } \\
\text { reported }\end{array}$ & $\begin{array}{l}\text { Not } \\
\text { reported }\end{array}$ & 75 & $\begin{array}{l}\text { Not } \\
\text { reported }\end{array}$ & $\begin{array}{l}\text { Not } \\
\text { reported }\end{array}$ & 68 & 0.2 \\
\hline Subak 2009 & $\begin{array}{l}\text { At } 18 \\
\text { months }(\mathrm{N}=\end{array}$ & $\begin{array}{l}\text { Not } \\
\text { reported }\end{array}$ & $\begin{array}{l}\text { Not } \\
\text { reported }\end{array}$ & 75 & $\begin{array}{l}\text { Not } \\
\text { reported }\end{array}$ & $\begin{array}{l}\text { Not } \\
\text { reported }\end{array}$ & 62 & 0.02 \\
\hline
\end{tabular}


Improvement rates based on women's perception (all types UI) (Continued)

Analysis I.3. Comparison I Weight loss versus no active intervention, Outcome 3 Quality of life and symptom scores.

Quality of life and symptom scores

\begin{tabular}{|c|c|c|c|c|c|c|}
\hline Study & Outcome & $\begin{array}{l}\text { Weight loss (to- } \\
\text { tal N) }\end{array}$ & $\begin{array}{l}\text { Weight loss, me- } \\
\text { dian (IQR) }\end{array}$ & $\begin{array}{l}\text { Control (total } \\
\mathrm{N})\end{array}$ & $\begin{array}{l}\text { Control, median } \\
\text { (IQR) }\end{array}$ & $\begin{array}{l}\text { Reported } \\
\text { value }\end{array}$ \\
\hline Subak 2005 & 3 months & & & & & \\
\hline Subak 2005 & $\begin{array}{l}\text { Incontinence Im- } \\
\text { pact Question- } \\
\text { naire (score range } \\
0-400 \text { with lower } \\
\text { score indicating } \\
\text { better quality of } \\
\text { life) }\end{array}$ & 19 & 37 (11 to 86$)$ & 21 & 89 (56 to 136$)$ & 0.01 \\
\hline Subak 2005 & $\begin{array}{l}\text { Urogenital } \\
\text { Distress Inven- } \\
\text { tory (score range } \\
0-300 \text { with lower } \\
\text { scores indicating } \\
\text { less distress) }\end{array}$ & 19 & 104 (67 to 122$)$ & 21 & 195 (156 to 228$)$ & $<0.0001$ \\
\hline Subak 2005 & $\begin{array}{l}\text { SF-36 physical } \\
\text { component } \\
\text { (higher scores in- } \\
\text { dicate better } \\
\text { quality of life) }\end{array}$ & 19 & 55 (49 to 58$)$ & 21 & 47 (41 to 50$)$ & 0.003 \\
\hline Subak 2005 & $\begin{array}{l}\text { SF-36 mental } \\
\text { component } \\
\text { (higher scores in- } \\
\text { dicate better } \\
\text { quality of life) }\end{array}$ & 19 & 48 (46 to 49$)$ & 21 & $51(48$ to 54$)$ & 0.09 \\
\hline
\end{tabular}


Analysis I.4. Comparison I Weight loss versus no active intervention, Outcome 4 Cure rates based on quantification of symptoms (all types UI).

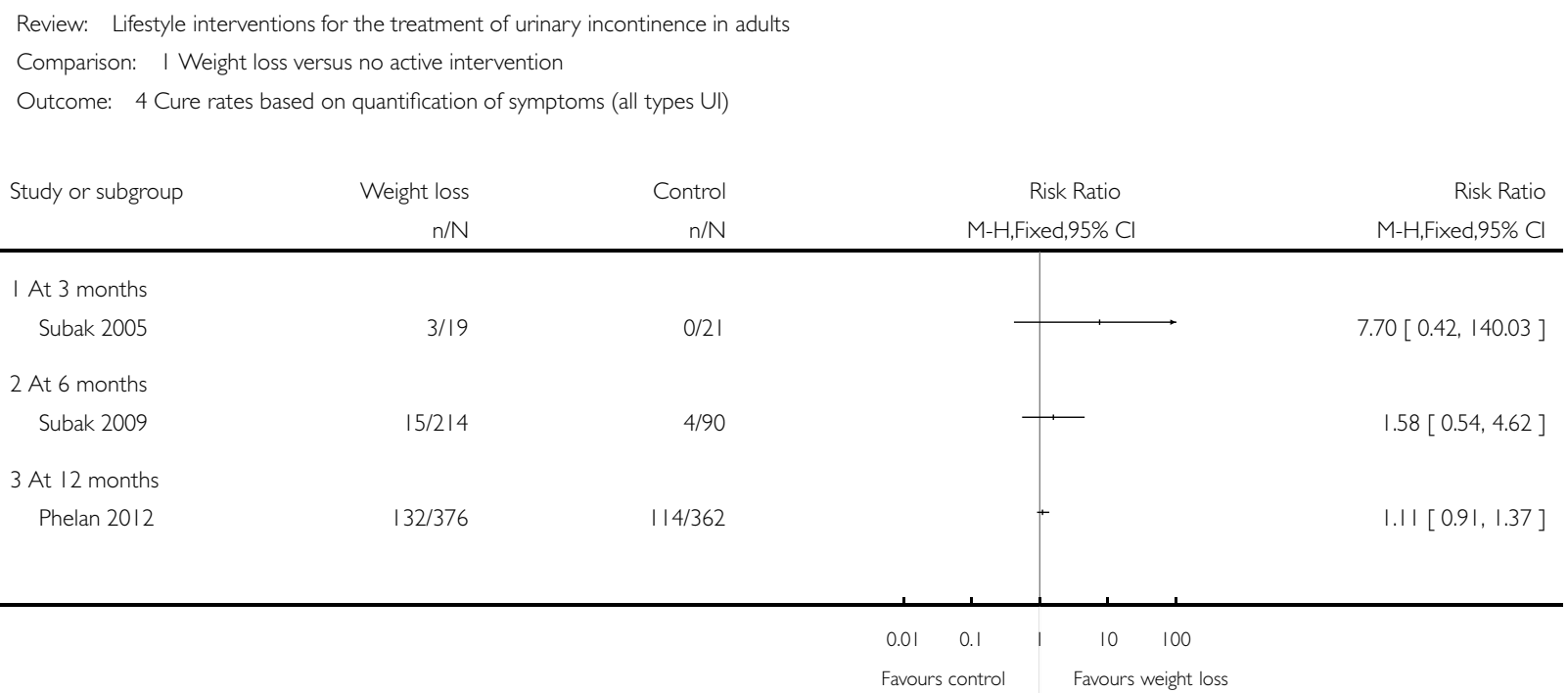

\section{Analysis I.5. Comparison I Weight loss versus no active intervention, Outcome 5 Cure rates based on quantification of symptoms (by type of UI).}

Cure rates based on quantification of symptoms (by type of UI)

\begin{tabular}{|c|c|c|c|c|c|c|c|c|}
\hline Study & Outcome & $\begin{array}{l}\text { Weight loss } \\
\text { (number } \\
\text { cured) }\end{array}$ & $\begin{array}{l}\text { Weight loss } \\
\text { (total N) }\end{array}$ & $\begin{array}{l}\text { Weight loss } \\
(\%)\end{array}$ & $\begin{array}{l}\text { Control } \\
\text { (number } \\
\text { cured) }\end{array}$ & $\begin{array}{l}\text { Control } \\
\text { (total N) }\end{array}$ & $\begin{array}{l}\text { Control } \\
(\%)\end{array}$ & $\begin{array}{l}\text { Reported } P \\
\text { value }\end{array}$ \\
\hline Subak 2009 & $\begin{array}{l}\text { Stress UI at } \\
6 \text { months }\end{array}$ & $\begin{array}{l}\text { Not } \\
\text { reported }\end{array}$ & $\begin{array}{l}\text { Not } \\
\text { reported }\end{array}$ & 27 & $\begin{array}{l}\text { Not } \\
\text { reported }\end{array}$ & $\begin{array}{l}\text { Not } \\
\text { reported }\end{array}$ & 15 & 0.004 \\
\hline Subak 2009 & $\begin{array}{l}\text { Urgency UI } \\
\text { at } 6 \text { months }\end{array}$ & $\begin{array}{l}\text { Not } \\
\text { reported }\end{array}$ & $\begin{array}{l}\text { Not } \\
\text { reported }\end{array}$ & 19 & $\begin{array}{l}\text { Not } \\
\text { reported }\end{array}$ & $\begin{array}{l}\text { Not } \\
\text { reported }\end{array}$ & 11 & 0.02 \\
\hline
\end{tabular}


Analysis I.6. Comparison I Weight loss versus no active intervention, Outcome 6 Improvement rates based on quantification of symptoms (all types UI).

Review: Lifestyle interventions for the treatment of urinary incontinence in adults

Comparison: I Weight loss versus no active intervention

Outcome: 6 Improvement rates based on quantification of symptoms (all types UI)

Study or subgroup Weight loss Control Risk Ratio Reight Ratio

$\mathrm{n} / \mathrm{N} \quad \mathrm{n} / \mathrm{N}$

n/N M-H,Fixed,95\% Cl M-H,Fixed,95\% Cl

\section{At 3 months} Subak 2005

$7 / 19 \quad 0 / 21$

Subtotal (95\% CI)

19

21

Total events: 7 (Weight loss), 0 (Control)

Heterogeneity: not applicable

Test for overall effect: $Z=1.96(P=0.050)$

2 At 6 months

$$
\text { Subak } 2009
$$

$88 / 214$

20/90

M-H,Fixed, $95 \%$ Cl

Subtotal (95\% CI)

214

90

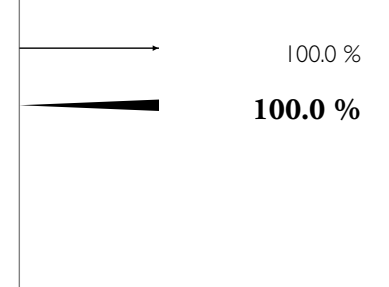

$100.0 \%$

Total events: 88 (Weight loss), 20 (Control)

Heterogeneity: not applicable

Test for overall effect: $Z=2.88(P=0.0039)$

3 At 12 months

Phelan 2012

Subak 2009

$\begin{array}{lr}139 / 376 & 119 / 362 \\ 95 / 207 & 27 / 87\end{array}$

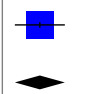

$100.0 \%$

Subtotal (95\% CI)

583

449

Total events: 234 (Weight loss), 146 (Control)

Heterogeneity: $\mathrm{Chi}^{2}=1.81, \mathrm{df}=\mathrm{I}(\mathrm{P}=0.18) ; \mathrm{I}^{2}=45 \%$

Test for overall effect: $Z=2.17(P=0.030)$

4 At 18 months

Subak 2009

$$
91 / 197
$$

$36 / 90$

Subtotal $(95 \% \mathrm{CI})$

197

90

Total events: 91 (Weight loss), 36 (Control)

Heterogeneity: not applicable

Test for overall effect: $Z=0.96(P=0.34)$

$100.0 \%$

$100.0 \%$

$76.1 \%$

$23.9 \%$

$100.0 \%$

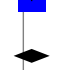

$\longrightarrow$
$1.85[1.22,2.81]$

$1.85[1.22,2.81]$

I.I $5[0.86,1.55]$

$1.15[0.86,1.55]$

$1.12[0.92,1.37]$

$1.48[1.05,2.09]$

$1.21[1.02,1.44]$

$16.50[1.01,270.78]$

(.21 [ $1.02,1.44]$

$15[0.86,1.55]$ 
Analysis I.7. Comparison I Weight loss versus no active intervention, Outcome 7 Improvement rates based on quantification of symptoms (by type of UI).

Improvement rates based on quantification of symptoms (by type of UI)

\begin{tabular}{|c|c|c|c|c|c|c|c|c|}
\hline Study & Outcome & $\begin{array}{l}\text { Weight loss } \\
\text { (number } \\
\text { cured) }\end{array}$ & $\begin{array}{l}\text { Weight loss } \\
\text { (total) }\end{array}$ & $\begin{array}{l}\text { Weight loss } \\
(\%)\end{array}$ & $\begin{array}{l}\text { Control } \\
\text { (number } \\
\text { cured) }\end{array}$ & $\begin{array}{l}\text { Control } \\
\text { (total) }\end{array}$ & $\begin{array}{l}\text { Control } \\
(\%)\end{array}$ & $\begin{array}{l}\text { Reported P } \\
\text { value }\end{array}$ \\
\hline Subak 2009 & $\begin{array}{l}\text { Stress UI at } \\
6 \text { months }\end{array}$ & $\begin{array}{l}\text { Not } \\
\text { reported }\end{array}$ & $\begin{array}{l}\text { Not } \\
\text { reported }\end{array}$ & 51 & $\begin{array}{l}\text { Not } \\
\text { reported }\end{array}$ & $\begin{array}{l}\text { Not } \\
\text { reported }\end{array}$ & 34 & 0.01 \\
\hline Subak 2009 & $\begin{array}{l}\text { Urgency UI } \\
\text { at } 6 \text { months }\end{array}$ & $\begin{array}{l}\text { Not } \\
\text { reported }\end{array}$ & $\begin{array}{l}\text { Not } \\
\text { reported }\end{array}$ & 41 & $\begin{array}{l}\text { Not } \\
\text { reported }\end{array}$ & $\begin{array}{l}\text { Not } \\
\text { reported }\end{array}$ & 29 & 0.04 \\
\hline Subak 2009 & $\begin{array}{l}\text { Stress UI at } \\
6 \text { months }\end{array}$ & $\begin{array}{l}\text { Not } \\
\text { reported }\end{array}$ & $\begin{array}{l}\text { Not } \\
\text { reported }\end{array}$ & 51 & $\begin{array}{l}\text { Not } \\
\text { reported }\end{array}$ & $\begin{array}{l}\text { Not } \\
\text { reported }\end{array}$ & 34 & 0.01 \\
\hline Subak 2009 & $\begin{array}{l}\text { Urgency UI } \\
\text { at } 6 \text { months }\end{array}$ & $\begin{array}{l}\text { Not } \\
\text { reported }\end{array}$ & $\begin{array}{l}\text { Not } \\
\text { reported }\end{array}$ & 41 & $\begin{array}{l}\text { Not } \\
\text { reported }\end{array}$ & $\begin{array}{l}\text { Not } \\
\text { reported }\end{array}$ & 29 & 0.04 \\
\hline Subak 2009 & $\begin{array}{l}\text { Stress UI at } \\
18 \text { months }\end{array}$ & $\begin{array}{l}\text { Not } \\
\text { reported }\end{array}$ & $\begin{array}{l}\text { Not } \\
\text { reported }\end{array}$ & 61 & $\begin{array}{l}\text { Not } \\
\text { reported }\end{array}$ & $\begin{array}{l}\text { Not } \\
\text { reported }\end{array}$ & 62 & 0.92 \\
\hline Subak 2009 & $\begin{array}{l}\text { Ur- } \\
\text { gency UI at } \\
18 \text { months }\end{array}$ & $\begin{array}{l}\text { Not } \\
\text { reported }\end{array}$ & $\begin{array}{l}\text { Not } \\
\text { reported }\end{array}$ & 47 & $\begin{array}{l}\text { Not } \\
\text { reported }\end{array}$ & $\begin{array}{l}\text { Not } \\
\text { reported }\end{array}$ & 34 & 0.03 \\
\hline
\end{tabular}

Analysis I.8. Comparison I Weight loss versus no active intervention, Outcome 8 Prevalence of weekly urinary incontinence after intervention (all types UI).

Review: Lifestyle interventions for the treatment of urinary incontinence in adults

Comparison: I Weight loss versus no active intervention

Outcome: 8 Prevalence of weekly urinary incontinence after intervention (all types UI)

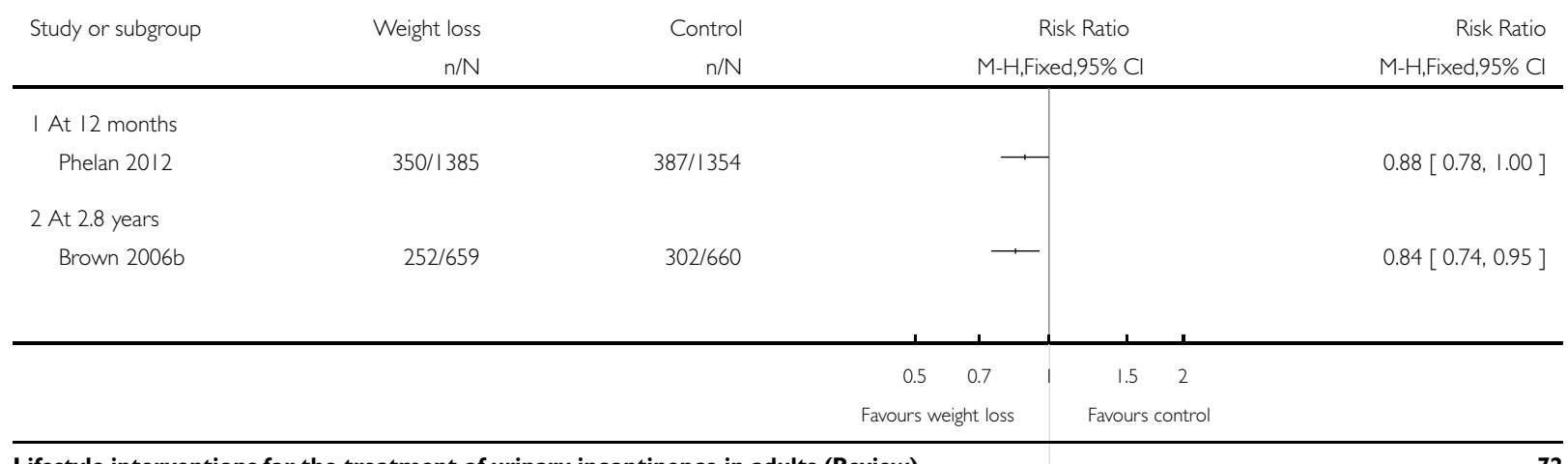

Lifestyle interventions for the treatment of urinary incontinence in adults (Review) 
Analysis I.9. Comparison I Weight loss versus no active intervention, Outcome 9 Prevalence of weekly urinary incontinence after intervention (by type of UI).

Prevalence of weekly urinary incontinence after intervention (by type of UI)

\begin{tabular}{|c|c|c|c|c|c|c|c|c|c|}
\hline Study & Outcome & $\begin{array}{l}\text { Weight } \\
\text { loss (num- } \\
\text { ber } \\
\text { with UI) }\end{array}$ & $\begin{array}{l}\text { Weight } \\
\text { loss (total } \\
\text { N) }\end{array}$ & $\begin{array}{l}\text { Weight } \\
\text { loss (\%) }\end{array}$ & $\begin{array}{l}\text { Control } \\
\text { (number } \\
\text { with UI) }\end{array}$ & $\begin{array}{l}\text { Control } \\
\text { (total N) }\end{array}$ & $\begin{array}{l}\text { Control } \\
(\%)\end{array}$ & $\begin{array}{l}\text { Reported } \\
\text { P value }\end{array}$ & $\begin{array}{l}\text { Reported } \\
\text { adjusted } \\
\text { odds ratio } \\
(95 \% \mathrm{CI})\end{array}$ \\
\hline $\begin{array}{l}\text { Brown } \\
2006 b\end{array}$ & $\begin{array}{l}\text { SUI at } 2.8 \\
\text { years }\end{array}$ & 206 & 659 & 31 & 242 & 660 & 37 & 0.04 & $\begin{array}{l}0.80(0.64 \\
\text { to } 1.01)\end{array}$ \\
\hline $\begin{array}{l}\text { Brown } \\
2006 b\end{array}$ & $\begin{array}{l}\text { UUI at } 2.8 \\
\text { years }\end{array}$ & 156 & 659 & 24 & 169 & 660 & 26 & 0.41 & $\begin{array}{l}\text { Not } \\
\text { reported }\end{array}$ \\
\hline $\begin{array}{l}\text { Phelan } \\
2012\end{array}$ & $\begin{array}{l}\text { SUI at } 1 \\
\text { year }\end{array}$ & 145 & 1385 & 11 & 173 & 1354 & 13 & 0.07 & $\begin{array}{l}0.73(0.55 \\
\text { to } 0.96)\end{array}$ \\
\hline $\begin{array}{l}\text { Phelan } \\
2012\end{array}$ & $\begin{array}{l}\text { UUI at } 1 \\
\text { year }\end{array}$ & $\begin{array}{l}\text { Not } \\
\text { reported }\end{array}$ & $\begin{array}{l}\text { Not } \\
\text { reported }\end{array}$ & $\begin{array}{l}\text { Not } \\
\text { reported }\end{array}$ & $\begin{array}{l}\text { Not } \\
\text { reported }\end{array}$ & $\begin{array}{l}\text { Not } \\
\text { reported }\end{array}$ & $\begin{array}{l}\text { Not } \\
\text { reported }\end{array}$ & $\begin{array}{l}\text { Not } \\
\text { reported }\end{array}$ & $\begin{array}{l}0.93(0.70 \\
\text { to } 1.23)\end{array}$ \\
\hline
\end{tabular}

Analysis I.I0. Comparison I Weight loss versus no active intervention, Outcome 10 Incontinent episodes per week (\% change from baseline; all UI types).

Review: Lifestyle interventions for the treatment of urinary incontinence in adults

Comparison: I Weight loss versus no active intervention

Outcome: 10 Incontinent episodes per week (\% change from baseline; all UI types)

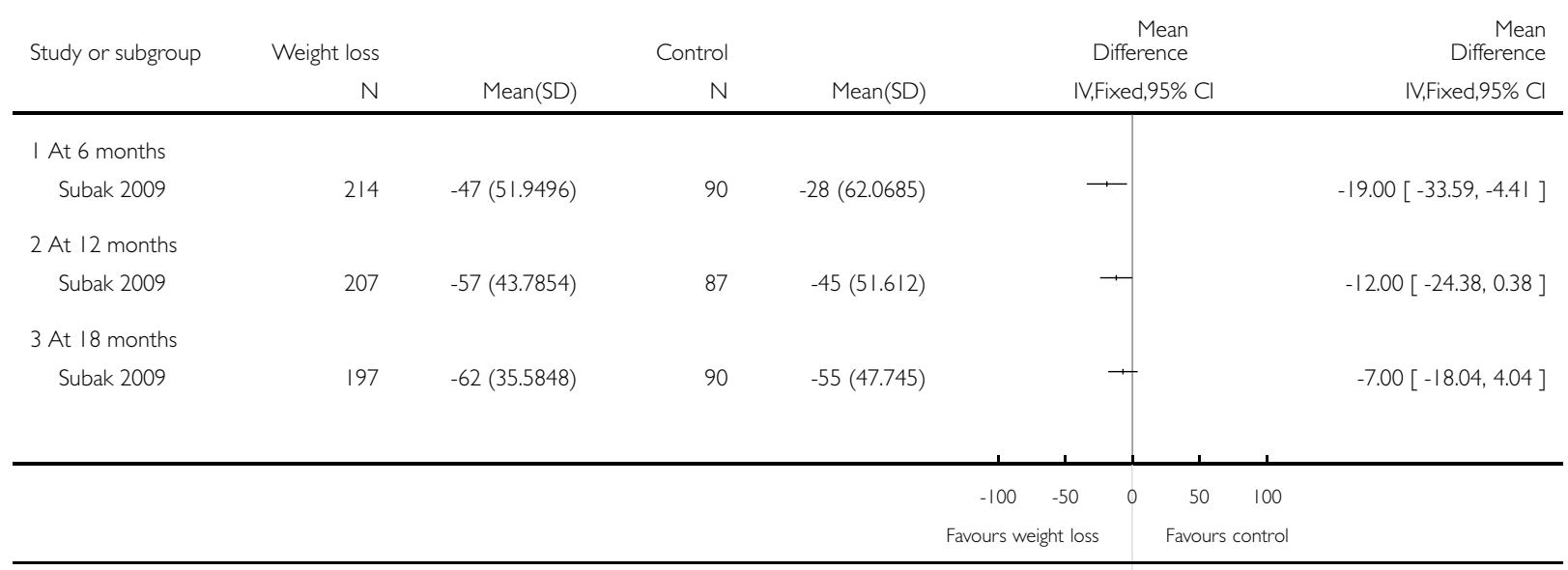

Lifestyle interventions for the treatment of urinary incontinence in adults (Review) 
Analysis I.I I. Comparison I Weight loss versus no active intervention, Outcome I I Incontinence episodes per week (\% change from baseline; by type of UI).

Incontinence episodes per week (\% change from baseline; by type of UI)

\begin{tabular}{|c|c|c|c|c|c|c|}
\hline Study & Outcome & $\begin{array}{l}\text { Weight loss (to- } \\
\text { tal N) }\end{array}$ & $\begin{array}{l}\text { Weight loss } \\
\text { (\% change from } \\
\text { baseline) }\end{array}$ & $\begin{array}{l}\text { Control (total } \\
\text { N) }\end{array}$ & $\begin{array}{l}\text { Control } \\
\text { (\% change from } \\
\text { baseline) }\end{array}$ & $\begin{array}{l}\text { Reported } \\
\text { value }\end{array}$ \\
\hline Subak 2005 & $\begin{array}{l}\text { All UI } \\
\text { at } 3 \text { months, me- } \\
\text { dian (IQR) }\end{array}$ & 19 & $-60(-89$ to -30$)$ & 21 & $-15(-25$ to 9$)$ & 0.0005 \\
\hline Subak 2005 & $\begin{array}{l}\text { Stress UI at } 3 \\
\text { months, median } \\
\text { (IQR) }\end{array}$ & 19 & $-92(-100$ to -66$)$ & 21 & 5 (-63 to 33$)$ & 0.003 \\
\hline Subak 2005 & $\begin{array}{l}\text { Urgency UI at } 3 \\
\text { months, median } \\
\text { (IQR) }\end{array}$ & 19 & $-70(-100$ to -16$)$ & 21 & $-11(-67$ to 69$)$ & 0.03 \\
\hline \multicolumn{7}{|l|}{ Subak 2005} \\
\hline \multicolumn{7}{|l|}{ Subak 2005} \\
\hline \multicolumn{7}{|l|}{ Subak 2005} \\
\hline \multicolumn{7}{|l|}{ Subak 2005} \\
\hline \multicolumn{7}{|l|}{ Subak 2005} \\
\hline \multicolumn{7}{|l|}{ Subak 2005} \\
\hline Subak 2009 & $\begin{array}{l}\text { All } \\
\text { UI at } 6 \text { months, } \\
\text { mean }(95 \% \mathrm{CI})\end{array}$ & 214 & $-47(-54$ to -40$)$ & 90 & $-28(-41$ to -13$)$ & 0.01 \\
\hline Subak 2009 & $\begin{array}{l}\text { Stress } \\
\text { UI at } 6 \text { months, } \\
\text { mean }(95 \% \mathrm{CI})\end{array}$ & 214 & $-58(-67$ to -46$)$ & 90 & $-33(-50$ to -9$)$ & 0.02 \\
\hline Subak 2009 & $\begin{array}{l}\text { Urgency UI at } \\
6 \text { months, mean } \\
(95 \% \mathrm{CI})\end{array}$ & 214 & $-42(-51$ to -32$)$ & 90 & $-26(-44$ to -3$)$ & 0.14 \\
\hline Subak 2009 & $\begin{array}{l}\text { All } \\
\text { UI at } 12 \text { months, } \\
\text { mean }(95 \% \mathrm{CI})\end{array}$ & 207 & $-57(-63$ to -50$)$ & 87 & $-45(-56$ to -32$)$ & 0.08 \\
\hline
\end{tabular}


Incontinence episodes per week (\% change from baseline; by type of UI) (Continued)

\begin{tabular}{|c|c|c|c|c|c|c|}
\hline Subak 2009 & $\begin{array}{l}\text { Stress } \\
\text { UI at } 12 \text { months, } \\
\text { mean }(95 \% \mathrm{CI})\end{array}$ & 207 & $-66(-71$ to -59$)$ & 87 & $-45(-59$ to -27$)$ & $<0.001$ \\
\hline Subak 2009 & $\begin{array}{l}\text { Urgency UI at } \\
12 \text { months, mean } \\
(95 \% \mathrm{CI})\end{array}$ & 207 & $-50(-59$ to -39$)$ & 87 & $-48(-63$ to -29$)$ & 0.87 \\
\hline Subak 2009 & $\begin{array}{l}\text { All } \\
\text { UI at } 18 \text { months, } \\
\text { mean }(95 \% \mathrm{CI})\end{array}$ & 197 & $-62(-67$ to -55$)$ & 90 & $-55(-65$ to -43$)$ & 0.3 \\
\hline Subak 2009 & $\begin{array}{l}\text { Stress } \\
\text { UI at } 18 \text { months, } \\
\text { mean }(95 \% \mathrm{CI})\end{array}$ & 197 & $-69(-76$ to -61$)$ & 90 & $-62(-73$ to -48$)$ & 0.32 \\
\hline Subak 2009 & $\begin{array}{l}\text { Urgency UI at } \\
18 \text { months, mean } \\
(95 \% \mathrm{CI})\end{array}$ & 197 & $-56(-64$ to -46$)$ & 90 & $-49(-64$ to -28$)$ & 0.46 \\
\hline
\end{tabular}

Analysis 2.I. Comparison 2 Soy-rich diet versus control, Outcome I Number of women with UI episodes: soy-rich diet versus control.

Number of women with UI episodes: soy-rich diet versus control

\begin{tabular}{llllll}
\hline Study & Outcome & Soy-rich diet $(\mathbf{n} / \mathbf{N})$ & Soy-rich diet $(\%)$ & Control diet (n/N) & Control diet (\%) \\
\hline Manonai 2006 & $\begin{array}{l}\text { SUI episodes: before } \\
\text { (baseline) }\end{array}$ & $22 / 36$ & 61 & $23 / 36$ & 63 \\
\hline Manonai 2006 & SUI episodes: after & $22 / 36$ & 61 & $18 / 36$ & 51 \\
\hline Manonai 2006 & $\begin{array}{l}\text { UUI episodes: before } \\
\text { (baseline) }\end{array}$ & $7 / 36$ & 19 & $4 / 36$ & 11 \\
\hline Manonai 2006 & UUI episodes: after & $6 / 36$ & 17 & $8 / 36$ & 22 \\
\hline
\end{tabular}

Analysis 2.2. Comparison 2 Soy-rich diet versus control, Outcome 2 Mean UI symptom scores (SD; 0 = none, $\mathrm{I}$ = mild, 2 = moderate, 3 = severe): soy-rich diet versus control.

Mean UI symptom scores (SD; 0 = none, 1 = mild, 2 = moderate, 3 = severe): soy-rich diet versus control

\begin{tabular}{|c|c|c|c|}
\hline Study & Outcome & Soy-rich diet $(\mathrm{n}=36)$ & Soy-rich diet $(\mathrm{n}=36)$ \\
\hline Manonai 2006 & SUI episodes: before (baseline) & $0.67(0.68)$ & $0.75(0.65)$ \\
\hline Manonai 2006 & SUI episodes: after & $0.72(0.66)$ & $0.72(0.74)$ \\
\hline
\end{tabular}


Mean UI symptom scores $(\mathrm{SD} ; \mathbf{0}=$ none, $\mathbf{1}$ = mild, $\mathbf{2}$ = moderate, 3 = severe): soy-rich diet versus control (Continued)

\begin{tabular}{llll}
\hline Manonai 2006 & Reported P value & $>0.05$ & $>0.05$ \\
\hline Manonai 2006 & UUI episodes: before (baseline) & $0.17(0.38)$ & $0.14(0.35)$ \\
\hline Manonai 2006 & UUI episodes: after & $0.19(0.47)$ & $0.25(0.50)$ \\
\hline Manonai 2006 & Reported P value & $>0.05$ & $<0.05$ \\
\hline
\end{tabular}

\section{Analysis 3.I. Comparison 3 Increase in fluid intake versus decrease in fluid intake, Outcome I Median} number of daily UI episodes (IQR).

Median number of daily UI episodes (IQR)

\begin{tabular}{|c|c|c|c|c|c|}
\hline Study & Type of UI & Baseline & $\begin{array}{l}\text { Caffeine-free } \\
\text { baseline }\end{array}$ & $\begin{array}{l}\text { Caffeine-free } \\
\text { and increasing fluids }\end{array}$ & $\begin{array}{l}\text { Caffeine-free } \\
\text { and decreasing flu- } \\
\text { ids }\end{array}$ \\
\hline Swithinbank 2005 & $\begin{array}{l}\text { Urodynamic stress } \\
\text { incontinence (SUI), } \\
\mathrm{n}=39\end{array}$ & $1.6(0.6$ to 2.8$)$ & $0.8(0.1$ to 1.9$)$ & 0.7 (0.3 to 3$)$ & $0.5(0.2$ to 2.1$)$ \\
\hline Swithinbank 2005 & $\begin{array}{l}\text { Idiopathic detrusor } \\
\text { overactivity (IDO), } \\
\mathrm{n}=30\end{array}$ & $0.9(0.4$ to 2$)$ & $0.6(0.2$ to 1.8$)$ & $1.1(0.2$ to 3$)$ & 0.5 (0.2 to 1.2$)$ \\
\hline
\end{tabular}

Analysis 3.2. Comparison 3 Increase in fluid intake versus decrease in fluid intake, Outcome 2 Median number of daily UI episodes (range).

Median number of daily UI episodes (range)

\begin{tabular}{|c|c|c|c|c|}
\hline Study & Randomised group & $\mathbf{N}$ & Median (range) & $\begin{array}{l}\text { Reported P value } \\
\text { compared with baseline }\end{array}$ \\
\hline Hashim 2008 & Baseline & 24 & $0(0,4.8)$ & \\
\hline Hashim 2008 & $25 \%$ less fluid & 24 & $0(0,5.5)$ & 1.0 \\
\hline Hashim 2008 & $50 \%$ less fluid & 12 & $0(0,4.5)$ & 0.69 \\
\hline Hashim 2008 & $25 \%$ more fluid & 21 & $0(0,10.3)$ & 1.00 \\
\hline Hashim 2008 & $50 \%$ more fluid & 14 & $0(0,12.8)$ & 0.69 \\
\hline
\end{tabular}


Analysis 3.3. Comparison 3 Increase in fluid intake versus decrease in fluid intake, Outcome 3 Mean number of daily UI episodes (any UI).

Mean number of daily UI episodes (any UI)

\begin{tabular}{l|llll}
\hline Study & Time period & $\begin{array}{l}\text { Maintain fluid } \\
(\mathbf{N}=\mathbf{1 4})\end{array}$ & Increase fluid (N= 10) & Decrease fluid (N = 8) \\
\hline Dowd 1996 & Week 1 (baseline) & 0.48 & 0.6 & 0.54 \\
\hline Dowd 1996 & Week 2 & 0.71 & 0.61 & 0.26 \\
\hline Dowd 1996 & Week 3 & 0.81 & 0.67 & 0.17 \\
\hline Dowd 1996 & Week 4 & 0.57 & 0.5 & 0.14 \\
\hline Dowd 1996 & Week 5 & 0.48 & 0.55 & 0.07 \\
\hline
\end{tabular}

Analysis 4.I. Comparison 4 Caffeine reduction versus control, Outcome I Mean quality of life scores.

Mean quality of life scores

\begin{tabular}{|c|c|c|c|c|}
\hline Study & Outcome & Caffeine substitution & Caffeine exposure & $\begin{array}{l}\text { Reported } \\
\text { P value }\end{array}$ \\
\hline Wells 2011 & $\begin{array}{l}\text { ICIQ Overactive Bladder } \\
\text { (ICIQ-OAB) total score (N } \\
=11) \text {; } \\
0-16 \text { overall score with } \\
\text { greater values indicating in- } \\
\text { creased symptom severity }\end{array}$ & 4.64 & 6.55 & $<0.01$ \\
\hline Wells 2011 & $\begin{array}{l}\text { ICIQ Overactive Bladder } \\
\text { Symptoms Quality of Life } \\
\text { (ICIQ-OABqol) score }(\mathrm{N}= \\
11) ; 25-160 \text { overall score } \\
\text { with greater values indi- } \\
\text { cating increased impact on } \\
\text { quality of life }\end{array}$ & & & \\
\hline Wells 2011 & $\begin{array}{l}\text { 1) How regularly bladder } \\
\text { symptoms interfered with } \\
\text { the ability to get a good } \\
\text { night's rest }\end{array}$ & 2.64 & 4.09 & $<0.01$ \\
\hline Wells 2011 & $\begin{array}{l}\text { 2) How often bladder symp- } \\
\text { toms caused anxiety or } \\
\text { worry }\end{array}$ & 1.73 & 2.64 & $<0.05$ \\
\hline
\end{tabular}




\begin{tabular}{l|l|l|l|}
\hline Wells 2011 & $\begin{array}{l}\text { 3) How much bladder } \\
\text { symptoms interfered with } \\
\text { everyday life overall }\end{array}$ & 5.73 & $<0.01$ \\
\hline Wells 2011 & $\begin{array}{l}\text { 4) Total scores for the ICIQ- } \\
\text { OABqol }\end{array}$ & 68.91 & 0.065 \\
\hline
\end{tabular}

\section{Analysis 4.2. Comparison 4 Caffeine reduction versus control, Outcome 2 Mean number of UI episodes per} 24 hours (SD).

Review: Lifestyle interventions for the treatment of urinary incontinence in adults

Comparison: 4 Caffeine reduction versus control

Outcome: 2 Mean number of $U$ l episodes per 24 hours (SD)

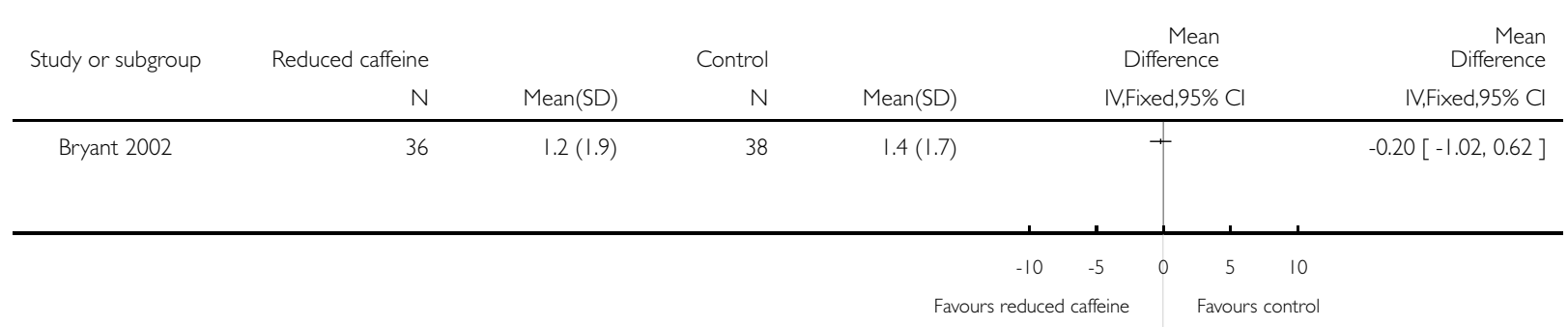




\section{Analysis 5.I. Comparison 5 Lifestyle weight loss versus metformin, Outcome I Prevalence of weekly UI after intervention.}

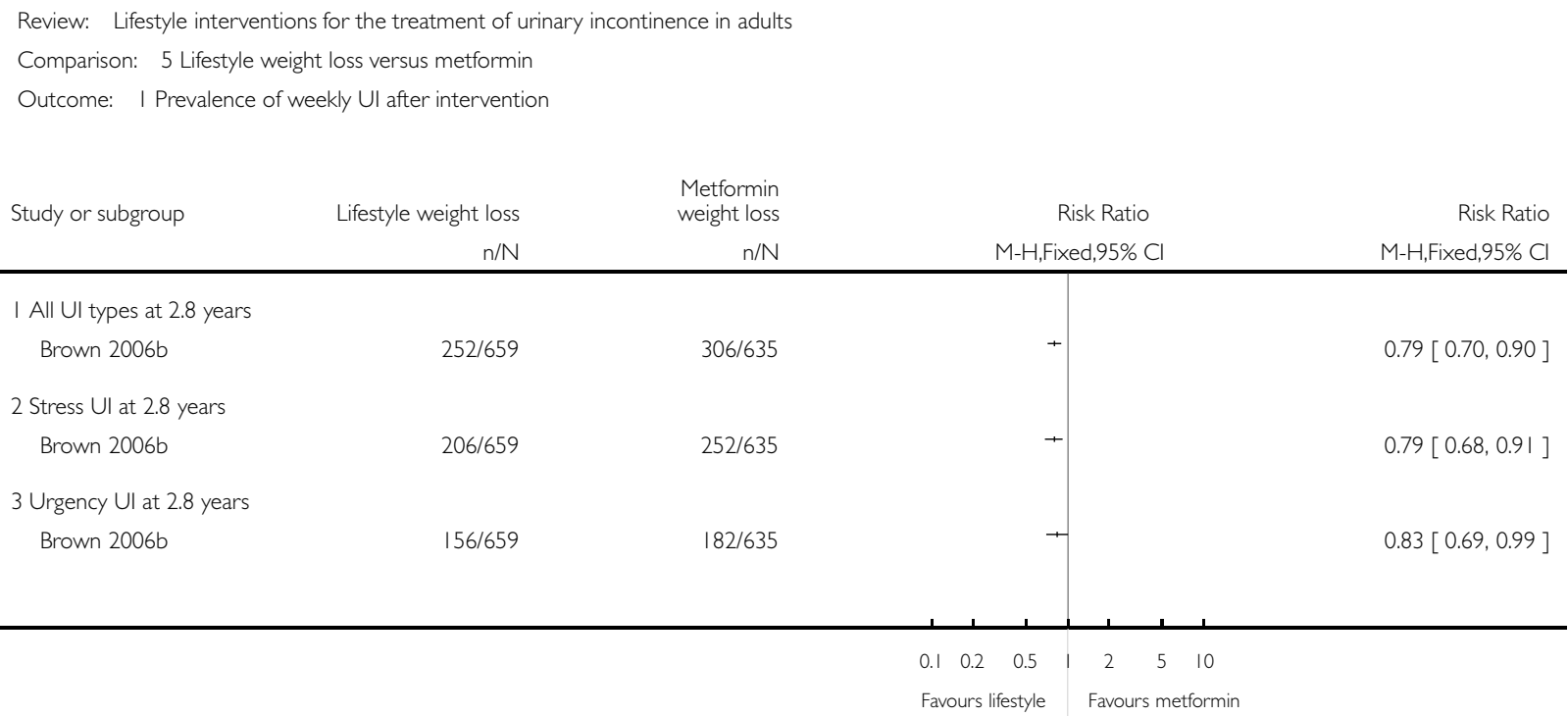

\section{A P PENDICES}

\section{Appendix I. Additional search of ClinicalTrials.gov}

After the main searching for this review was completed, searching and assessment of 1151 records from ClinicalTrials.gov was completed (date of last search: 28 November 2013; via the Central Register of Studies (CRS) software) using the following search terms: Continent OR continence OR incontinent OR incontinence OR overactive OR overactivity (in the simple search command line) After screening 1151 records we identified four that were potentially eligible for this review. As this search was completed after the main search was completed (and its results had been fully incorporated into the review) these four trials were added to Studies awaiting classification so that they can be fully assessed for the next version of the review.

\section{H I S T O R Y}

Protocol first published: Issue 1, 2002

Review first published: Issue 12, 2015 


\begin{tabular}{lll}
\hline Date & Event & Description \\
\hline 7 July 2010 & New citation required and minor changes & new review authors \\
\hline 7 July 2010 & Amended & protocol amended \\
\hline
\end{tabular}

\section{CONTRIBUTIONSOFAUTHORS}

All authors contributed to the initial design and writing of the protocol. MI and KW led study selection, data abstraction and analysis, and wrote the first draft. CM and MW provided critical revisions of the draft for important intellectual content. All authors provided final approval of the version to publish.

\section{DECLARATIONSOF INTEREST}

M Imamura: none known

K Williams: none known

M Wells: none known

C McGrother: none known

\section{SOURCES OF SUPPORT}

\section{Internal sources}

- No sources of support supplied

\section{External sources}

- National Institute for Health Research (NIHR), UK.

This project was supported by the National Institute for Health Research, via Cochrane Infrastructure, Cochrane Programme Grant or Cochrane Incentive funding to the Incontinence Group. The views and opinions expressed therein are those of the authors and do not necessarily reflect those of the Systematic Reviews Programme, NIHR, NHS or the Department of Health.

\section{DIFFERENCES BETWEEN PROTOCOLANDREVIEW}

Selection criteria for Types of participants has been amended after the review commenced. The protocol stated that only adults with urinary incontinence (UI) would be considered for inclusion. Due to the limited number of studies that met this criterion, we also included data from trials where some, but not all, participants had UI at baseline regardless of the proportion of people with UI or availability of data subgrouped by incontinence status.

As the recommendation to assess the quality of evidence using the GRADE approach and also to include 'Summary of findings' tables became prominent during the course of the review, we attempted to undertake the assessment, even though this was not mentioned in the protocol. The GRADE and 'Summary of findings' outcomes were thus defined after the review commenced.

Searches of MEDLINE, EMBASE, CINAHL included in the specialised register, and searches of the reference lists of relevant articles, had been planned originally but were not spelt out in the protocol. Descriptions of these searches have been added to the review for the sake of clarity.

Lifestyle interventions for the treatment of urinary incontinence in adults (Review)

Copyright @ 2015 The Cochrane Collaboration. Published by John Wiley \& Sons, Ltd. 
ClinicalTrials.gov has been searched in response to a comment from an external referee.

Lifestyle interventions for the treatment of urinary incontinence in adults (Review)

Copyright $(2) 2015$ The Cochrane Collaboration. Published by John Wiley \& Sons, Ltd. 